\title{
Meridional Distributions of Historical Zonal Averages and Their Use to Quantify the Global and Spheroidal Mean Near-Surface Temperature of the Terrestrial Atmosphere
}

\author{
Gerhard Kramm$^{1}$, Martina Berger ${ }^{2}$, Ralph Dlugi² ${ }^{\text {, Nicole Mölders }}{ }^{3}$ \\ ${ }^{1}$ Engineering Meteorology Consulting, Fairbanks, AK, USA; ${ }^{2}$ Arbeitsgruppe Atmosphärische Prozesse (AGAP), \\ Munich, Germany; ${ }^{3}$ Department of Atmospheric Sciences and Geophysical Institute, University of Alaska Fairbanks, \\ Fairbanks, AK, USA
}

Correspondence to: Gerhard Kramm, gerhardkramm46@gmail.com; Martina Berger, berger.martina@arcor.de; Ralph Dlugi,rdlugi@gmx.de; Nicole Mölders, cmoelders@alaska.edu

Keywords: Global Mean Temperature, Spheroidal Mean Temperature, Climatological Mean Values for the Parallels of Latitude, Zonal Averages, Normal Temperature, Temperature Anomaly, Isothermal Charts, Solar Climate

Received: November 28, $2019 \quad$ Accepted: March 8, $2020 \quad$ Published: March 11, 2020

Copyright $\odot 2020$ by author(s) and Scientific Research Publishing Inc.

This work is licensed under the Creative Commons Attribution International License (CC BY 4.0).

http://creativecommons.org/licenses/by/4.0/

\section{(c) (i) Open Access}

\section{ABSTRACT}

The zonal averages of temperature (the so-called normal temperatures) for numerous parallels of latitude published between 1852 and 1913 by Dove, Forbes, Ferrel, Spitaler, Batchelder, Arrhenius, von Bezold, Hopfner, von Hann, and Börnstein were used to quantify the global (spherical) and spheroidal mean near-surface temperature of the terrestrial atmosphere. Only the datasets of Dove and Forbes published in the 1850 s provided global averages below $\langle T\rangle=14^{\circ} \mathrm{C}$, mainly due to the poor coverage of the Southern Hemisphere by observations during that time. The global averages derived from the distributions of normal temperatures published between 1877 and 1913 ranged from $\langle T\rangle=14.0^{\circ} \mathrm{C}$ (Batchelder) to $\langle T\rangle=15.1^{\circ} \mathrm{C}$ (Ferrel). The differences between the global and the spheroidal mean nearsurface air temperature are marginal. To examine the uncertainty due to interannual variability and different years considered in the historic zonal mean temperature distributions, the historical normal temperatures were perturbed within $\pm 2 \sigma$ to obtain ensembles of 50 realizations for each dataset. Numerical integrations of the perturbed distributions indicate uncertainties in the global averages in the range of $\pm 0.3^{\circ} \mathrm{C}$ to $\pm 0.6^{\circ} \mathrm{C}$ and depended on the number of available normal temperatures. Compared to our results, the global mean temperature of $\langle T\rangle=15.0^{\circ} \mathrm{C}$ published by von Hann in 1897 and von Bezold in 1901 and 1906 is notably too high, while $\langle T\rangle=14.4^{\circ} \mathrm{C}$ published by von Hann in 1908 seems to be more 
adequate within the range of uncertainty. The HadCRUT4 record provided $\langle T\rangle \cong 13.7^{\circ} \mathrm{C}$ for $1851-1880$ and $\langle T\rangle=13.6^{\circ} \mathrm{C}$ for $1881-1910$. The Berkeley record provided $\langle T\rangle=13.6^{\circ} \mathrm{C}$ and $\langle T\rangle \cong 13.5^{\circ} \mathrm{C}$ for these periods, respectively. The NASA GISS record yielded $\langle T\rangle=13.6^{\circ} \mathrm{C}$ for 1881-1910 as well. These results are notably lower than those based on the historic zonal means. For 1991-2018, the HadCRUT4, Berkeley, and NASA GISS records provided $\langle T\rangle=14.4^{\circ} \mathrm{C},\langle T\rangle=14.5^{\circ} \mathrm{C}$, and $\langle T\rangle=14.5^{\circ} \mathrm{C}$, respectively. The comparison of the 1991-2018 globally averaged near-surface temperature with those derived from distributions of zonal temperature averages for numerous parallels of latitude suggests no change for the past 100 years.

\section{INTRODUCTION}

Analyses of global surface-temperature change have been routinely carried out by several groups, including the NASA Goddard Institute for Space Studies (NASA GISS), the NOAA National Climatic Data Center (NCDC), and a joint effort of the UKMet Office Hadley Centre and the University of East Anglia Climatic Research Unit (HadCRU) [1]. The record of the anomaly of this global temperature with respect to the climatological normal (CLINO) 1961-1990 for 1850 to 2018, the so-called HadCRUT4 data, and the Berkeley record [2] for the same period as well as the NASA GISS data for 1880 to 2018 are shown in Figure 1. The latter two temperature-anomaly records were originally expressed with respect to the CLINO 1951-1980, but for comparison we related them to the CLINO 1961-1990 as well which has been retained as a standard reference period for long-term climate change assessments [3]. The results of the first GISS analyses of global surface-temperature change were published in 1981 [4]. The first series of the HadCRU observational surface-temperature data set is related to Jones [5]. Since Jones et al. [6] found for this CLINO 1961-1990 a global mean surface air temperature of $\langle T\rangle=14.0^{\circ} \mathrm{C} \quad\left(\langle T\rangle_{S H}=13.4^{\circ} \mathrm{C}\right.$ for the Southern Hemisphere, $\mathrm{SH}$, and $\langle T\rangle_{N H}=14.6^{\circ} \mathrm{C}$ for the Northern Hemisphere, $\mathrm{NH}$ ), we can estimate the global mean temperature for any climatological period (usually, at least, 30 years). The HadCRUT4 records, for instance, provided $\langle T\rangle=13.7^{\circ} \mathrm{C} \quad\left(\langle T\rangle_{S H}=13.1^{\circ} \mathrm{C}\right.$ and $\left.\langle T\rangle_{N H}=14.3^{\circ} \mathrm{C}\right)$ for $1851-1880$ and $\langle T\rangle=13.6^{\circ} \mathrm{C}$ $\left(\langle T\rangle_{S H}=13.0^{\circ} \mathrm{C}\right.$ and $\left.\langle T\rangle_{N H}=14.3^{\circ} \mathrm{C}\right)$ for $1881-1910$. The Berkeley record provided $\langle T\rangle=13.6^{\circ} \mathrm{C}$ and $\langle T\rangle=13.5^{\circ} \mathrm{C}$ for these periods, respectively. The NASA GISS records yielded $\langle T\rangle=13.6^{\circ} \mathrm{C}$ $\left(\langle T\rangle_{S H}=13.0^{\circ} \mathrm{C}\right.$ and $\left.\langle T\rangle_{N H}=14.2^{\circ} \mathrm{C}\right)$ for 1881-1910. When we considered 1991-2018, the HadCrut4 record yielded $\langle T\rangle=14.4^{\circ} \mathrm{C}\left(\langle T\rangle_{S H}=13.7^{\circ} \mathrm{C}\right.$ and $\left.\langle T\rangle_{N H}=15.2^{\circ} \mathrm{C}\right)$, the Berkeley record provided

$\langle T\rangle=14.5^{\circ} \mathrm{C}$, and the NASA GISS record provides $\langle T\rangle=14.5^{\circ} \mathrm{C} \quad\left(\langle T\rangle_{S H}=13.7^{\circ} \mathrm{C}\right.$ and $\left.\langle T\rangle_{N H}=15.2^{\circ} \mathrm{C}\right)$. Thus, these results suggest an increase in the globally averaged near-surface temperature during the past 100 years of $0.8^{\circ} \mathrm{C}, 1.0^{\circ} \mathrm{C}$, and $0.9^{\circ} \mathrm{C}$, respectively.

In 1900, von Bezold [7] (who became famous due to his five papers on the thermodynamics of the atmosphere and especially by introducing the potential temperature into the literature in 1888 [8]) estimated the climatological means of solar radiation (in German: "Sonnenstrahlung"), air temperature ("Lufttemperatur"), air pressure ("Luftdruck"), cloudiness ("Bewölkung"), and precipitation ("Niederschlag") for numerous parallels of latitude, so-called zonal averages (see Figure 2 and Figure 5). His estimates are based on: 1) Meech's [9] solar-radiation data, 2) the temperature data of Spitaler [10] (referred to as vB1901-1) and Batchelder [11] (referred to as vB1901-2), 3) Ferrel's [12] air-pressure data, 4) Murray's [13] precipitation data, and 5) Arrhenius' [14] cloudiness data that are based on Teisserenc de Bort's chart of cloudiness distribution. All these data are listed in von Hann's (ennobled by Austrian emperor Franz Joseph in 1910) first of his three volumes of the Handbook of Climatology [15, 16]. This epoch-making work on general and regional climatology included data and eyewitness descriptions of weather and climate [17]. The first edition was already published in 1883 [18]. Von Hann [15, 16] also reported the results of other climate researchers like Dove [19], Schoch [20], Satorius von Waltershausen [21], 


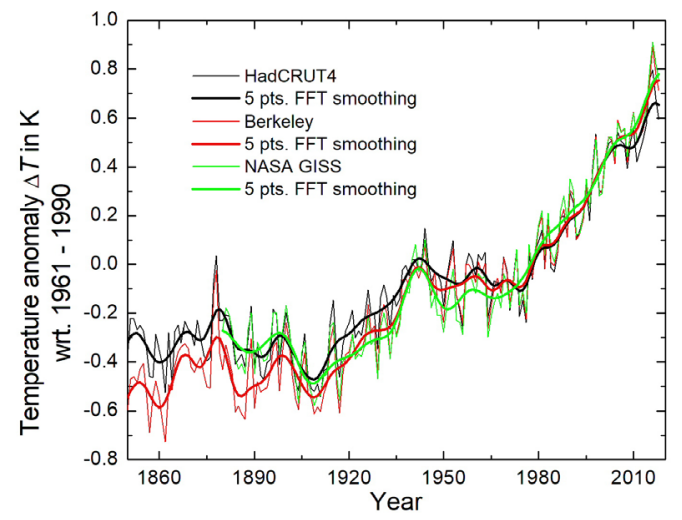

Figure 1. Time series of the annual temperature anomaly $\Delta T$ with respect to the climate normal 1961-1990 represented by the HADCRUT4 data for 1850 to 2018 (Morice et al. [22], but updated). Also shown are the Berkeley record for the same period (Rhode et al. [2], but updated), and the NASA GISS data for 1880 to 2018 (Hansen et al. [1], but updated).

\begin{tabular}{|c|c|c|c|c|c|c|c|c|c|c|c|c|c|}
\hline \multicolumn{2}{|c|}{ Geogr. Breite } & \multicolumn{2}{|c|}{$\begin{array}{l}\text { Sonnen- } \\
\text { strahlung }\end{array}$} & $S_{p 1}$ & $8 R$ & BATC & LER & \multicolumn{2}{|c|}{$\underset{\mathrm{mm}}{\text { L.uftdruck }}$} & \multicolumn{2}{|c|}{$\begin{array}{c}\text { Niederschlag } \\
\mathrm{em}\end{array}$} & \multicolumn{2}{|c|}{$\begin{array}{l}\text { Bewōlkung } \\
\text { Procent }\end{array}$} \\
\hline $\sin \phi$ & $\phi$ & $D$ & $\Delta D$ & $t$ & $\Delta t$ & $t$ & $\Delta t$ & $b$ & $\Delta b$ & & $\Delta p$ & & \\
\hline 1.00 & $0^{\circ} \mathrm{N}$ & 151.6 & & .0 & & -20.0 & & - & & - & & - & \\
\hline 0.95 & 7148 & & & & $\begin{array}{l}8.7 \\
6.7\end{array}$ & & $\begin{array}{l}8.5 \\
6.6\end{array}$ & $75^{8.7}$ & & 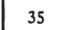 & & & \\
\hline 0.90 & 649 & 189.8 & & 1.6 & .7 & -4.9 & .6 & & & 40 & & & \\
\hline 0.85 & $5^{8} 13$ & 215.3 & 2 & & 3.1 & 2 & 3.2 & 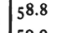 & $\begin{array}{r}+0.4 \\
+1.1\end{array}$ & 50 & $\begin{array}{r}+10 \\
+8\end{array}$ & 6I & \\
\hline & $\begin{array}{ll}538 \\
\end{array}$ & 237.0 & 18.6 & 5 & & 3.4 & 3.8 & 5 & & $5^{8}$ & 0 & 60 & \\
\hline 0.75 & 4835 & $\begin{array}{l}255.6 \\
272.2\end{array}$ & 16.6 & $\begin{array}{r}0.8 \\
10.6\end{array}$ & 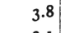 & $\begin{array}{l}2 \\
6\end{array}$ & 3.4 & & +0.7 & 58 & & 57 & \\
\hline & 4426 & $\begin{array}{l}272.2 \\
286.7\end{array}$ & 14.5 & & & & 9 & 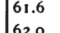 & & 55 & & 53 & \\
\hline & 4038 & $\begin{array}{l}286.7 \\
299.4\end{array}$ & 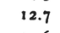 & & 4 & & 2.5 & 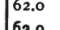 & .0 & 53 & & $5^{\circ}$ & \\
\hline & $3^{6} 5^{2}$ & $\begin{array}{l}299.4 \\
311.0\end{array}$ & II. & & & & .2 & & & 53 & & 47 & \\
\hline 0.55 & 3322 & \begin{tabular}{|l}
311.0 \\
321.0
\end{tabular} & 10.0 & 20 & $\circ$ & & 2.0 & $\begin{array}{l}6 \\
6\end{array}$ & - & 5 & +5 & & \\
\hline & 300 & $\begin{array}{l}321 \\
330\end{array}$ & 9.1 & 2 & 9 & 20.2 & .7 & & & 60 & & & \\
\hline 5 & 2645 & $\begin{array}{l}330.1 \\
337.6\end{array}$ & 7 & & 7 & 21.9 & 1.5 & 6 & -0 . & 64 & & 39 & \\
\hline & 23 & 3 & 6 & 2 & & .4 & .3 & 6 & & 69 & & 8 & \\
\hline o. & 2030 & 3 & 5 & & 0.6 & 7 & 1.1 & 5 & - & 80 & +29 & 39 & \\
\hline & 1728 & 3 & & & & & .7 & & - & 99 & & & \\
\hline & 1429 & 3 & 3 & & 2 & 26.5 & 0.5 & 5 & -0.2 & 9 & 6 & 40 & \\
\hline 0.2 & 1132 & 3 & & & & 27.0 & 0.1 & & & 5 & & 8 & \\
\hline & $83^{8}$ & 3 & 1.7 & 4 & & .1 & -0.1 & & & 5 & & $5^{2}$ & \\
\hline & 544 & 3 & & & & & & & & 36 & & 54 & \\
\hline & $25^{2}$ & 15 & & & & & & & & 6 & & 1 & \\
\hline 0.00 & $0^{\circ} 0$ & 365.24 & - & 25.9 & & 6 & & 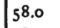 & & 55 & & 58 & 1 \\
\hline 0.05 & -252 & 364.8 & & 25.7 & .3 & 4 & & 58.3 & & 1 & & & \\
\hline & -544 & 3 & & 25.4 & & & & & 0.3 & 36 & $\begin{array}{r}-8 \\
-8\end{array}$ & 60 & \\
\hline & $-83^{8}$ & $36 \mathrm{I.9}$ & & 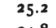 & - & 9 & -0.4 & 58.8 & $\begin{array}{r}+0.7 \\
+0.7\end{array}$ & 8 & - & $5^{8}$ & \\
\hline & -1132 & 358.6 & & 24.8 & & 5 & & & & 2 & & 56 & \\
\hline 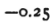 & -1429 & 3 & & 2 & -0.8 & & & 60.2 & + & 30 & & 53 & \\
\hline & -1728 & 349.8 & & & & & & & & 97 & & $5 t$ & \\
\hline-0. & -2030 & 3 & & & & & & .8 & & 71 & & 48 & \\
\hline & -2 & 6 & & & & & & & & 65 & & 46 & \\
\hline-0. & -2645 & 330.1 & - & & & & & 63 & & 65 & + & 45 & \\
\hline & -30 & 21.0 & -1 & & 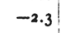 & & & & 5 & 66 & & 46 & \\
\hline & $\begin{array}{l}-3322 \\
-3652\end{array}$ & & -11 & & 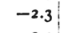 & & -2 & 61.7 & & $\begin{array}{l}72 \\
83\end{array}$ & + & 53 & \\
\hline- & -4038 & 286.7 & & 11.5 & & 11.8 & & & & 97 & & 57 & \\
\hline & -4426 & 272.2 & & 9.2 & & 9.2 & $\begin{array}{l}-2 \\
-2\end{array}$ & 57.2 & & 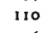 & + & 1 & \\
\hline & -4835 & 255.6 & -18 & & -2.5 & 3 & -3 & & 4.0 & 16 & & 65 & \\
\hline & & 37.0 & & 2 & & & -3.3 & 50.0 & & 3 & & 9 & \\
\hline-0.8 & $-58+3$ & & -2 & & - & -0.1 & - & 44 & -4.2 & 105 & -10 & 74 & - \\
\hline & -64 & 189.8 & & & & & & & & 95 & & & - \\
\hline & -7 & & -17 & - & - & - & 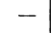 & & 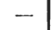 & - & - & & \\
\hline & & & & & & & & & & & & & \\
\hline
\end{tabular}

Figure 2. Von Bezold's [7] table (digitized by Google) of climatological means of solar radiation ("Sonnenstrahlung" in thermal days [9]), temperature ("Temperatur" in ${ }^{\circ} \mathrm{C}$ ), air pressure ("Luftdruck" in $\mathrm{mm} \mathrm{Hg}$ ), precipitation ("Niederschlag" in $\mathrm{cm}$ ), and cloudiness ("Bewölkung" in \%) for numerous parallels of latitude ("Geographische Breite" $\phi$ in ${ }^{\circ}$ ). Values in parenthesis are uncertain. The normal-temperature-datasets are referred to as vB1901-1 ("Spitaler") and vB1901-2 ("Batchelder"). 
Ferrel [12], and Spitaler [10]. Their results are listed in Table 1. Thus, von Hann $[15,16]$ concluded that the average temperature for the Earth as a whole is about $\langle T\rangle=15.0^{\circ} \mathrm{C}$, where both hemispheres have nearly the same temperatures, but the Southern Hemisphere would probably be slightly cooler because heat is carried across the equator by the strong southeast trade drift. Note that the original datasets of Dove [19], Ferrel [12], and Spitaler [10] used in our study are referred to as Do1852, Fe1877, and Sp1885, respectively (Table 2 ).

A slight improvement of Dove's data was derived by Forbes [23] referred to as Fo1859 (Table 2). Furthermore, Spitaler [10] used the isothermal charts of Wild [24] and von Hann [25]. Whereas Batchelder [11] and Arrhenius [14,26] considered Buchan's [27] isothermal charts which are based on the observations of the "Challenger" Expedition. The datasets of Batchelder and Arrhenius are referred to as Ba1894, A1896-1, and A1896-2, respectively (Table 2). Spitaler [10], Batchelder [11], and Arrhenius [14, 26] considered the $5^{\text {th }}$ and the $10^{\text {th }}$ degree of latitude, respectively. In contrast to this, von Bezold [7] used an equidistant distribution in $\sin \phi$, where $\phi$ is the latitude. Thus, von Bezold's datasets differ slightly from those of the original ones due to his interpolation procedure.

Von Bezold [7] also estimated the annual mean temperature for the Earth and confirmed von Hann's $[15,16]$ value of $\langle T\rangle=15.0^{\circ} \mathrm{C}$. Von Bezold's result is based on the table shown in Figure 2. In his presentation of von Bezold's [7] paper, however, von Hann [30] argued that Batchelder's [11] temperature values for the Tropics were undoubtedly too high because the isotherms of the "Challenger" reports were based on too high temperature averages (locally $1^{\circ} \mathrm{C}-2^{\circ} \mathrm{C}$ ). Von Hann [30] suggested an average temperature for the Earth of $\langle T\rangle=14.7^{\circ} \mathrm{C}$. Von Bezold's [7] table was eventually adopted by Börnstein [31], who only considered Spitaler's [10] meridional distribution of zonal averages of temperature. Note that the zonal averages of temperature are also called the normal temperatures [11, 18].

In 1906, von Bezold [29] presented slightly improved results for the climatological means of the near-surface air temperature along numerous parallels of latitude (referred to as vB1906, Figure 3). Again, von Bezold estimated the annual mean temperature for the Earth as $\langle T\rangle=15.0^{\circ} \mathrm{C}$.

Von Hann [32] re-examined the climatological mean temperatures along numerous parallels of latitude in the first volume of the third edition of his handbook. He not only considered the normal-temperature-datasets of Spitaler [10] and Batchelder [11], but also those of Hopfner [33]. Hopfner followed Dove's [19] epoch-making work, but he considered Buchan's [27] isothermal charts available for each month of the year and the whole year, respectively. Based on these isothermal charts (already used by Batchelder

Table 1. Average temperature for the Northern Hemisphere (NH), Southern Hemisphere ( $\mathrm{SH}$ ), and the Earth as reported by von Hann $([15,16])$.

\begin{tabular}{ccccc}
\hline Author & Year of publication & $\mathrm{NH}\left({ }^{\circ} \mathrm{C}\right)$ & $\mathrm{SH}\left({ }^{\circ} \mathrm{C}\right)$ & $\operatorname{Earth}^{*}\left({ }^{\circ} \mathrm{C}\right)$ \\
\hline Dove [19] & 1852 & 15.5 & - & - \\
Schoch [20] & 1856 & 15.1 & 14.9 & 15.0 \\
Satorius von Waltershausen [21] & 1865 & - & 15.8 & - \\
Ferrel [12] & 1877 & 15.3 & 16.0 & 15.7 \\
Spitaler [10] & 1885 & 15.4 & 14.8 & 15.1 \\
von Hann [28] & 1882 & - & 15.4 & - \\
von Hann [15, 16] & $1897 / 1903$ & - & 14.7 & -
\end{tabular}

*) Based on Equation (9). 
Table 2. Normal-temperature-datasets for numerous parallels of latitude as published by Dove [19], Forbes [23], Ferrel [12], Spitaler [10], Batchelder [11], Arrhenius [14, 26], Hopfner [33], Defant and Obst [36], von Hann-Süring [38], and Sellers [39]. Bold numbers denote the Thermal Equator.

Author and data set (temperatures in ${ }^{\circ} \mathrm{C}$ )

\begin{tabular}{|c|c|c|c|c|c|c|c|c|c|c|c|c|}
\hline $\begin{array}{l}\text { Latitude } \\
\text { in }^{\circ}\end{array}$ & 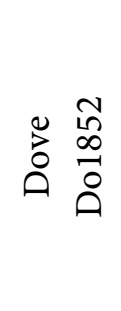 & 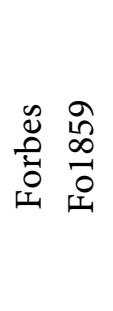 & 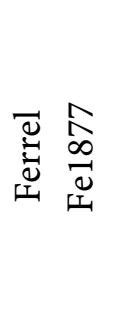 & 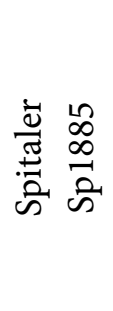 & 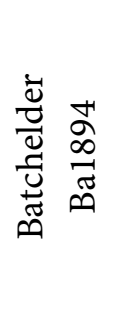 & 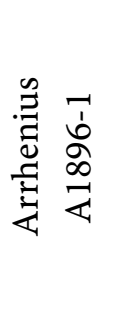 & 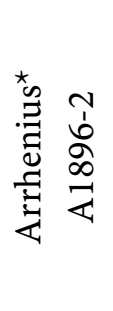 & 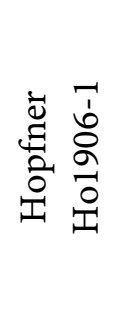 & 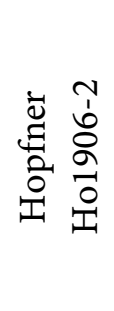 & 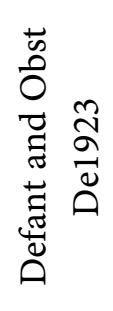 & 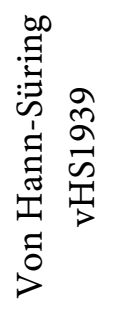 & 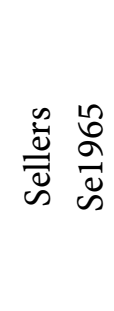 \\
\hline $90 \mathrm{~N}$ & -16.5 & -16.5 & - & -20 & - & - & - & - & - & -22.7 & -22.7 & - \\
\hline 85 & - & - & - & - & - & - & - & - & - & - & -21.2 & -23.5 \\
\hline 80 & -14 & -14 & -15.3 & -16.5 & -16.9 & - & - & -16.1 & -16.4 & -17.1 & -17.2 & - \\
\hline 75 & - & - & - & -13.3 & - & - & - & - & - & - & -14.7 & -15.8 \\
\hline 70 & -8.9 & -8.7 & -9.8 & -9.9 & -10.1 & - & - & -10.1 & -9.6 & -10.7 & -10.7 & - \\
\hline 65 & - & - & - & -4.3 & - & -5.5 & -7 & - & - & - & -5.8 & -7.1 \\
\hline 60 & -1 & -1.2 & -1.5 & -0.8 & -1.3 & - & - & -1.1 & -0.8 & -1.1 & -1.1 & - \\
\hline 55 & - & - & - & 2.3 & - & 2.5 & 1.2 & - & - & - & 2.3 & 0.6 \\
\hline 50 & 5.4 & 5.8 & 6.3 & 5.6 & 5.8 & - & - & 5.8 & 6.2 & 5.8 & 5.8 & - \\
\hline 45 & - & - & - & 9.6 & - & 10.3 & 8.7 & - & - & - & 9.8 & 7.6 \\
\hline 40 & 13.6 & 13.6 & 13.6 & 14 & 14 & - & - & 14.6 & 14.5 & 14.1 & 14.1 & - \\
\hline 35 & - & - & - & 17.1 & - & 17.5 & 15.3 & - & - & - & 17.2 & 14.1 \\
\hline 30 & 21 & 21 & 19.8 & 20.3 & 20.2 & - & - & 20.8 & 20.7 & 20.4 & 20.4 & - \\
\hline 25 & - & - & - & 23.7 & - & 23.1 & 21.9 & - & - & - & 23.6 & 20.5 \\
\hline 20 & 25.2 & 25.3 & 25.3 & 25.6 & 24.9 & - & - & 25.3 & 25.2 & 25.3 & 25.3 & - \\
\hline 15 & - & - & - & 26.3 & - & 26.2 & 25.4 & - & - & - & 26.3 & 25.2 \\
\hline 10 & 26.6 & 26.6 & 27.2 & 26.4 & 27.1 & - & - & 26.7 & 26.8 & 26.8 & 26.7 & - \\
\hline 5 & - & - & - & 26.1 & - & 26.7 & 25.5 & - & - & - & 26.4 & 25.6 \\
\hline 0 & 26.5 & 26.5 & 26.7 & 25.9 & 26.6 & - & - & 26.4 & 26.3 & 26.3 & 26.2 & - \\
\hline
\end{tabular}




\section{Continued}

\begin{tabular}{|c|c|c|c|c|c|c|c|c|c|c|c|c|}
\hline-5 & - & - & - & 25.5 & - & 26.1 & 25.1 & - & - & - & 25.8 & 24.9 \\
\hline-10 & 25.5 & 25.6 & 25.9 & 25 & 25.7 & - & - & 25.6 & 25.4 & 25.5 & 25.3 & - \\
\hline-15 & - & - & - & 24.2 & - & 24.3 & 23.2 & - & - & - & 24.4 & 23.4 \\
\hline-20 & 23.4 & 23.4 & 23.7 & 22.7 & 23.3 & - & - & 23 & 22.9 & 23 & 22.9 & - \\
\hline-25 & - & - & - & 20.9 & - & 20.6 & 19.7 & - & - & - & 20.9 & 18.9 \\
\hline-30 & 19.4 & 19.4 & 19.3 & 18.5 & 18.3 & - & - & 18 & 18.3 & 18.4 & 18.4 & - \\
\hline-35 & - & - & - & 15.2 & - & 14.8 & 14.5 & - & - & - & 15.2 & 13.6 \\
\hline-40 & 12.5 & 12.6 & 14.4 & 11.8 & 12.2 & - & - & 11.9 & 11.7 & 11.9 & 11.9 & - \\
\hline-45 & - & - & - & 8.9 & - & 8.8 & 8.7 & - & - & - & 8.8 & 8.8 \\
\hline-50 & - & - & 8.8 & 5.9 & 5.3 & - & - & 5.7 & 5.1 & 5.4 & 5.8 & - \\
\hline-55 & - & - & - & 3.2 & - & 2.1 & 2.1 & - & - & - & 1.3 & 1.3 \\
\hline-60 & - & - & 1.8 & 0.2 & - & - & - & - & -0.8 & -3.2 & -3.4 & - \\
\hline-65 & - & - & - & - & - & - & - & - & - & - & -8.2 & -10.9 \\
\hline-70 & - & - & - & -4.9 & - & - & - & - & - & -12 & -13.6 & - \\
\hline-75 & - & - & - & - & - & - & - & - & - & - & -20.2 & -29.4 \\
\hline-80 & - & - & - & -8.4 & - & - & - & - & - & -20.6 & -27 & - \\
\hline-85 & - & - & - & - & - & - & - & - & - & - & -31.4 & -47.8 \\
\hline$-90 \mathrm{~S}$ & - & - & - & -9.3 & - & - & - & - & - & -25 & -33.1 & - \\
\hline
\end{tabular}

*) Re-corrected to mean terrain height above sea level.

[11] and Arrhenius [14, 26]), Hopfner [33] derived two slightly different normal-temperature-datasets for numerous parallels of latitude: 1) the twelve-monthly means and 2) directly taken from the chart of annual isotherms. These two normal-temperature-datasets are referred to as Ho1906-1 and Ho1906-2 (Table 2). Figure 4 shows von Hann's normal-temperature dataset (referred to as vH1908). Based on these data, he suggested $\langle T\rangle=14.4^{\circ} \mathrm{C}$ (see also Lockyer [34]). Börnstein [35] also re-examined the climatological mean values of solar radiation, air temperature, air pressure, precipitation, and cloudiness along numerous parallels of latitude (Figure 5). Börnstein's normal-temperature-dataset, referred to as Bö1913, completely agrees with von Bezold's [29] vB1906.

Obviously, the results of well-known climate researchers for the average temperature of the nearsurface air temperature published during the second half of the $19^{\text {th }}$ century and the first two decades of the $20^{\text {th }}$ century are notably higher than those derived from the HadCRUT4, Berkeley, and NASA GISS 
v. Bezold, Ober Strahlungsnormalen und Mittellinien der Temperatur.

Mitteltemperaturen der Breitenkreise ').

\begin{tabular}{|c|c|c|c|c|c|c|c|}
\hline \multirow{2}{*}{$\sin \varphi$} & \multicolumn{3}{|c|}{ Nördliche Halbkugel } & & \multicolumn{3}{|c|}{ Südliche Halbkugel } \\
\hline & Jahr & Januar & Juli & & Jahr & Januar & Juli \\
\hline 0.00 & 25.9 & 26.2 & 25.5 & & 25.9 & 26.2 & 25.5 \\
\hline 0.05 & 26.1 & 26.2 & 26.1 & & 25.7 & 26.2 & 25.2 \\
\hline 0.10 & 26.3 & 26.2 & 26.4 & & $25 . \overline{5}$ & 26.1 & 24.8 \\
\hline 0.15 & 26.4 & 25.9 & 26.5 & & 25.2 & 26.0 & 24.3 \\
\hline 0.20 & 26.4 & 25.2 & 27.0 & & 24.9 & 25.9 & 23.7 \\
\hline 0.25 & 26.3 & 24.1 & 27.8 & 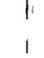 & 24.4 & 25.7 & 22.8 \\
\hline 0.30 & 26.1 & 22.8 & 28.1 & & 23.5 & 25.6 & 21.7 \\
\hline 0.35 & 25.4 & 21.5 & 28.1 & & 22.6 & 25.5 & 20.4 \\
\hline 0.40 & 24.3 & 19.5 & 28.0 & & 21.5 & 25.0 & 18.9 \\
\hline 0.44 & - & 17.4 & - & 1 & - & - & - \\
\hline $0.4 !$ & 22.5 & 16.9 & 27.8 & 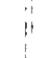 & 20.2 & 24.2 & 17.4 \\
\hline 0.48 & - & 15.0 & - & 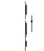 & - & - & - \\
\hline 0.50 & 20.3 & 13.9 & 27.4 & 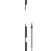 & 18.6 & 22.9 & 15.3 \\
\hline 0.51 & - & - & - & 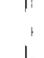 & - & - & 15.0 \\
\hline 0.52 & - & 12.6 & - & $!$ & - & - & - \\
\hline 0.55 & 18.3 & 10.5 & 26.4 & i. & 16.5 & 20.6 & 13.5 \\
\hline 0.58 & - & - & - & & 15.0 & - & - \\
\hline 0.60 & 16.1 & 7.0 & 25.0 & & 14.1 & $1 \times .2$ & 11.5 \\
\hline 0.62 & 15.0 & - & - & & - & 17.4 & - \\
\hline 0.65 & 13.7 & 3.5 & 23.5 & & 11.6 & 15.9 & 9.5 \\
\hline 0.67 & - & - & - & 1 & - & 15.0 & - \\
\hline 0.70 & 10.3 & -1.6 & 21.1 & & 9.2 & 13.0 & 7.0 \\
\hline 0.71 & - & - & - & ! & - & 12.6 & - \\
\hline 0.75 & 6.8 & -6.0 & 18.8 & ! & 6.7 & 9.5 & 4.4 \\
\hline 0.78 & - & - & 17.4 & i & - & - & - \\
\hline 0.80 & 3.5 & -9.7 & 16.5 & 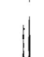 & (2.9) & - & - \\
\hline 0.84 & - & - & 15.0 & & - & - & - \\
\hline 0.85 & 0.4 & -13.2 & 14.7 & 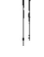 & $(-1.6)$ & - & - \\
\hline 0.90 & -3.6 & -21.5 & 12.8 & & $(-7.4)$ & - & - \\
\hline 0.95 & -11.1 & -26.9 & 6.0 & & $(-13.9)$ & - & - \\
\hline 1.00 & $(-22.7)$ & $(-: 36.0)$ & 0.0 & 4 & $(-25.0)$ & - & - \\
\hline
\end{tabular}

Die Sinusse sind hier nur ihrem absoluten Werte nach ohne Rücksicht auf das Vorzeichen angegeben.

Figure 3. Von Bezold's [29] table (digitized by Google) of mean annual and mean monthly (January and July) temperatures for numerous parallels of latitude (characterized by the sine of the respective angle) of both the Northern Hemisphere ("Nördliche Halbkugel") and the Southern Hemisphere ("südliche Halbkugel"). Temperatures are in ${ }^{\circ} \mathrm{C}$. Values in parenthesis are uncertain. The normal-temperature-dataset is referred to as $\mathrm{vB1906.Note}$ that von Bezold considered $|\sin \varphi|$, where $\varphi$ is the latitude. 
Mittlere Temperatur der Breitegrade.

\begin{tabular}{|c|c|c|c|c|c|c|c|c|c|c|c|}
\hline & \multicolumn{2}{|c|}{$\begin{array}{l}\text { Landbe- } \\
\text { deckung } \\
\text { in Proz. }\end{array}$} & \multicolumn{3}{|c|}{$\begin{array}{l}\text { Mittlere Temperatur, } \\
\text { Spitaler, } \\
\text { Batchelder, Hopfner }\end{array}$} & \multirow{2}{*}{ 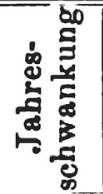 } & \multicolumn{5}{|c|}{ Nach Hopfner allein } \\
\hline & a & b & Jahr & Jan. & Juli & & Jan. & |April | & Juli & Okt. & | Jahr \\
\hline N-Po & - & - & $-22,7$ & -41 & -1 & 40 & - & - & - & - & - \\
\hline 80 & 22 & 24 & $-17,4$ & $-33,5$ & & 35,2 & $-33,3$ & $3-20,4$ & 1,9 & $-16,0$ & $-16,1$ \\
\hline 0 & 55 & 54 & $-10,3$ & $-26,4$ & 6,9 & 33,3 & $-26,4$ & $\mid-12,7$ & 6,7 & 9,2 & $-10,1$ \\
\hline 60 & 61 & 64 & $-1,0$ & $-15,9$ & 14,0 & 29,9 & $-16,1$ & $1-2,2$ & 14,0 & 0,1 & $-1,1$ \\
\hline . & 56 & 55 & 5,9 & $-7,1$ & 18,0 & 25,1 & 7,2 & 5,2 & 17,9 & 6,9 & 5,8 \\
\hline 40 & 46 & 47 & 14,1 & 5,5 & 24, & 18,5 & 5,9 & 13,1 & 24,2 & 15,7 & 14,6 \\
\hline 20 & 43 & 42 & 20,4 & 14,7 & 27,3 & 12,6 & 15,0 & 20,1 & 27,2 & 21.8 & 20,8 \\
\hline 20 & 33 & 32 & 25,3 & 21, & 28,0 & 6,1 & 21,9 & 25,2 & 27,8 & 26,4 & 25,3 \\
\hline 10 & 24 & 24 & 26,8 & 25,8 & 26.9 & 1,1 & 25,8 & 27,2 & 27,0 & 26,9 & 26,8 \\
\hline$\AA \mathrm{q}$. & 22 & 23 & 26,3 & 26,5 & 25 , & 0,9 & 26,5 & 26,6 & 25,7 & 26,5 & 26,4 \\
\hline 10 & 20 & 23 & 25,4 & 26,4 & 23,9 & 2,5 & 26,7 & 25,9 & 23,8 & 25,7 & 25,6 \\
\hline 20 & 24 & 23 & 23, & 25 & 19 & 5,5 & 25,2 & 24,0 & 19,4 & 22,8 & 23,0 \\
\hline 30 & 20 & 18 & 18,4 & 21,6 & 14,5 & 7,1 & 21,2 & 18,7 & 14,3 & 18,0 & 18 \\
\hline 40 & 4 & 5 & 11,9 & 15,4 & 8 & 6,6 & 15,1 & 12,5 & 8,4 & 11,7 & 11,9 \\
\hline & 2 & 2 & 5, & 8,4 & 3,0 & 5,4 & 8,6 & 5,4 & 3,1 & 0, & 5,7 \\
\hline 60 & 0 & 1 & $-1,6$ & 2,7 & $-7,6$ & 10,3 & 1,7 & $7 \mid-0,2$ & - & $-0,9$ & - \\
\hline 0 & - & - & $-11,5$ & $-0,8$ & $-22,2$ & $(21,4)$ & - & - & - & - & - \\
\hline & 一 & - & $(-10,8)$ & $(-6,5)$ & $-31,5$ & $(25,0)$ & - & - & - & - & - \\
\hline S-Po & - & - & & 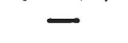 & 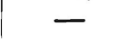 & (2) & - & - & - & - & - \\
\hline
\end{tabular}

Figure 4. Von Hann's [32] table (digitized by Google) of annual and monthly (January, April, July, and October) mean temperatures for numerous parallels of latitude with respect to Spitaler [10], Batchelder [11], and Hopfner [33]. Temperatures are in ${ }^{\circ} \mathrm{C}$. Land coverage ("Landbedeckung") is in \%. Values in parenthesis are uncertain. This dataset is referred to as vH1908.

records. The goal our paper is, therefore, to assess the results of von Hann and his fellow climate researchers. Since Defant and Obst [36], Köppen [37], von Hann-Süring [38], and Sellers [39] also published meridional distributions of the normal temperatures, we used their datasets for additional assessment. These normal-temperature datasets are referred to as De1923, K1936, vHS1939, and Se1965, respectively. Eventually, Haurwitz and Austin [40] and Blüthgen [41] adopted vHS1939.

Since three different temperature scales related to de Réaumur (e.g., Dove), Celsius (e.g., von Hann), and Fahrenheit (e.g., Buchan) were used, we used the original sources to check all datasets adopted and converted by others. No serious conversion error was detected.

\section{THE GLOBALLY AVERAGED SURFACE TEMPERATURE}

The average over the Earth' surface reads [42-44]

$$
\langle\psi\rangle=\frac{\int_{\Omega} \psi(r, \theta, \varphi) r^{2}(\theta, \varphi) \mathrm{d} \Omega}{\int_{\Omega} r^{2}(\theta, \varphi) \mathrm{d} \Omega}=\frac{\int_{0}^{2 \pi} \int_{0}^{\pi} \psi(r, \theta, \varphi) r^{2}(\theta, \varphi) \sin \theta \mathrm{d} \theta \mathrm{d} \varphi}{\int_{0}^{2 \pi} \int_{0}^{\pi} r^{2}(\theta, \varphi) \sin \theta \mathrm{d} \theta \mathrm{d} \varphi}
$$

Here, $\psi(r, \theta, \varphi)$ is an arbitrary variable, $r(\theta, \varphi)$ is the radius, $\Omega=4 \pi$ is the solid angle of the entire planet, and $\mathrm{d} \Omega=\sin \theta \mathrm{d} \theta \mathrm{d} \varphi$ is the differential solid angle, where $\theta$ and $\varphi$ are the zenith and azimuthal angles, respectively, in a spherical coordinate frame (Figure 6). Note that $\theta$ ranges from 0 to $\pi$, and $\varphi$ ranges from 0 to $2 \pi$. 
Klimatologische Mittelwerte der Breitenkreise.

\begin{tabular}{|c|c|c|c|c|c|c|c|}
\hline \multicolumn{3}{|c|}{ Geographische Breite } & \multirow{2}{*}{$\begin{array}{l}\text { Sonnen- } \\
\text { strahlung }\end{array}$} & \multirow{2}{*}{$\begin{array}{c}\text { Tem- } \\
\text { peratur }\end{array}$} & \multirow{2}{*}{$\begin{array}{l}\text { Luftdruck } \\
\qquad \mathrm{mm}\end{array}$} & \multirow{2}{*}{$\begin{array}{c}\text { Nieder- } \\
\text { schlag } \\
\text { mm }\end{array}$} & \multirow{2}{*}{$\begin{array}{c}\text { Be- } \\
\text { woolkung } \\
\text { Proz. }\end{array}$} \\
\hline Sinus & Win & kel & & & & & \\
\hline 1,00 & $90^{\circ}$ & $\mathbf{N}$ & $151,6^{d}$ & $\left(-22,7^{\circ}\right)$ & - & - & - \\
\hline 0,95 & $71^{\circ}$ & $48^{\prime}$ & 169,2 & $-11,1$ & 758,7 & $19+5$ & - \\
\hline 0,90 & & 9 & 189,8 & $-3,6$ & 758,4 & - & 60 \\
\hline 0,85 & & 13 & 215,3 & 0,4 & 758,8 & 1610 & 61 \\
\hline 0,80 & 53 & 8 & 237,0 & 3,5 & 759,9 & - & 60 \\
\hline 0,75 & 48 & 35 & 255,6 & 6,8 & 760,9 & 895 & 57 \\
\hline 0,70 & 44 & 26 & 272,2 & 10,3 & 761,6 & - & 53 \\
\hline 0,65 & 40 & 38 & 286,7 & 13,7 & 762,0 & 475 & 50 \\
\hline 0,60 & 36 & 52 & 299,4 & 16,1 & 762,0 & - & 47 \\
\hline 0,55 & 33 & 22 & 311,0 & 18,3 & 761,9 & 455 & 44 \\
\hline 0,50 & 30 & o & 321,0 & 20,3 & 761,7 & - & 42 \\
\hline 0,45 & 26 & 45 & 330,1 & 22,5 & 761,1 & 575 & 39 \\
\hline 0,40 & 23 & 34 & 337,6 & 24,3 & 760,3 & - & 38 \\
\hline 0,35 & 20 & 30 & 344,3 & 25,4 & 759,3 & 865 & 39 \\
\hline 0,30 & 17 & 28 & 349,8 & 26,1 & 758,7 & - & 42 \\
\hline 0,25 & 14 & 29 & 354,8 & 26,3 & 758,1 & 990 & 45 \\
\hline 0,20 & 11 & 32 & 358,6 & 26,4 & 757,9 & - & 48 \\
\hline 0,15 & 8 & 38 & 361,9 & 26,4 & 757,9 & 690 & 52 \\
\hline 0,10 & 5 & 44 & 363,6 & 26,3 & 757,9 & - & 54 \\
\hline 0,05 & 2 & 52 & 364,8 & 26,1 & 758,0 & 300 & 57 \\
\hline 0,00 & o & 0 & 365,24 & 25,9 & 758,0 & - & 58 \\
\hline$-0,05$ & -2 & 52 & 364,8 & 25,7 & 758,3 & - & 60 \\
\hline$-0,10$ & -5 & 44 & 363,6 & 25,5 & 758,5 & - & 60 \\
\hline$-0,15$ & -8 & 38 & 361,9 & 25,2 & 758,8 & - & 58 \\
\hline$-0,20$ & -11 & 32 & 358,6 & 24,9 & 759.5 & - & 56 \\
\hline$-0,25$ & -14 & 29 & 354,8 & 24,4 & 760,2 & - & 53 \\
\hline$-0,30$ & -17 & 28 & 349,8 & 23,5 & 761,0 & - & 51 \\
\hline$-0,35$ & -20 & 30 & 344,3 & 22,6 & 761,8 & - & 48 \\
\hline$-0,40$ & -23 & 34 & 337,6 & 21,5 & 762,6 & - & 46 \\
\hline$-0,45$ & -26 & 45 & 330,1 & 20,2 & 763,2 & -- & 45 \\
\hline$-0,50$ & -30 & 0 & 321,0 & 18,6 & 763,5 & - & 46 \\
\hline$-0,55$ & -33 & 22 & 311,0 & 16,5 & 763,0 & - & 49 \\
\hline$-0,60$ & --36 & 52 & 299,4 & 14,1 & 761,7 & - & 53 \\
\hline$-0,65$ & -40 & 38 & 286,7 & 11,6 & 759,9 & - & 57 \\
\hline$-0,70$ & -44 & 26 & 272,2 & 9,2 & 757,2 & - & 61 \\
\hline$-0,75$ & -48 & 35 & 255,6 & 6,7 & 754,0 & - & 65 \\
\hline$-0,80$ & -53 & 8 & 237,0 & $(2,9)$ & 750,0 & - & 69 \\
\hline$-0,85$ & -58 & 13 & 215,3 & $(-1,6)$ & 744,5 & - & 74 \\
\hline$-0,90$ & -64 & 9 & 189,8 & $(-7,4)$ & 740,3 & - & - \\
\hline$-0,95$ & $-i 1$ & 48 & 169,2 & $(-13,9)$ & - & - & - \\
\hline$-1,00$ & -90 & $\mathrm{~S}$ & 151,6 & $(-25,0)$ & - & - & - \\
\hline
\end{tabular}

Figure 5. Börnstein's [35] table (digitized by Google) of climatological means of solar radiation ("Sonnenstrahlung" in thermal days [9]), temperature ("Temperatur" in ${ }^{\circ} \mathrm{C}$ ), air pressure ("Luftdruck" in $\mathrm{mm} \mathrm{Hg}$ ), precipitation ("Niederschlag" in $\mathrm{mm}$ ), and cloudiness ("Bewölkung" in \%) for numerous parallels of latitude ("Geographische Breite" in ").Values in parenthesis are uncertain. The dataset of the normal temperatures is referred to as Bö1913. 


\subsection{Spherical Averaging}

For a spherical shape of the Earth, we have $r_{E}=r=$ const. and, hence, $\psi(r, \theta, \varphi)=\psi(\theta, \varphi)$. Usually, $r_{E}$ is represented by the volumetric mean radius of $r_{E, V} \cong 6371.0 \mathrm{~km}$. Thus, Equation (1) can be written as $[10,42,44,46]$

$$
\langle\psi\rangle=\frac{r_{E}^{2} \int_{0}^{2 \pi} \int_{0}^{\pi} \psi(\theta, \varphi) \sin \theta \mathrm{d} \theta \mathrm{d} \varphi}{r_{E}^{2} \int_{0}^{2 \pi} \int_{0}^{\pi} \sin \theta \mathrm{d} \theta \mathrm{d} \varphi}=\frac{1}{4 \pi} \int_{0}^{2 \pi} \int_{0}^{\pi} \psi(\theta, \varphi) \sin \theta \mathrm{d} \theta \mathrm{d} \varphi
$$

Since the average along a parallel of latitude, i.e., the zonal average, is defined by [44, 46-49]

$$
\bar{\psi}(\theta)=\frac{1}{2 \pi} \int_{0}^{2 \pi} \psi(\theta, \varphi) \mathrm{d} \varphi
$$

Equation (2) can be written as

$$
\langle\psi\rangle=\frac{1}{4 \pi} \int_{0}^{2 \pi} \int_{0}^{\pi} \psi(\theta, \varphi) \sin \theta \mathrm{d} \theta \mathrm{d} \varphi=\frac{2 \pi}{4 \pi} \int_{0}^{\pi} \sin \theta \mathrm{d} \theta\left(\frac{1}{2 \pi} \int_{0}^{2 \pi} \psi(\theta, \varphi) \mathrm{d} \varphi\right)=\frac{1}{2} \int_{0}^{\pi} \bar{\psi}(\theta) \sin \theta \mathrm{d} \theta
$$

Inserting the averages for both the northern and the southern hemispheres given by [10]

$$
\langle\psi\rangle_{N H}=\frac{1}{2 \pi} \int_{0}^{2 \pi} \int_{0}^{\pi / 2} \psi(\theta, \varphi) \sin \theta \mathrm{d} \theta \mathrm{d} \varphi=\int_{0}^{\pi / 2} \bar{\psi}(\theta) \sin \theta \mathrm{d} \theta
$$

and

$$
\langle\psi\rangle_{S H}=\frac{1}{2 \pi} \int_{0}^{2 \pi} \int_{\pi / 2}^{\pi} \psi(\theta, \varphi) \sin \theta \mathrm{d} \theta \mathrm{d} \varphi=\int_{\pi / 2}^{\pi} \bar{\psi}(\theta) \sin \theta \mathrm{d} \theta
$$

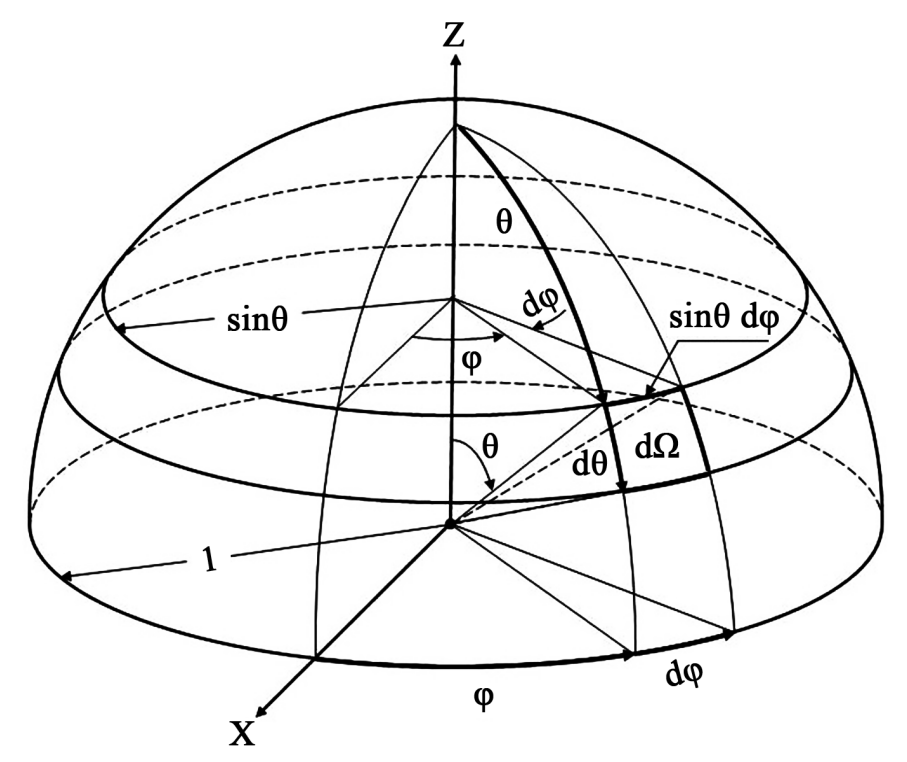

Figure 6. Mathematical representation of the solid angle. Here, $d \Omega=\sin \theta d \theta d \varphi$ is the differential solid angle, where $\theta$ and $\varphi$ are the zenith and azimuthal angles, respectively (adopted from Kasten and Raschke [45]). 
leads to

$$
\langle\psi\rangle=\frac{1}{2}\left(\langle\psi\rangle_{N H}+\langle\psi\rangle_{S H}\right)
$$

When we set, for instance, $\psi(\theta, \varphi)=T(\theta, \varphi)$, we obtain the globally averaged near-surface air temperature

$$
\langle T\rangle=\frac{1}{2} \int_{0}^{\pi} \bar{T}(\theta) \sin \theta \mathrm{d} \theta=\frac{1}{2}\left(\langle T\rangle_{N H}+\langle T\rangle_{S H}\right)
$$

Since the angle of the latitude, $\phi$, and the zenith angle, $\theta$, are related to each other by $\phi=\pi / 2-\theta$, Equation (8) can be written as

$$
\langle T\rangle=\frac{1}{2} \int_{-\pi / 2}^{\pi / 2} \bar{T}(\phi) \cos \phi \mathrm{d} \phi=\frac{1}{2}\left(\langle T\rangle_{N H}+\langle T\rangle_{S H}\right)
$$

with

$$
\langle T\rangle_{N H}=\int_{0}^{\pi / 2} \bar{T}(\phi) \cos \phi \mathrm{d} \phi
$$

and

$$
\langle T\rangle_{S H}=\int_{-\pi / 2}^{0} \bar{T}(\phi) \cos \phi \mathrm{d} \phi
$$

\subsection{Spheroidal Averaging}

The Earth is, of course, not a sphere, but in a first approximation an oblate ellipsoid of revolution, i.e. an oblate spheroid, flattened at the poles and bulging at the Equator due to centrifugal forces. This oblate spheroid serves as a surface of reference for the mathematical reduction of geodetic and cartographic data [50]. Its parameters are the semi-major axis $a \cong 6378.1 \mathrm{~km}$, the semi-minor axis $c \cong 6356.8 \mathrm{~km}$ and the flattening $f=(a-c) / a=0.003353$ according to the World Geodetic System 1984 (WGS84) [50]. With respect to a Cartesian frame with its origin in the center of mass and its vertical axis congruent with Earth's rotation axis, we have

$$
\frac{x^{2}}{a^{2}}+\frac{z^{2}}{c^{2}}=1
$$

The coordinates are given by $x=a \cos \left(\frac{\pi}{2}-\theta\right)=a \sin \theta$ and $z=c \sin \left(\frac{\pi}{2}-\theta\right)=c \cos \theta$. The ellipsoidal radius is

$$
r(\theta)=r_{E, V}+\Delta r(\theta)=r_{E, V}\left(1+\frac{\Delta r(\theta)}{r_{E, V}}\right)
$$

where $\Delta r(\theta)$ is the difference between $r(\theta)$ and $r_{E, V}$ of the Earth. The ratio $\delta=\Delta r(\theta) / r_{E, V}$ ranges from $\delta=-0.00223$ at the Poles to $\delta=0.00111$ at the Equator (Figure 7). Using Equation (13) leads to

$$
A_{E}=\int_{0}^{2 \pi} \int_{0}^{\pi} r^{2}(\theta, \varphi) \sin \theta \mathrm{d} \theta \mathrm{d} \varphi=2 \pi r_{E, V}^{2} \int_{0}^{\pi}(1+\delta)^{2} \sin \theta \mathrm{d} \theta
$$

Since the surface of an oblate spheroid is also given by [51]

$$
A_{E}=2 \pi a\left(a+\frac{c^{2}}{\sqrt{a^{2}-c^{2}}} \operatorname{arsinh}\left(\frac{\sqrt{a^{2}-c^{2}}}{c}\right)\right)
$$




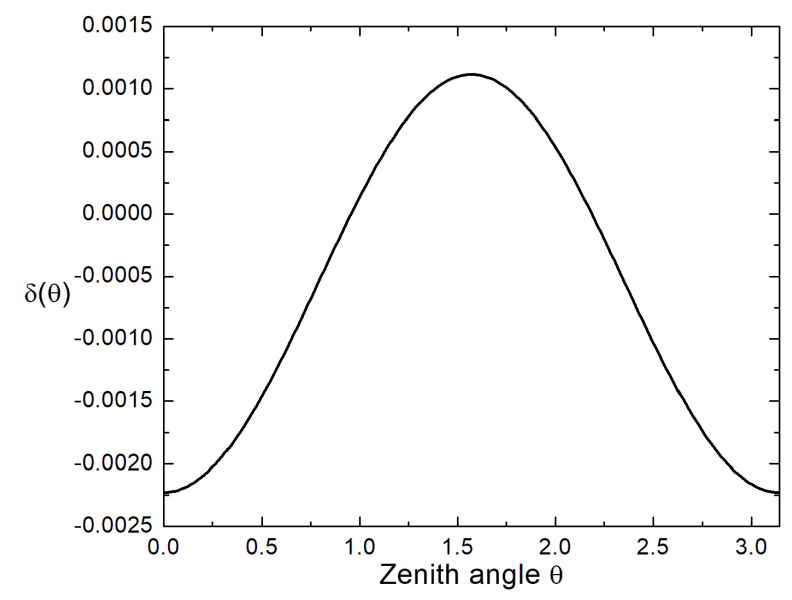

Figure 7. The ratio $\delta=\Delta r(\theta) / r_{E, V}$ as a function of the zenith angle $\theta$.

or in the re-arranged form

$$
A_{E}=2 \pi a^{2}+\pi \frac{c^{2}}{e} \ln \left(\frac{1+e}{1-e}\right)
$$

with $e=\sqrt{1-(c / a)^{2}}$, we have

$$
\int_{0}^{\pi}(1+\delta)^{2} \sin \theta \mathrm{d} \theta=2
$$

The equivalent spherical radius is $r_{E, A} \cong r_{E, V} \cong 6371.0 \mathrm{~km}$. In the case of a sphere, the rule $A^{3}=36 \pi V^{2}$ is exactly fulfilled, where $A$ and $V$ are the surface and the volume, respectively. Since of all surfaces of the same area, the sphere has the greatest volume, we have $A^{3} \geq 36 \pi V^{2}$ [52]. Consequently, $r_{E, A}$ is marginally larger than $r_{E, V}$, but this difference is negligible. Thus, we may write

$$
\langle\psi\rangle=\frac{1}{4 \pi} \int_{0}^{2 \pi} \int_{0}^{\pi} \psi(\delta, \theta, \varphi)(1+\delta)^{2} \sin \theta \mathrm{d} \theta \mathrm{d} \varphi
$$

Using again the zonal average defined by Equation (3) leads to

$$
\langle\psi\rangle=\frac{1}{2} \int_{0}^{\pi} \bar{\psi}(\theta)(1+\delta)^{2} \sin \theta \mathrm{d} \theta
$$

Inserting the averages for both the Northern and Southern Hemispheres defined by

$$
\langle\psi\rangle_{N H}=\int_{0}^{\pi / 2} \bar{\psi}(\theta)(1+\delta)^{2} \sin \theta \mathrm{d} \theta
$$

and

$$
\langle\psi\rangle_{S H}=\int_{\pi / 2}^{\pi} \bar{\psi}(\theta)(1+\delta)^{2} \sin \theta \mathrm{d} \theta
$$

leads to

$$
\langle\psi\rangle=\frac{1}{2}\left(\langle\psi\rangle_{N H}+\langle\psi\rangle_{S H}\right)
$$

Thus, the globally averaged near-surface air temperature is given by 


$$
\langle T\rangle=\frac{1}{2} \int_{0}^{\pi} \bar{T}(\theta)(1+\delta)^{2} \sin \theta \mathrm{d} \theta=\frac{1}{2}\left(\langle T\rangle_{N H}+\langle T\rangle_{S H}\right)
$$

As in the case of spherical averaging, $\theta$ can be substituted by $\phi$.

\section{DISCUSSION OF THE HISTORIC DATA}

\subsection{The Problem of the Incomplete Spatial Coverage by Meteorological Stations}

Hansen and Lebedeff [53] already discussed the problem of the incomplete spatial coverage of the Earth's surface by the network of meteorological stations. They correctly stated:

"The principal limitation of this data set for global or hemispheric analysis is the incomplete spatial coverage, illustrated in Figure 1 [here, Figure 8] for four dates. Although the number and geographical extent of recording stations on land areas increased strongly between 1870 and 1900, there were still large areas in Africa and South America, and all of Antarctica, without coverage in 1900. Substantial station data for Antarctica begins in the 1950s. Large ocean areas remain without fixed meteorological stations at all times."

However, as expressed by Equations (8) and (9), the uncertainty regarding observations in the south-polar region is of minor importance in determining the globally averaged near-surface temperature. Furthermore, von Hann and his fellow climate researchers not only gathered data from meteorological stations, but also eyewitness descriptions of weather and climate. Over land, the near-surface dry- and wet-bulb temperatures as well as the maximum and minimum temperatures were measured in thermometer boxes (Stevenson's screens) at a height of $2 \mathrm{~m}$ or so above the ground using a standardized thermometer equipment as illustrated in Figure 9. The standardization of land stations goes back to the First Meteorological Congress held in Vienna in September 1873. Such an equipment suitable for sea-going conditions was also used aboard the H.M.S. Challenger during her 1873 to 1876 voyage [27], where either hourly or two-hourly meteorological observations were performed.

Measurements of the sea-surface temperature have been performed since the mid-1 $8^{\text {th }}$ century; mainly wooden and canvas buckets served to take water probes. Krümmel [54] already discussed the accuracy of methods to measure the sea-surface and deep-sea temperatures. During the voyage of H.M.S. Challenger, the sea-surface temperature was observed every two hours [27].

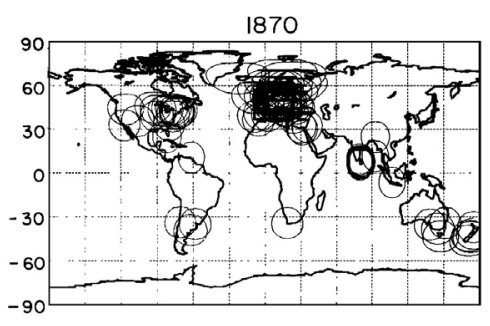

1930

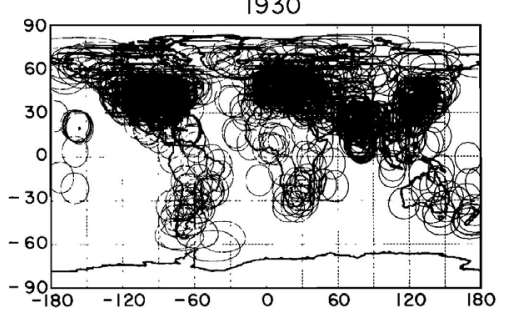

1900

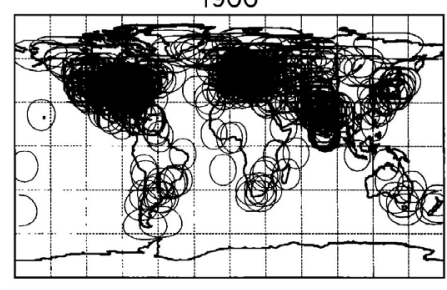

1960

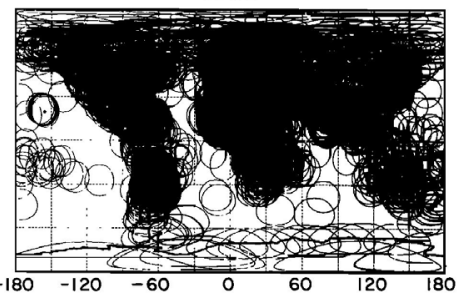

Figure 8. Global distribution of meteorological stations with near-surface air temperature records for $1870,1900,1930$ and 1960 . A circle of 1200-km radius is drawn around each station (adopted from Hansen and Lebedeff [53]). 


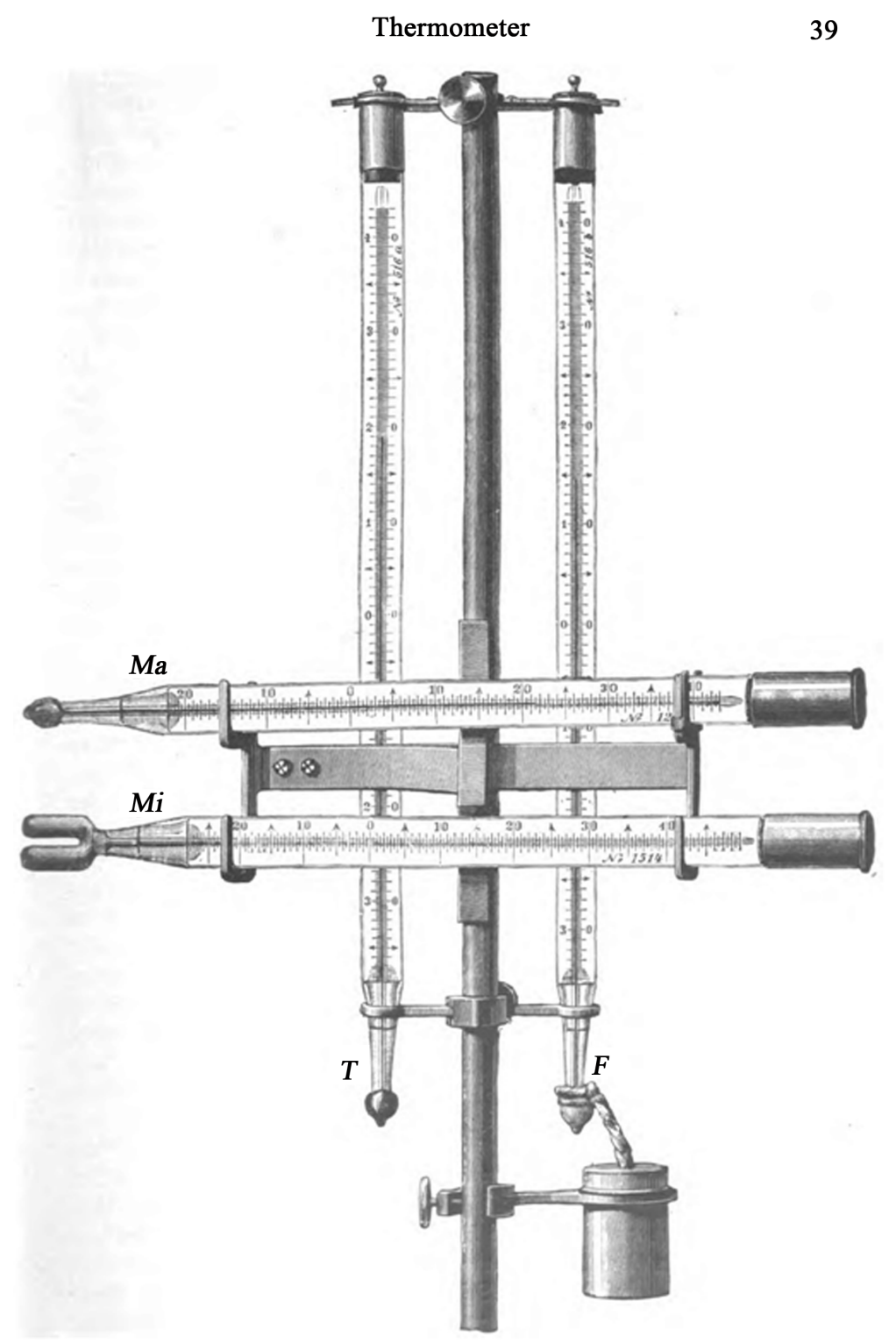

Figure 9. Typical thermometer equipment for measuring the dry-bulb ( $\mathrm{T}$, "trocken") and wet-bulb (F, "feucht") temperatures as well as the maximum (Ma) and minimum (Mi) temperatures in thermometer boxes (Stevenson's screens) over land (adopted from Börnstein [31]).

Nonetheless, even today, network density and design affect the regional averages over landscapes. In 2009, PaiMazumber and Mölders [55] used the results of their WRF simulations performed over Russia for July and December 2005, 2006, and 2007 to create a "dataset" for assessing this impact theoretically. Based on the values at all WRF grid points, they calculated regional averages for various quantities for $2.8^{\circ} \times 2.8^{\circ}$ areas as the "reference." Then, regional averages determined based on 40 artificial networks and the actual 411 "sites" locations of a real network were compared with the reference regional averages. The 40 networks encompassed 10 networks of 500,400, 200, or 100 different randomly taken WRF grid points as sites. The results showed that the real network's site distribution misrepresents the landscape. Such misrepresentation leads to differences in regional averages that show geographical and temporal trends for most quantities: Errors are lower over shores of large lakes than coasts and lowest over flatland followed by low and high mountain ranges; offsets in timing occur during frontal passages when several sites are passed at 
nearly the same time. Generally, the real network underestimated regional averages of sea-level pressure, wind speed, and precipitation over Russia up to $4.8 \mathrm{hPa}(4.8 \mathrm{hPa}), 0.7 \mathrm{~m} \cdot \mathrm{s}^{-1}\left(0.5 \mathrm{~m} \cdot \mathrm{s}^{-1}\right)$, and $0.2 \mathrm{~mm} \mathrm{day}{ }^{-1}$ and overestimates regional averages of $2 \mathrm{~m}$ temperature, downward shortwave radiation, and soil temperature up to $1.9 \mathrm{~K}(1.4 \mathrm{~K}), 19 \mathrm{~W} \cdot \mathrm{m}^{-2}\left(14 \mathrm{~W} \cdot \mathrm{m}^{-2}\right)$, and $1.5 \mathrm{~K}(1.8 \mathrm{~K})$ in July (December) [55].

\subsection{Historical Isothermal Charts}

Alexander von Humboldt was the first who drew annual isotherms on a map of the Earth in 1817 [56]. He used the temperature averages of 58 locations available around the world [57]. Based on the course of these isotherms, von Humboldt deduced the simplest laws of the heat distribution on the Earth's surface. In his blog contribution "The first isothermal world maps", Mike Klein, Senior Cartographic Specialist in the Geography and Map Division at the Library of Congress, stated:

"Humboldt withheld publishing his idea in the form of a generalized world map while he waited for data from weather stations around the world. Thus, the isotherm concept remained virtually unknown outside of the broader scientific community until 1838, when it was given wider recognition on the map below [here Figure 10]. Titled Alexander von Humboldt's System der Isotherm-Kurven in Merkator's Projection, it was published in Germany by Heinrich Berghaus in his Physikalischer Atlas, the first comprehensive physical world atlas."

Figure 10 shows this isothermal chart published by Heinrich Berghaus in the 1845 Edition of his Physikalischer Atlas. (Note that the correct spelling is Mercator, but not Merkator as used in von Humboldt's isothermal chart.)

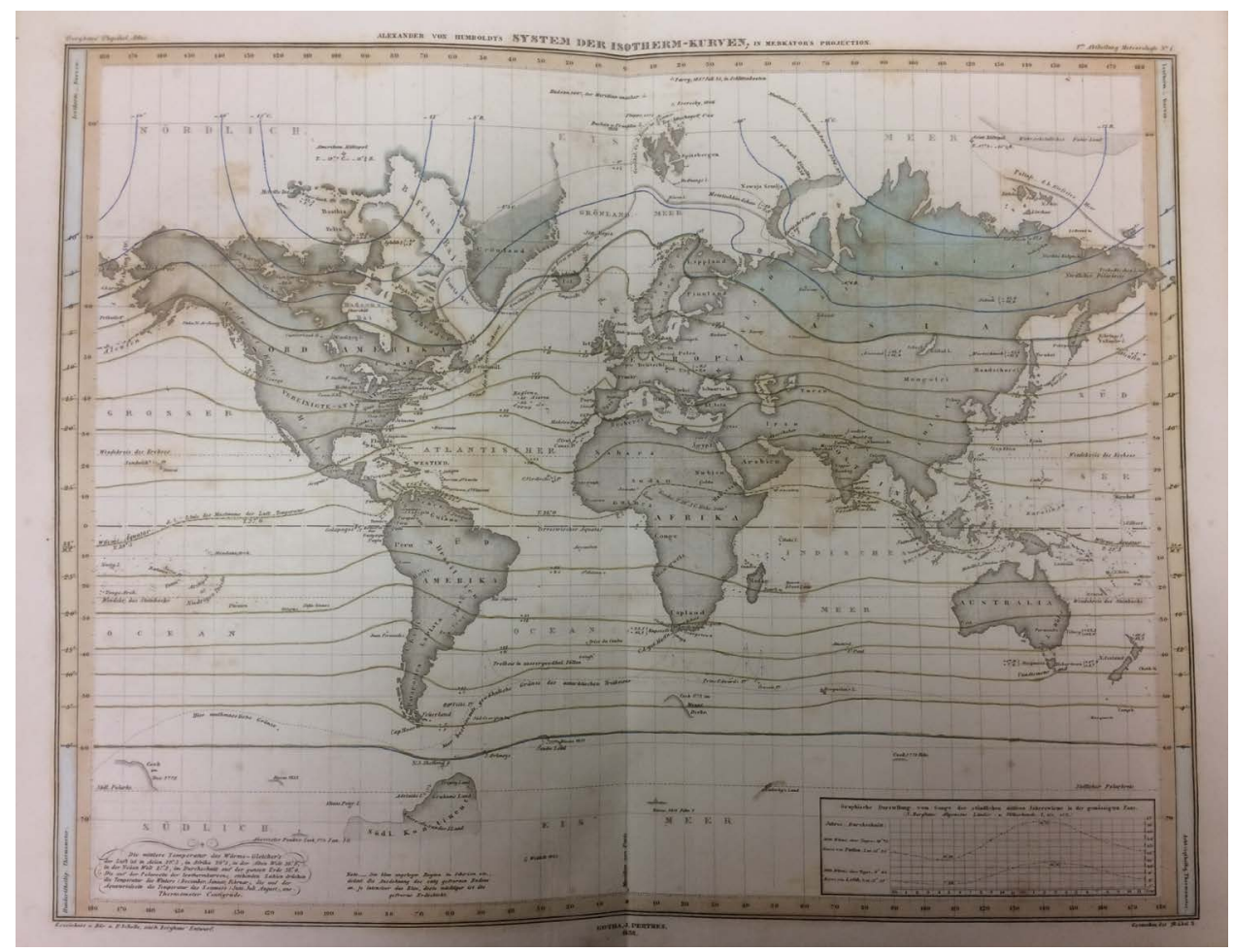

Figure 10. Alexander von Humboldt's system of the isotherm curves in Mercator's Projection. It was published in Germany by Heinrich Berghaus in his 1845 Edition of the Physikalischer Atlas (adopted from https://blogs.loc.gov/maps/2018/04/the-first-isothermic-world-maps/). Note that von Humboldt used both the Celsius scale (left side of the chart) and the de Réaumur scale (right side of the chart). 
Batchelder [11] reviewed earlier observations and the use of isothermal charts. By quoting von Hann [18], he underlined the importance to distinguish between water and land masses:

"Durch den Umstand, dass ein Parallelkreis teils über Land, teils über Wasser verläuft, entstehen klimatische Unterschiede zwischen West und Ost, oder Verschiedenheiten des Klimas nach den Meridianen, welche im solaren Klima nicht vorhanden wären. Neben der ungleichen Erwärmung und Erkaltung von Wasser und Land werden ausserdem durch das Vorhandensein des Landes gewisse konstante Luft- und Meeresströmungen erzeugt, welche ebenfalls eine Verschiedenheit des Klimas unter verschiedenen Meridianen desselben Parallels bedingen.”

The translation from German into English given by Batchelder [11] reads:

"Owing to the fact that a circle of latitude passes partly over land and partly over water, there arise climatic differences between West and East, or variations of the climate according to the longitudes, that in the solar climate would not exist. Following the dissimilar warming and cooling of water and land there are, moreover, set up, owing to the presence of the land, certain constant air and sea currents which also make possible a difference of climate on different meridians of the same parallel."

The notion "solar climate" is discussed in Subsection 3.3.

Von Hann [18] and Spitaler [10] also discussed Forbes' [23] formula for determining the average (or normal) temperature of a parallel of latitude derived for the Northern Hemisphere

$$
T(\phi)=\underbrace{A+B \cos ^{m}(\phi)}_{\text {water globe }}+\underbrace{C n \cos (2 \phi)}_{\text {land effect }}
$$

where $n$ is the fraction of land compared to the circumference of the respective parallel. The coefficients $A$, $B, C$, and the exponent $m$ must be derived from observations. Forbes [23] derived (here expressed with respect to the Celsius scale): $A=-10.8^{\circ} \mathrm{C}, B=32.9^{\circ} \mathrm{C}, C=21.2^{\circ} \mathrm{C}$, and $m=1.25$. Forbes also discussed the temperature difference between an aqueous globe $(n=0)$ and a rocky one $(n=1)$. Figure 11 shows the meridional distributions of the zonal averages of temperature, $\bar{T}(\phi)$, between $50^{\circ} \mathrm{N}$ and $50^{\circ} \mathrm{S}$. Forbes found for the latitude of $45^{\circ}$ a surface temperature of $51.0^{\circ} \mathrm{F} \cong 10.6^{\circ} \mathrm{C}$ for both the aqueous globe and the rocky one. For the Equator, he obtained $71.7^{\circ} \mathrm{F} \cong 22.1^{\circ} \mathrm{C}$ for $n=0$ and $109.8^{\circ} \mathrm{F} \cong 43.2^{\circ} \mathrm{C}$ for $n=1$. However, it is unlikely that in both cases the effect of the atmosphere would be the same. With respect to this result, von Hann [16] stated:

"Between latitude $40^{\circ}$ and latitude $50^{\circ}$ is the parallel on which both water and land hemispheres have the same temperature. In higher latitudes, the water hemisphere is warmer than the land hemisphere. Even Dove's isothermal charts of the northern hemisphere show that the transition takes place between latitudes $40^{\circ}$ and $45^{\circ}$, and the graphic representation, above referred to, shows more precisely that this transition occurs at latitude $42.5^{\circ}$. Beyond this latitude, as far as the pole, a water hemisphere is warmer than a hemisphere wholly covered by land."

In his paper on von Hann's contribution to modern climatology, Kahlig [58] reported that von Hann used a three-term moving average (running mean) procedure with unequal weights $(1 / 4,1 / 2,1 / 4)$, called "hanning" (e.g., [59]), to smooth the raw data of land fraction listed in von Hann's $[15,16]$ table of the "Mean temperatures of the Parallels of Latitude" in his Handbook of Climatology (pp. 199-200). The raw data and the smoothed ones are listed in columns $a$ and $b$ in von Hann's table (Figure 4). Thus, von Hann was able to handle Forbes' [23] formula (Equation (24)) in a sophisticated manner.

Isothermal charts as developed by Dove [19], Wild [24], von Hann [25] and Buchan [27] played an important role in deriving the normal temperatures for numerous parallels of latitude. Schoch [20] used Dove's [19] isothermal charts, Spitaler [10] used those of Wild [24] and von Hann [25] (eventually published in Berghaus' Physikalischer Atlas), Batchelder [11], Arrhenius [14], and Hopfner [33] used Buchan's [27] isothermal charts. The isothermal charts shown in Figures 12-16 were published by von Hann 


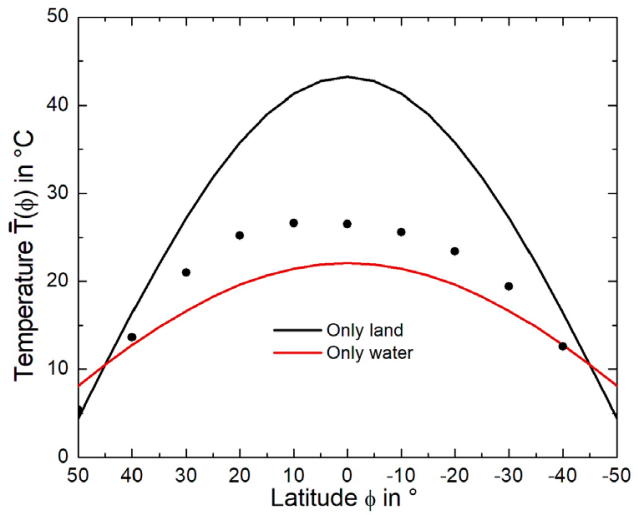

Figure 11. Meridional distributions of the zonal averages of temperature, $\bar{T}(\phi)$, between $50^{\circ} \mathrm{N}$ and $50^{\circ} \mathrm{S}$ for an aqueous globe $(n=0)$ and a rocky one $(n=1)$ based on Forbes' [23] formula (Equation (24)). Dots represent dataset Do1852 [19] (see Table 2).

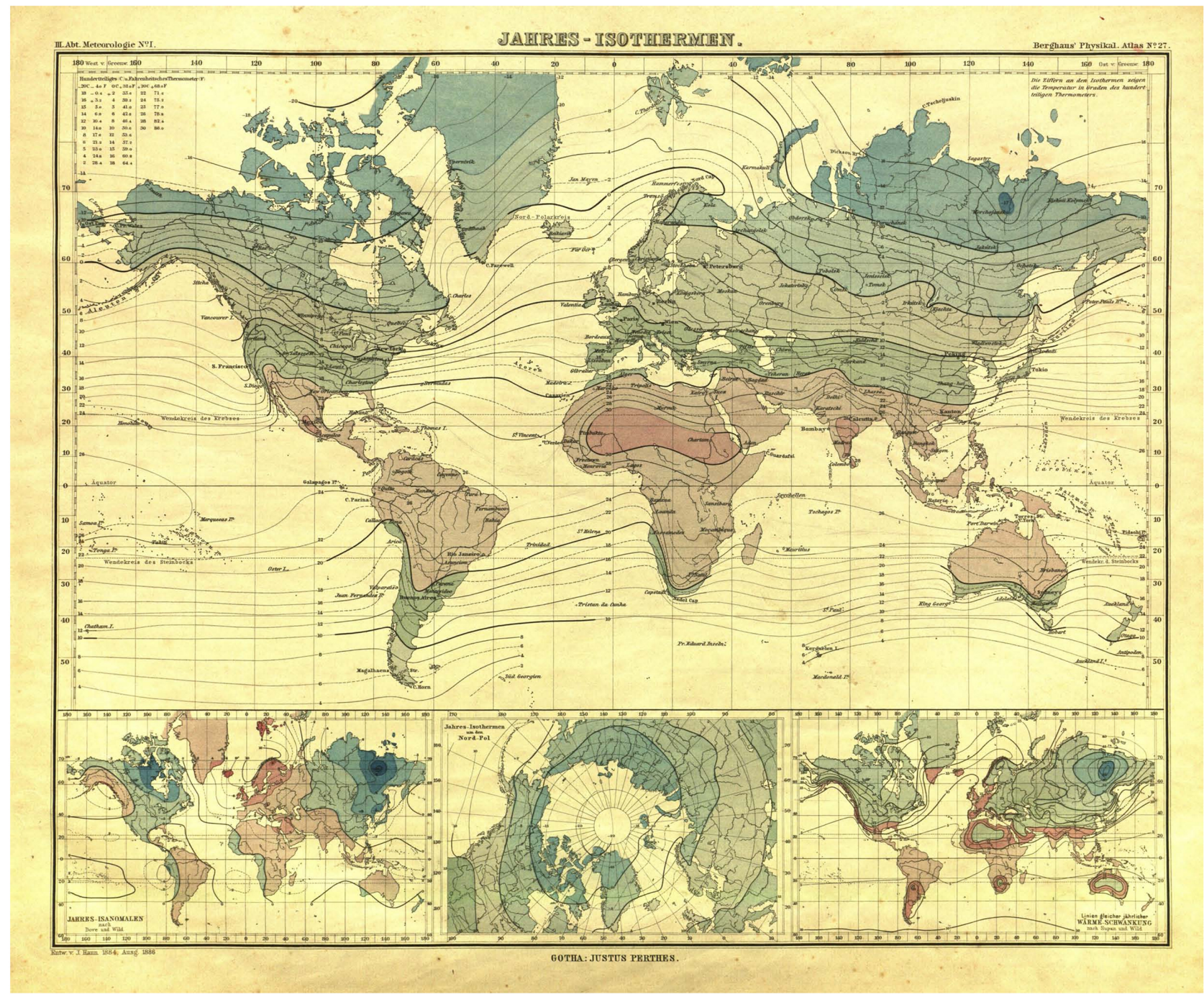

Figure 12. Von Hann's [25] annual isotherms of the Earth published in Berghaus' Physikalischer Atlasin 1887. Temperatures are in ${ }^{\circ} \mathrm{C}$. 


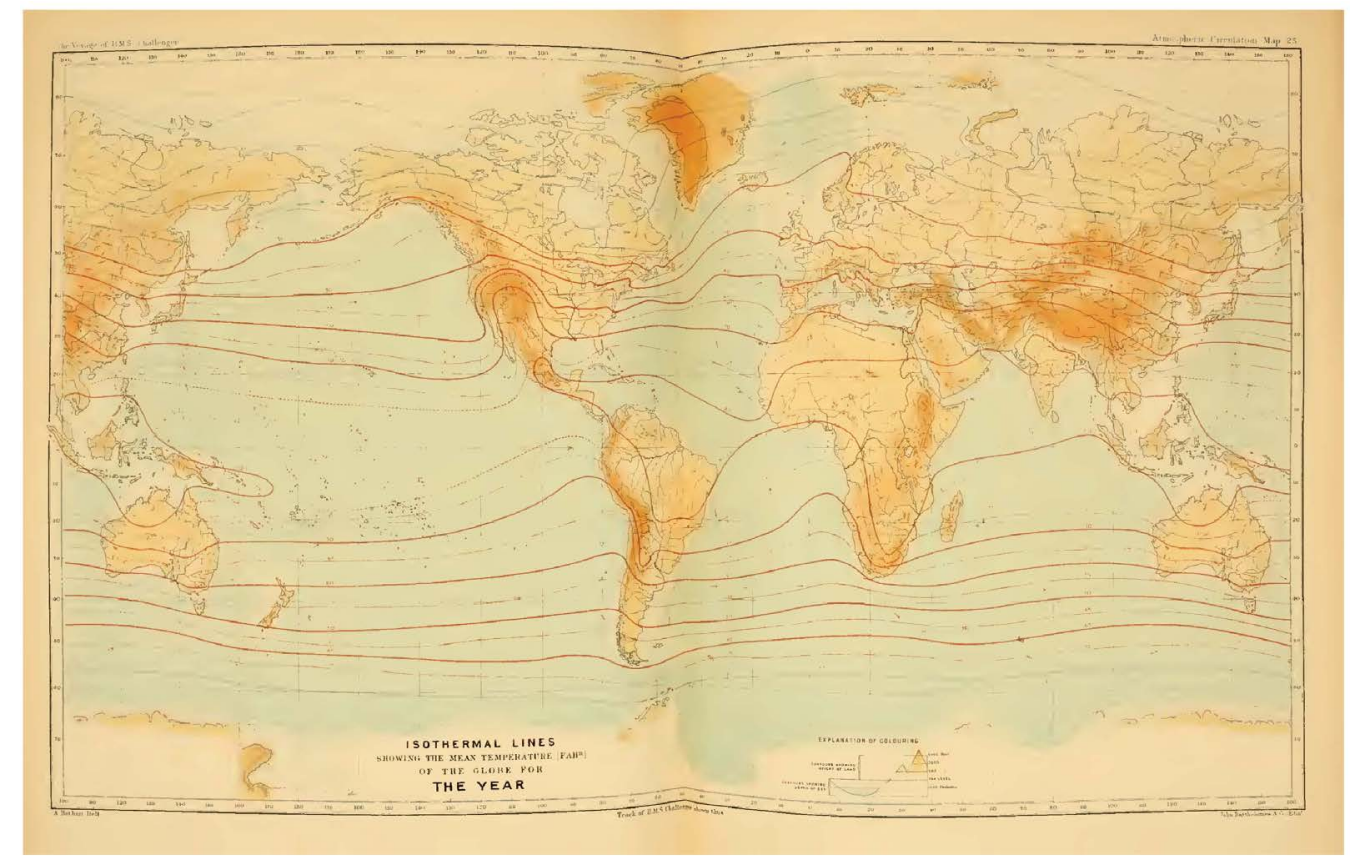

Figure 13. Buchan's [27] annual isotherms of the Earth published in the Challenger reports in 1889. Temperatures are in ${ }^{\circ} \mathrm{F}$.

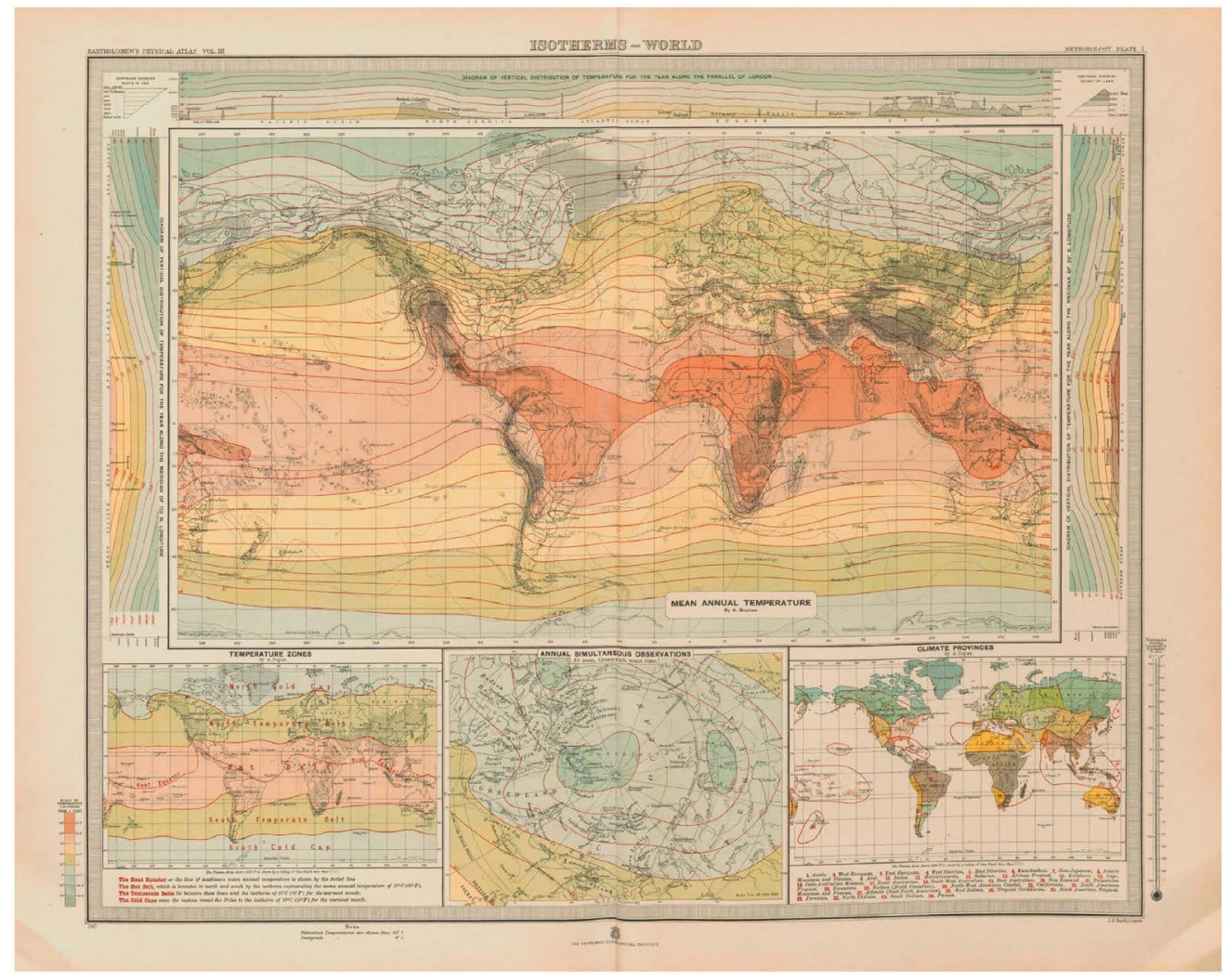

Figure 14. As in Figure 13, but prepared by Bartholomew and Herbertson and edited by Alexander Buchan [60] (adopted from the ETH-Bibliothek Zürich https://doi.org/10.3931/e-rara-71030). Temperatures are in ${ }^{\circ} \mathrm{F}$. 


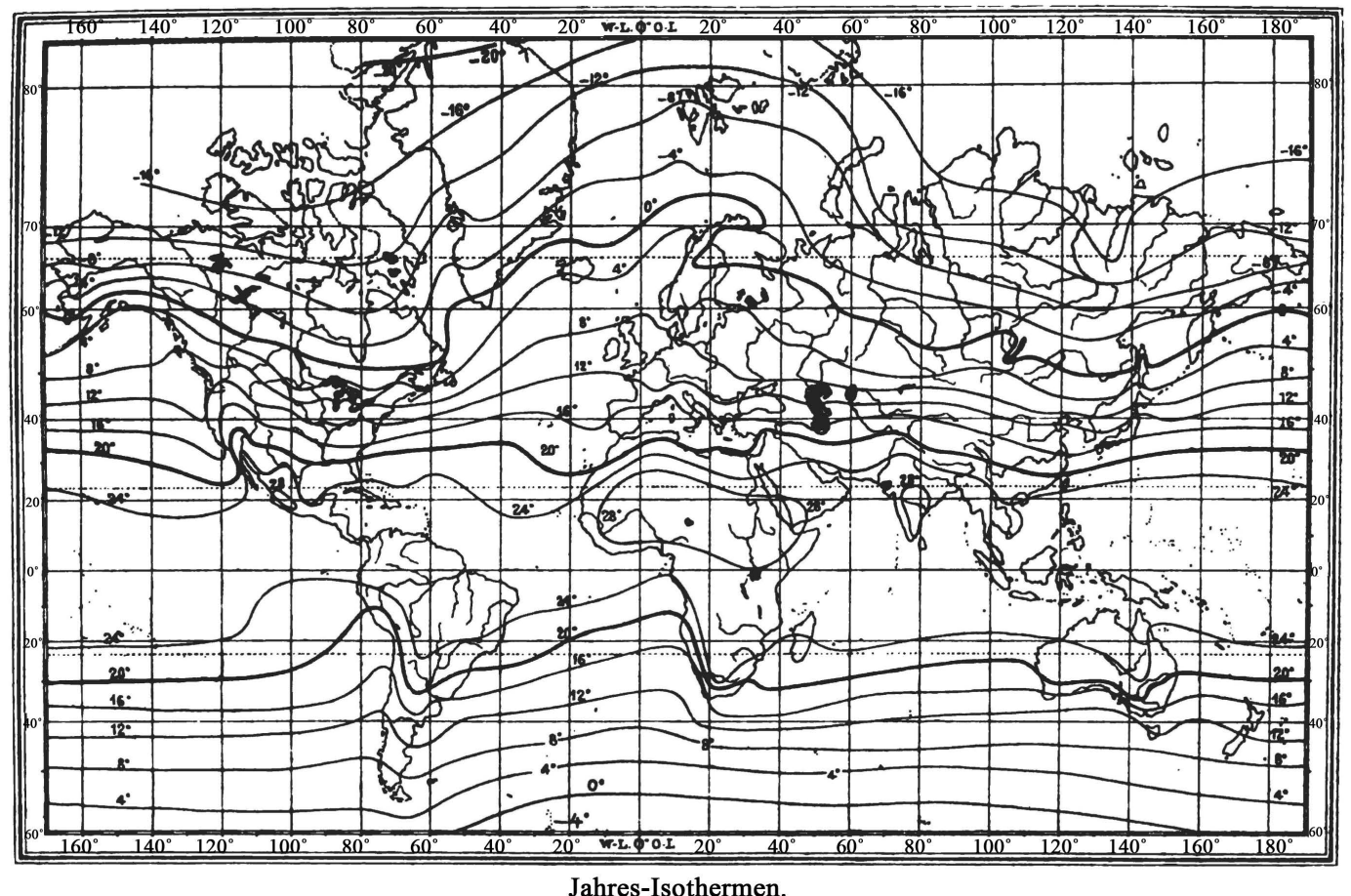

Figure 15. As in Figure 12, but published by von Hann [57] in his "Lehrbuch der Meteorologie" (Textbook on Meteorology). Temperatures are in ${ }^{\circ} \mathrm{C}$.

Tafel I.

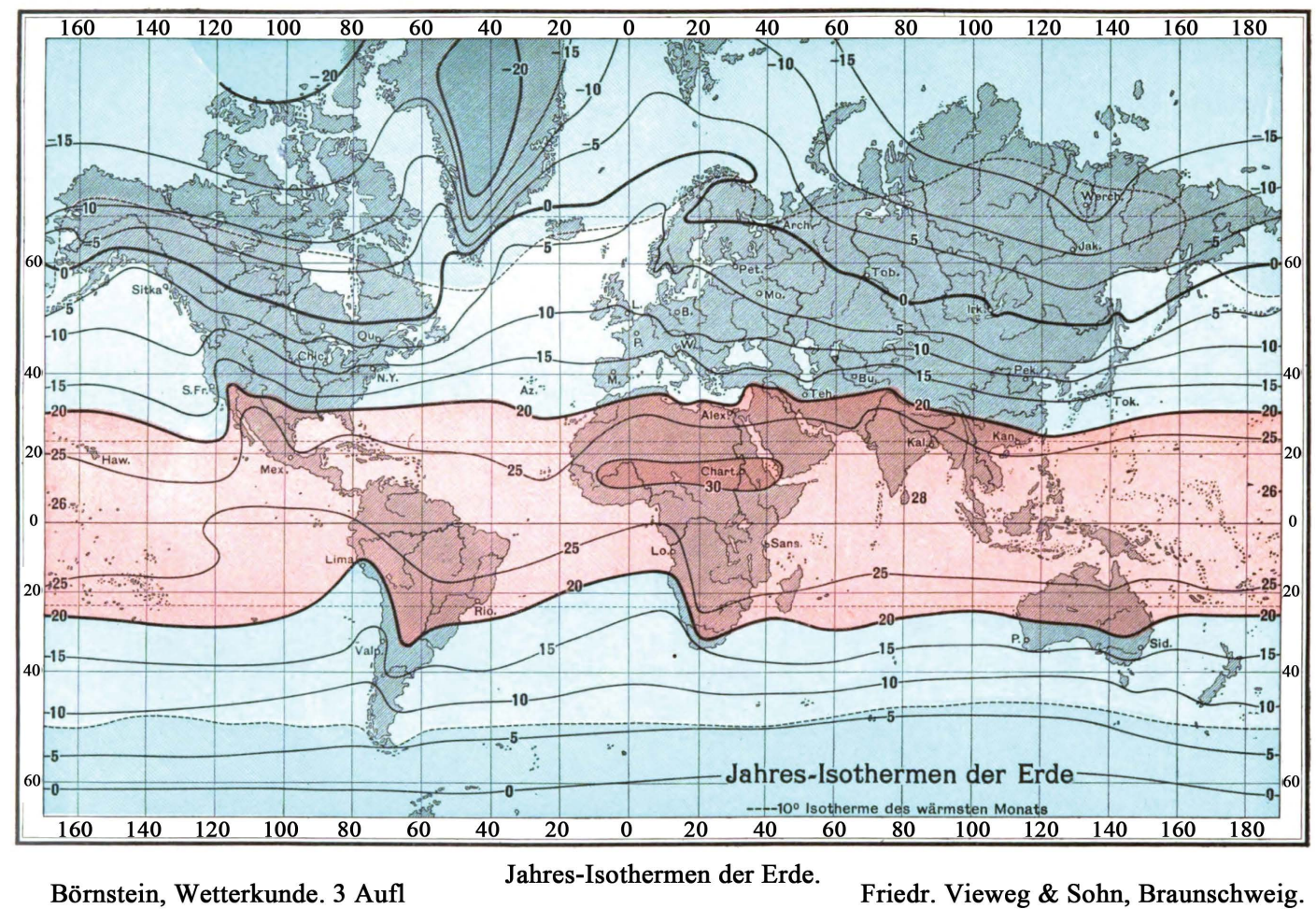

Figure 16. Börnstein's [31,35] annual isotherms of the Earth (digitized by Google).Temperatures are in ${ }^{\circ} \mathrm{C}$. The dashed lines indicate the $10^{\circ}$-isotherms of the warmest month. 
[25] in 1887, Buchan [27, 60] in 1889 and 1899, von Hann [57] in 1906, and Börnstein [31, 35] in 1906/ 1913, respectively. Dove [19] used monthly means, seasonal means and annual means determined from the longest so far accessible series of observations at 900 stations. As reported by von Hann [25], his isothermal chart is based on all information available to him in January 1884 . This information also included Wild's [24] isothermal charts for the Russian Empire. Buchan's [27] isothermal chart not only included the observations of the Challenger Expedition, but also the observations performed at 1620 stations during the fifteen-year period 1870-1884, except in the United States, where the observations started in October 1871, when the Signal Service of the War Department took charge of the Meteorological System of the United States. In his report "Summary of International Meteorological Observations", Dunwoody [61] stated, for instance (Figure 17):

Recognizing the importance of daily simultaneous observations covering the greatest possible part of the earth's surface as bearing upon the solution of many of the problems of meteorology, the Meteorological Congress convened at Vienna in September, 1873, formulated the plan of international observations conducted uuder the auspices and largely at the expense of the United States Weather Service from 1875 to 1887 , inclusive.

This system of observations was proposed before the Congress by Brig. Gen. Albert J. Myer, Chief Signal Officer, U. S. Army, who undertook, on the part of the United States, the collection, compilation, and publication of the observations, and the distribution of the printed reports to co-operating abservers throughout the world.

During the period, 1875 to 1887 , the number of land stations, exclusive of United States and international polar stations, inereased to a total of 459 , and monthly reports were received from nearly 600 vessels distributed over the principal marine highways of the globe. For the entire period a grand aggregate of over 150,000 monthly reports, representing upward of 5,000,000 daily simultaneous observations, were received and prepared for publication at the office of the Chief Signal Officer at Washington City.

The following-named countries co-operated during a part or the whole of the period 1875 to 1887: Algeria, Australia, Austro-Hungary, Belgium, Brazil, Great Britain, Canada, Cape Colony, Chile, China, Costa Rica, Denmark, Egypt, France, Germany, Greece, Hawaiian Islands, India, Italy, Japan, Mauritius, Mexico, The Netherlands, Norway, Russia, Scotland, Spain, Sweden, Switzerland, and Turkey. In addition to reports furnished by regular services of the several countries, observations were made and forwarded from the islands of the North Atlantic Ocean, and from Central America, northern South America, Bering Island, the Aleutian Islands, Alaska, Greenland, and Iceland. The co-operation of the United States Navy was begun in 1877; observations were also received from a number of vessels of the merchant marine during that year. The co-operation of the navies of Great Britain, France, Sweden, Italy, and Portugal, and a number of the great steamship companies, foreign and domestic, and also of the "New York Herald Weather Service," closely followed. In 1877 sub-standard barometers for comparing and correcting ships' barometers were placed in the Maritime Exchange, New York City, and in the Merchants Exchange, San Francisco, Cal. In 1882 marine agencies for the collection of vessel reports and the comparison of instruments were established at the principal seaports of the Atlantic coast, and a considerable number of instruments for taking observations were issued to vessels of the United States Navy and to captains of vessels of the merchant marine.

Details for the establishment of international polar stations were arranged at meteorologieal congresses held at Hamburg in 1879 and at Saint Petersburg in 1881, and it was resolved that the series of polar observations should begin August 1, 1882. One of the United States expeditions under the command of First Lieut. (now General) A. W. Greely sailed from Saint Johns, N. F., July 7, 1881, and reached Lady Franklin Bay August 11, 1881; the other, under the command of First Lieut. P. H. Ray, Eighth Infantry, Acting Signal Officer, sailed from San Francisco, Cal., July 18, 1881, and reached Point Barrow, Alaska, September 8, 1881. Additional international polar stations were established as follows: By Austro-Hungary, at Jan Mayen; by Denmark, at Godthaab; by Finland, at Sodalynka; by France, at Orange Bay; by Germany, at Kingawa Fiord, Cumberland Sound, and at Royal Bay, S. Georgian Islands; by Great Britain and Canada, at Fort Rae, British America; by Holland, at Dicksonhaven; by Norway, at Bossekop; by Russia, at the Lena Delta and Nova Zembla; and by Sweden, at Spitzbergen.

Figure 17. Excerpt from Dunwoody's [61] "Summary of international meteorological observations". 
DeCourthy Ward [62] assessed von Hann's [25] and Buchan's [27] isothermal charts together with those prepared by Bartholomew and Herbertson and edited by Buchan [60] for the comprehensive work "Atlas of Meteorology: a series of over four hundred maps". Figure 14 shows the isothermal chart of annual means. It is a reproduction of Buchan's isothermal chart that appeared in the Challenger reports, but revised by him [60]. Figure 14 also shows Supan's [63] temperature zones and climate provinces, and Dunwoody's [61] map of annual simultaneous observations. The isothermal charts of von Hann [57] (Figure 15) and Börnstein [31,35] (Figure 16) slightly differ from each other. Unfortunately, the isotherms were drawn at different intervals. Only the $0^{\circ} \mathrm{C}$ - and the $20^{\circ} \mathrm{C}$-isotherms are directly comparable.

More than 85 years later, Levitus [64] published the Climatological Atlas of the World Ocean. Figure 18 shows his global distribution of the annual mean potential temperature at the sea surface. Figure 19 shows the corresponding figure based on the Ocean Atlas 2018. These figures may be used to assess the distribution of the sea surface in the historical isothermal charts.

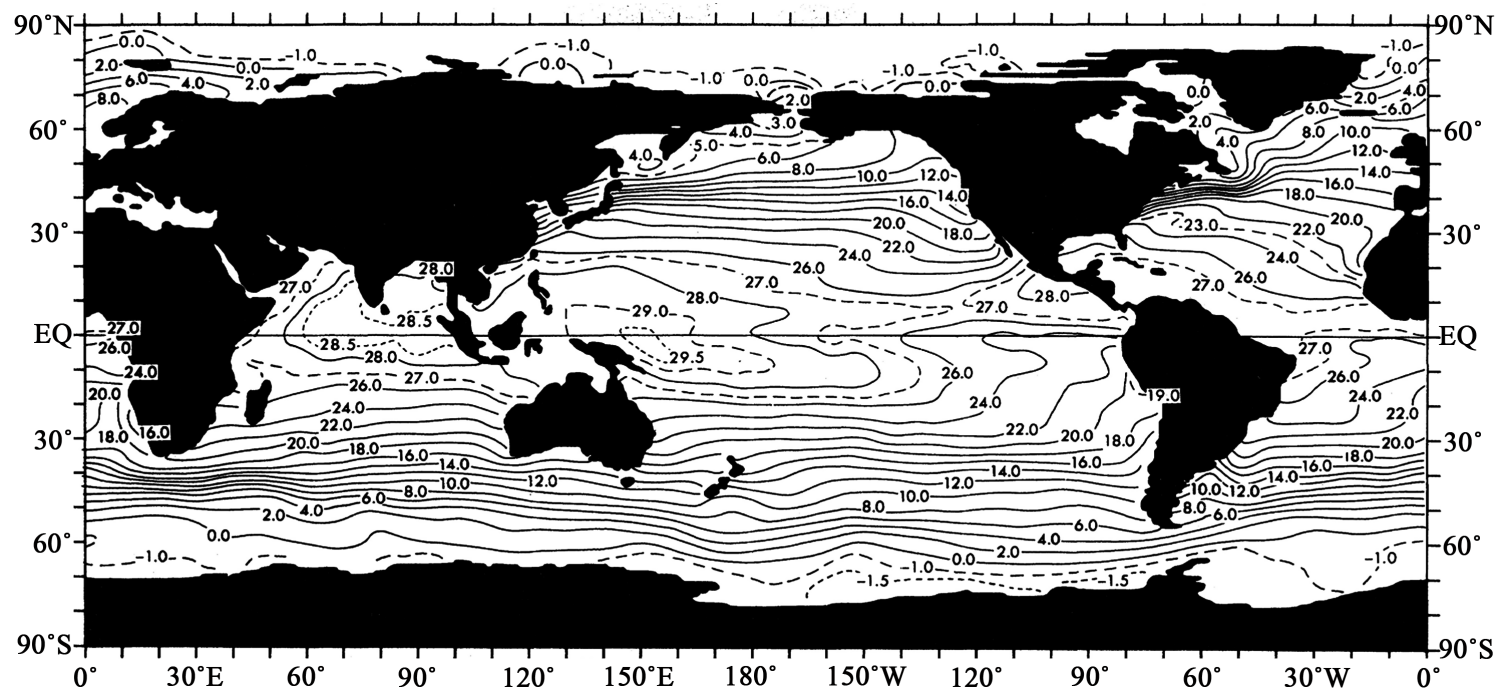

Figure 18. Levitus' [64] distribution of the annual potential temperature at the sea surface in ${ }^{\circ} \mathrm{C}$ (but taken from Peixoto and Oort [47]).

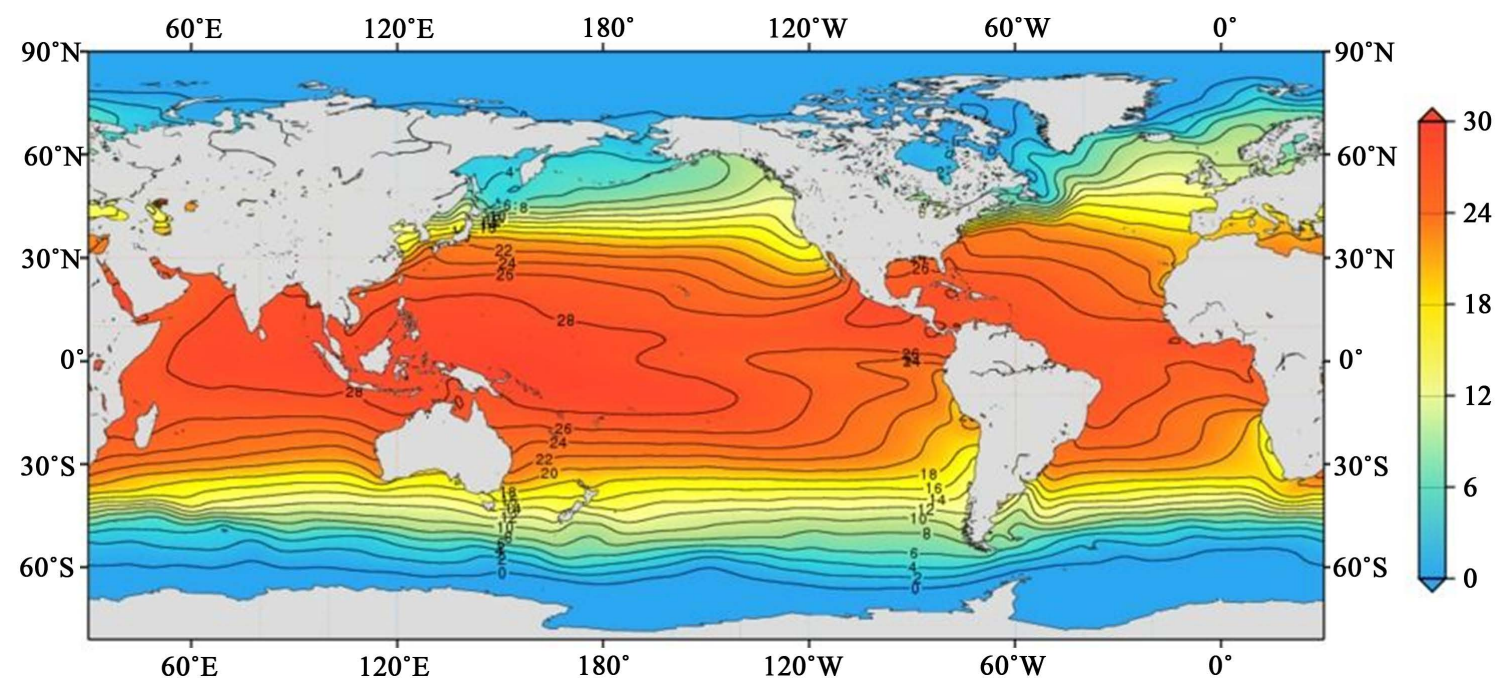

Figure 19. World Ocean Atlas Climatology (decadal average 1955-2017): Distribution of the annual sea-surface temperature in ${ }^{\circ} \mathrm{C}$ (one-degree grid) [65]. 
Spitaler [10] described his procedure to determine the normal temperature along the parallels of latitude as follows:

"Die Grundlage für die vorliegende Untersuchung lieferten die neuen Isothermenkarten von Wild und Prof. Hann, welche nach dem sämtlichen bis jetzt vorliegenden Beobachtungsmaterial der Erde gezeichnet wurden. Ich habe für jeden 10. Breitengrad von $5 \mathrm{zu} 5$ Längengraden, für die dazwischenliegenden Breitengrade aber nur für jeden 10. Längengrad die Temperatur des Jahresmittels bestimmt, sowie die mittleren Temperaturen der beiden extremen Monate Januar and Juli graphisch interpoliert und auf diese Weise einerseits aus je 72, andererseits aus je 36 äquidistanten Temperaturwerten die normale Temperatur der Breitenkreise bestimmt."

The translation reads:

"The basis for the present study was the new isothermal charts of Wild and Prof. Hann, which were drawn based on all the Earth's observation material available so far. For each 10th degree of latitude and for 5 to 5 degrees of longitude, but for the intermediate latitudes only for each 10th degree of longitude, I determined the annual-average temperature and interpolated the mean temperatures of the two extreme months of January and July graphically. In doing so, I determined the normal temperature of the parallels of latitude based on 72 and 36 equidistant temperature values, respectively."

Batchelder [11] determined the normal temperature of each $10^{\text {th }}$ degree of latitude, from $80^{\circ} \mathrm{N}$ to $50^{\circ} \mathrm{S}$, by averaging the observed temperatures at 36 equidistant points or stations on the circle, i.e., at every $10^{\text {th }}$ meridian. The temperatures at these 36 points were determined, when an isotherm did not happen to fall directly over the point, by interpolation between the nearest isotherms. Referring to Forbes [23], he stated:

"Although one authority considers that 'It is by no means an easy matter to deduce the mean temperature of a given parallel correctly from an isothermal chart,' yet as Buchan constructed his isotherms at intervals of $5^{\circ} \mathrm{F}$, interpolation was usually simple and direct, and the limit of error rarely rose above one degree. The most unsatisfactory cases of interpolation were those succession of isotherms) as in July, $130^{\circ} \mathrm{W}, 50^{\circ} \mathrm{N}$. Still, even here, $1^{\circ} \mathrm{F}$ seems usually the error. A peculiar case occurs in January over the northern Amazon basin; as the observer moves north ward over South America he finds the temperature fall from the central part until above the equator, where occurs an isolated area of $+85^{\circ}$ over the Isthmus of Panama. The neighborhood of this area is very difficult to interpolate for; to the north the nearest isotherm is that of $75^{\circ}$, a ten-degree skip, to the east and west are no neighboring isotherms, and far away to the south is the isotherm of $80^{\circ}$ on a falling gradient. In the case of the parallel of $80^{\circ} \mathrm{N}$ on the Annual Chart, too, the limit of error between $100^{\circ} \mathrm{W}$ and $130^{\circ} \mathrm{W}$ may rise as high as $4^{\circ} \mathrm{F}$. On the equator, owing to the slight gradient, the general limit of error is about $2^{\circ} \mathrm{F}$."

Hopfner [33] also determined this normal temperature of each $10^{\text {th }}$ degree of latitude, but from $80^{\circ} \mathrm{N}$ to $60^{\circ} \mathrm{S}$ by averaging the observed temperatures at 36 equidistant points or stations on the respective parallel of latitude. He also discussed the accuracy of the use of isothermal charts in detail.

As argued by Köppen [37], notable variation exists in the annual mean temperatures of the lower atmosphere, reduced to sea level, for numerous parallels of latitude (cf. Table 3).

As listed in Table 3, the temperature difference between the Equator and $80^{\circ} \mathrm{N}$ is $38^{\circ} \mathrm{C}$ (maximum) and $44^{\circ} \mathrm{C}$ (minimum). Whereas the difference between the Equator and $80^{\circ} \mathrm{S}$ is $42^{\circ} \mathrm{C}$ (maximum) and $48^{\circ} \mathrm{C}$ (minimum) [37]. Thus, when computing the near-surface temperature of the Earth, we must address possible uncertainty related to such variations in annual averages.

The reduction of temperatures to sea level seems to be a problem. Even though the reduction of air pressure to sea level is widely accepted, this is not the case of near-surface air temperature. In his textbook "Lehrbuch der Meteorologie" published in 1906, von Hann [57] stated: 
Table 3. Annual averages of the temperature of the lower atmosphere, reduced to sea level, for numerous parallels of latitude (adopted from Köppen [37]).

\begin{tabular}{cccccccccc}
\hline & \multicolumn{8}{c}{ Latitude in } \\
\cline { 2 - 9 } & 80 & 60 & 40 & 20 & 0 & -20 & -40 & -60 & -80 \\
\hline Maximum & -10 & 7 & 17 & 29 & 28 & 25 & 14 & 2 & -14 \\
Minimum & -20 & -8 & 9 & 23 & 24 & 18 & 9 & -5 & -24 \\
Difference & 10 & 15 & 8 & 6 & 4 & 7 & 5 & 7 & 10 \\
\hline
\end{tabular}

"Die Isothermen stellen die Temperaturverteilung auf der Erde so dar, wie wenn alle Orte, nach deren Temperaturaufzeichnungen sie entworfen worden sind, im Meeresniveau liegen würden. Die Temperaturmittel müssen daher, bevor man sie auf der Karte einträgt, auf das Meeresniveau reduziert werden, wozu die früher angeführten Erfahrungen über die Wärmeabnahme mit der Höhe benützt werden."

The translation reads:

"The isotherms represent the temperature distribution on Earth as if all the locations, which contributed to them with their temperature records, were at sea level. The temperature averages must, therefore, be reduced to sea level before entering the chart to which the previously mentioned experience about the heat decrease with height are used."

Buchan [60] argued (his temperature notation has been updated):

“The mean temperature falls about $5.5^{\circ} \mathrm{C}$ for every 1000 metres of ascent $\left(1^{\circ} \mathrm{F}\right.$ per 330 feet or $16^{\circ} \mathrm{F}$ per mile); but, in the Northern Hemisphere, between $30^{\circ} \mathrm{N}$ and $70^{\circ} \mathrm{N}$, the mean temperature decreases only $0.75^{\circ} \mathrm{C}\left(1.35^{\circ} \mathrm{F}\right)$ for every increase of a degree of latitude; i.e. $0.0068^{\circ} \mathrm{C}$ for every kilometre nearer the pole $\left(0.0197^{\circ} \mathrm{F}\right.$ per mile). The temperature therefore falls 800 times more in the same distance in a vertical direction than in a horizontal one. This may be expressed by saying that the vertical temperature gradient is 800 times steeper than the horizontal one. This contrast can be seen in the sections on Plate 1, where the vertical distances are much exaggerated when compared with the horizontal ones, and hence the sections greatly minimise the contrast."

Note that von Hann [66] argued in a similar manner. Based on the CRU dataset, Feulner et al. [67] recently illustrated the effect of station's elevation. They argued that the effect of land (and ice sheet) elevation combined with the lapse rate on the temperature distribution is apparent, making Antarctica, Greenland, and the large mountain ranges markedly cooler than their surroundings.

Sellers [39] did not apply such reduction to sea level in determining his mean annual surface temperatures. He stated:

"Temperatures given in [his] Table 1 are estimated mean annual surface temperatures and are lower than the sea level values often quoted in the meteorological literature (Haurwitz and Austin, 1944 [40]; Trewartha, 1954 [68]), especially between $20^{\circ} \mathrm{N}$ and $50^{\circ} \mathrm{N}$ and south of $60^{\circ} \mathrm{S}$. The average global surface temperature is about $286^{\circ} \mathrm{K}$, compared with $288^{\circ} \mathrm{K}$ for the average global sea level temperature."

We considered Arrhenius' $[14,26]$ data re-corrected to mean terrain height above sea level and Sellers' [39] data to illustrate the difference in the global average of the near-surface air temperature caused by zonal averages of temperatures at site elevation and those reduced to sea level. 
Sellers considered the physical and climatological data of $10^{\circ}$-latitude zones. Thus, we assigned his temperature data to the center of the respective latitude zones. Figure 20 reveals that Sellers'zonal temperature means are remarkably lower than those of the other authors. At latitudes beyond $60^{\circ} \mathrm{S}$, they are even lower than those in Köppen's [37] distribution of zonal mean minimum temperatures. Beyond $30^{\circ} \mathrm{S}$, Ferrel's [12] zonal temperature means slightly exceed Köppen's.

The normal temperatures determined by the authors considered in this study are not completely independent. As aforementioned, subsequent authors improved them using the rapidly increased number of weather observations in the $2^{\text {nd }}$ half of the $19^{\text {th }}$ century (Figure 8). The differences between Dove's [19] and Forbes' [23] values were still marginal, but Wild [24], von Hann [25] and Buchan [27, 60] used augmented weather information for editing their isothermal charts.

Graphic solutions have a long tradition in science and technology. Cremona-Maxwell diagrams, for instance, were used in statics with sufficient accuracy long before Konrad Zuse developed the first programmable computer in the late 1930s.

\subsection{Solar Climate versus Real Climate}

Forbes' [23] formula (see Equation (24)) of the asymmetric water and land distribution may be considered as the first attempt to explain the difference between the isotherms of the Earth's real climate and those of its so-called solar climate. According to von Hann [16, 18], the solar climate, sometimes also called the mathematical climate, refers to the thought model of an Earth in the absence of its atmosphere. Von Hann [16] stated

"If the surface of the earth were occupied altogether by land, and if there were no surrounding atmosphere, the condition of our planet would be somewhat similar to that of the moon at the present time. Under these conditions, the distribution of temperature over the earth would depend solely upon the amount of heat received from the sun at any given place, and upon the loss of heat by radiation at that place. As these two factors would necessarily be the same at all points along the same parallel of latitude, the zones of equal temperature would coincide with the parallels of latitude. Even the presence of a vapourless atmosphere would interfere but little with this

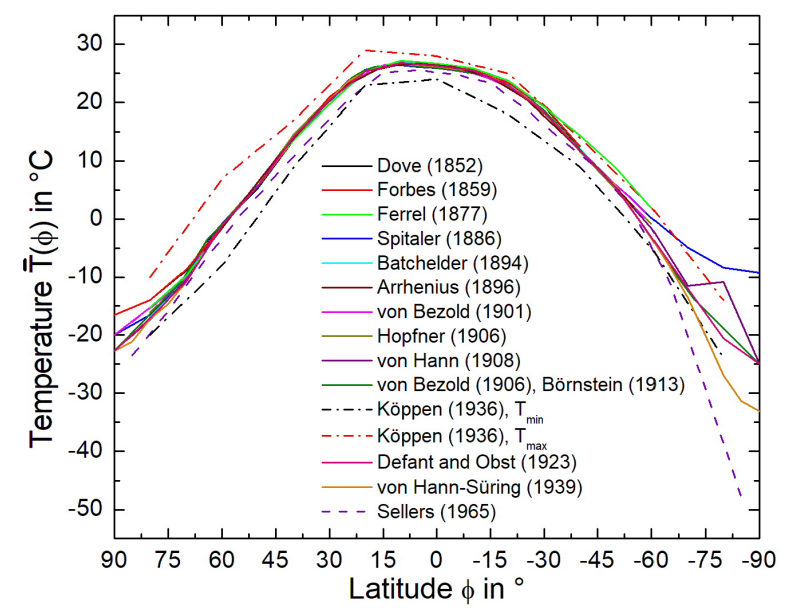

Figure 20. Comparison of the meridional distributions of zonal averages of temperature, $\bar{T}(\phi)$, as derived by Dove [19] (Do1852), Forbes [23] (Fo1859), Ferrel [12] (Fe1877), Spitaler [10] (Sp1885), Batchelder [11] (Ba1894), Arrhenius [26] (A1896-1), von Bezold [7] (vB1901-1), Hopfner [33] (Ho1906-1), von Hann [32] (vH1908), von Bezold [29] (vB1906), Börnstein [35] (Bö1913), Defant and Obst [36] (De1923), Köppen [37], von Hann-Süring [38] (vHS1939, eventually adopted by Haurwitz and Austin [40] and Blüthgen [41]), and Sellers [39] (Se1965). 
distribution of temperature, for only the absolute amounts of heat received at, and radiated from, the surface of the earth would thereby be affected. It is true that convectional currents would be produced under these conditions; but as there would be no reason for the more frequent occurrence of warm or cold air currents along some meridians than others, the distribution of temperature in zones bounded by the parallels of latitude would not thereby be interfered with."

The solar climate depends on the astronomic aspects like the distance between the Sun's center and the Earth (Earth-Moon barycenter), the obliquity of Earth's rotation axis with respect to the normal of the ecliptic plane, the angular velocity of the rotation, and the total solar irradiance (TSI) for $1 A U$. Only the absorbed solar radiation and the thermal effect related to the regolith should be considered. With respect to geological time scales, also changes in the precession of Earth's rotation axis, and long-term variations of the eccentricity, obliquity, and precession of the Perihelion caused by the Sun, Moon and planets of our solar system must be considered [69-75].

Figure 21 compares the meridional distributions of the zonal temperature averages of the real climate as given by Spitaler [10] (Sp1885), Arrhenius [26] (A1896-1), von Bezold [29] (vB1906), as well as von Hann-Süring [38] (vHS1939) and the solar climate predicted by Kramm et al. [44] for the year 2010. Kramm et al. [44] used the following local energy budget equation for a thin slab of $2 \mathrm{~cm}$ thickness adjacent to the surface of either the Earth's Moon or the Earth in the absence of its atmosphere:

$$
\vartheta \frac{\mathrm{d}}{\mathrm{d} t}\left\langle c \rho T_{\text {slab }}\right\rangle_{V}=\left(1-\alpha\left(\Theta_{0}, \theta, \varphi\right)\right) F \cos \Theta_{0}-\varepsilon(\theta, \varphi) \sigma T_{\text {slab }}^{4}(\theta, \varphi)-H_{s l}(\theta, \varphi),
$$

where $\langle\ldots\rangle_{V}$ is the volume average.Here, $t$ is time, $T_{\text {slab }}, \rho$, and $\mathcal{c}$, are the temperature, bulk density, and specific heat of this slab of soil, respectively. Furthermore, $\left(1-\alpha\left(\Theta_{0}, \theta, \varphi\right)\right) F \cos \Theta_{0}$ is the solar radiation absorbed by the slab, where $F$ is the solar irradiance reaching the surface, $\alpha\left(\Theta_{0}, \theta, \varphi\right)$ is the integral albedo inthe solar range, and $\Theta_{0}$ is the local zenith distance of the Sun's center.Kramm et al. [44] calculated $\alpha\left(\Theta_{0}, \theta, \varphi\right)$ by Keihm's [76] empirical formula rearranged to

$$
\alpha\left(\Theta_{0}\right)=\alpha_{0}+\left(\frac{\Theta_{0}}{45^{\circ}}\right)^{3}\left(a+b\left(\frac{\Theta_{0}}{45^{\circ}}\right)^{5}\right)
$$

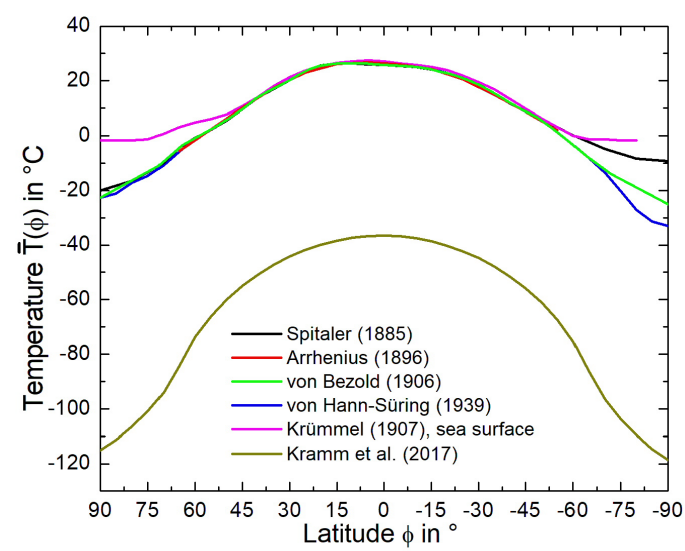

(a)

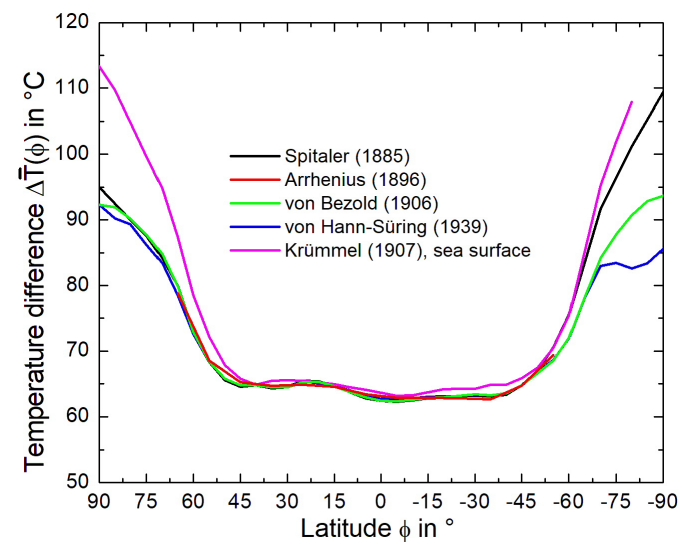

(b)

Figure 21. Meridional distributions of (a) the zonal averages of temperature, $\bar{T}(\phi)$, of the real climate, represented by Spitaler [10] (Sp1885), Arrhenius [26] (A1896-1), von Bezold [29] (vB1906), and von Hann-Süring [38] (vHS1939), the sea surface temperature given by Krümmel [54], and the solar climate derived by Kramm et al. [44], as well as (b) the difference, $\Delta \bar{T}(\phi)$, between the zonal averages of the real climate, the sea surface temperature only and those of the solar climate. 
where $\alpha_{0}=0.10$ is the normal albedo, and $a=0.045$ and $b=5.47 \times 10^{-4}$ are empirical values. With exception of Keihm's value for $b$, all other values are based on observations from the Lunar Reconnaissance Orbiter Diviner Lunar Radiometer Experiment $[77,78]$. In the case of the Earth, $\cos \Theta_{0}$ was determined using the rules of spherical trigonometry (e.g., $[74,75,79,80])$

$$
\begin{aligned}
\cos \Theta_{0} & =\sin \phi \sin \delta_{\text {Sun }}+\cos \phi \cos \delta_{\text {Sun }} \cos h \\
& =\cos \theta \sin \delta_{\text {Sun }}+\sin \theta \cos \delta_{\text {Sun }} \cos h
\end{aligned}
$$

Here, $\delta_{\text {Sun }}$ is the declination of the Sun, $\phi$ is latitude, and $h$ is the hour angle from the local meridian. The solar irradiance, $F$, is given by

$$
F=\left(\frac{r_{\text {Sun }}}{r}\right)^{2} F_{\text {Sun }}
$$

where $F_{\text {Sun }}$ is the solar emittance $[74,75,81,82], r_{\text {Sun }} \cong 6.963 \times 10^{5} \mathrm{~km}$ [83] is the radius of the Sun, and $r$ is the actual distance between the Sun's and Earth's centers. Inserting the mean distance, $r_{0}$ (nearly 1 $A U$ ), into Equation (28) provides the solar constant for the Earth

$$
S=\left(\frac{r_{\text {Sun }}}{r_{0}}\right)^{2} F_{\text {Sun }}
$$

Combining formulae (28) and (29) yields

$$
F=\left(\frac{r_{0}}{r}\right)^{2} S
$$

Furthermore, $F_{I R}=\varepsilon(\theta, \varphi) \sigma T_{\text {slab }}^{4}(\theta, \varphi)$ is the emitted radiation according to the power law of Stefan [84] and Boltzmann [85], where $\varepsilon(\theta, \varphi)$ is the integral relative emissivity, and $H_{s l}(\theta, \varphi)$ is the vertical component of the soil heat flux provided by a multi-layer soil model. The direction of $H_{s l}(\theta, \varphi)$ is governed by the difference between the absorbed solar radiation and the emitted infrared radiation. Moreover, the planetary and lunar ephemeris DE430 of the Jet Propulsion Laboratory (JPL) of the California Institute of Technology $[86,87]$ to compute $r$ and $\delta_{\text {Sun }}$. A TSI of $1361 \mathrm{~W} \cdot \mathrm{m}^{-2}$ at $1 A U$ was taken from Kopp and Lean [88] and Kopp et al. [89]. According to the TSI reconstruction by Kopp et al. [90], the TSI only changed by $\pm 1 \mathrm{~W} \cdot \mathrm{m}^{-2}$ during 1850 to 2015 . Thus, the solar climate derived by Kramm et al. [44] may be compared with the real climates represented by the datasets Sp1885 [10], A1896-1 [26], vB1906 [29], and vHS1939 [38].

Figure 21 also shows Krümmel's [54] meridional distribution of the zonal mean sea-surface temperatures (Figure 18 and Figure 19 may be considered to assess Krümmel's data.). Obviously, between $45^{\circ} \mathrm{N}$ and $45^{\circ} \mathrm{S}$, the meridional distributions of normal temperatures mainly follow those of the zonal mean sea surface temperatures. Already Forbes's formula (Equation (24)) illustrated in Figure 11 documents this fact. Krümmel's sea-surface data would provide $\left\langle T_{\text {sea }}\right\rangle=16.7^{\circ} \mathrm{C}$ for an aqueous globe. For comparison: Forbes' formula (Equation (24)) would provide $\left\langle T_{\text {sea }}\right\rangle=13.7^{\circ} \mathrm{C}$ for an aqueous globe and $\left\langle T_{\text {land }}\right\rangle=20.7^{\circ} \mathrm{C}$ for a rocky one.

The slab-temperature distribution predicted by Kramm et al. [44] fulfills the condition of the global radiation balance. Based on the globally averaged solar radiation of $\langle F\rangle=340.2 \mathrm{~W} \cdot \mathrm{m}^{-2}$ and the globally absorbed solar radiation is $\langle Q\rangle=279.7 \mathrm{~W} \cdot \mathrm{m}^{-2}$, the global albedo in the solar range is about $\alpha_{E}=0.178$. The globally emitted infrared radiation is $\left\langle F_{I R}\right\rangle=279.6 \mathrm{~W} \cdot \mathrm{m}^{-2}$. Thus, the radiative imbalance is $\langle Q\rangle-\left\langle F_{I R}\right\rangle \cong 0.1 \mathrm{~W} \cdot \mathrm{m}^{-2}$. It is compensated by the globally averaged soil heat flux. As listed in Table 4, the global average of this slab-temperature distribution is $\left\langle T_{\text {slab }}\right\rangle=-52.4^{\circ} \mathrm{C}=220.7 \mathrm{~K}$. Since

$\left\langle T_{\text {slab }}^{4}(\theta, \varphi)\right\rangle^{1 / 4}=266.4 \mathrm{~K}$, one obtains $\left\langle T_{\text {slab }}\right\rangle=0.828\left\langle T_{\text {slab }}^{4}(\theta, \varphi)\right\rangle^{1 / 4}$ for the obliquely rotating Earth in the absence of its atmosphere. 
Figure 21(a) shows the meridional distributions of zonal averages of the solar irradiance, $\bar{F}(\theta)$, the absorbed solar irradiance, $\bar{Q}(\theta)$, and various normal temperatures related to them for the Earth in the absence of its atmosphere. In contrast to Kramm et al. [44], Defant and Obst [36] used a solar constant of $S=2 \mathrm{cal} \cdot \mathrm{cm}^{-2} \cdot \mathrm{min} \cong 1394.6 \mathrm{~W} \cdot \mathrm{m}^{-2}$. Replacing their too high solar constant with the current one would provide a meridional distribution of $\bar{F}(\theta)$ that substantially agrees with that of Kramm et al. [44]. Based on Equation (4), integration of $\bar{F}(\theta)$ from $\theta=0$ to $\theta=\pi$ provides for Defant and Obst's original data $\langle F\rangle=348.2 \mathrm{~W} \cdot \mathrm{m}^{-2}$ and for the corrected data $\langle F\rangle=340.2 \mathrm{~W} \cdot \mathrm{m}^{-2}$, respectively. The integration of $\bar{Q}(\theta)$ from $\theta=0$ to $\theta=\pi$ yields, of course, $\langle Q\rangle=279.7 \mathrm{~W} \cdot \mathrm{m}^{-2}$, mentioned before.

Defant and Obst [36] used the power law of Stefan [84] and Boltzmann [85] to derive the zonal average of a so-called radiation temperature, $T_{F}(\theta)$, from $\bar{F}(\theta)$. They assumed that the emitted radiation is equal to the completely absorbed solar irradiance. They compared the meridional distribution of this radiation temperature with that of the real zonal temperature means, $\bar{T}(\theta)$, and interpreted the difference $\bar{T}(\theta)-T_{F}(\theta)$ as the heat protection due to the atmosphere. The meridional distributions of both $\bar{T}(\theta)$ and $T_{F}(\theta)$ are illustrated in Figure 21(b). Based on Equation (8), the integration of $\overline{T_{F}}(\theta)$ and $\bar{T}(\theta)$ from $\theta=0$ to $\theta=\pi$ provides $\left\langle T_{F}\right\rangle=10.0^{\circ} \mathrm{C}$ and $\langle T\rangle=13.9^{\circ} \mathrm{C}$, respectively.

This procedure, however, is incorrect from physical and mathematical points of view. Since the local radiation balance is given by [91]

$$
Q(\theta, \varphi)=\left(1-\alpha\left(\Theta_{0}, \theta, \varphi\right)\right) F \cos \Theta_{0}=\sigma T_{s}^{4}(\theta, \varphi)
$$

where $Q(\theta, \varphi)$ is the absorbed solar irradiance, and $T_{s}$ is the local surface temperature, zonal averaging would provide (see Equation (3))

$$
\bar{Q}(\theta)=\frac{1}{2 \pi} \int_{0}^{2 \pi}\left(1-\alpha\left(\Theta_{0}, \theta, \varphi\right)\right) F \cos \Theta_{0} \mathrm{~d} \varphi=\frac{\sigma}{2 \pi} \int_{0}^{2 \pi} T_{s}^{4}(\theta, \varphi) \mathrm{d} \varphi
$$

and, hence,

$$
\bar{Q}(\theta)=\overline{T_{s}^{4}}(\theta)
$$

In accord with the general inequality of Gerlich and Tscheuschner [91],

$$
\overline{T_{s}}=\int_{X} T_{s} \mathrm{~d} W \leq \sqrt[4]{\int_{X} T_{s}^{4} \mathrm{~d} W}=\sqrt[4]{\bar{T}_{s}^{4}}
$$

for a non-negative measurable function $T_{s}$ and a probability measure $W$, the zonal average of the surface temperature, fulfills the inequality

$$
\overline{T_{s}}(\theta) \leq T_{Q}(\theta)=\sqrt[4]{\bar{Q}(\theta) / \sigma}=\sqrt[4]{\overline{T_{s}^{4}}(\theta)}
$$

In the case of completely absorbed solar irradiance, i.e., $\alpha\left(\Theta_{0}, \theta, \varphi\right)=0$, we would have $\bar{Q}(\theta)=\bar{F}(\theta)$ and, hence, $T_{Q}(\theta)=T_{F}(\theta)$. Thus, as illustrated in Figure 22(b), any zonal average of the surface temperature, $\bar{T}_{s}(\theta)$ based on Equation (31) is usually much smaller than the corresponding radiation temperature $T_{F}(\theta)$. Based on Equation (4), the integration of $\overline{T_{s}}(\theta)$ from $\theta=0$ to $\theta=\pi$ provided $\left\langle T_{s}\right\rangle=157.2 \mathrm{~K}$. This global mean surface temperature substantially agrees with result of Gerlich and Tscheuschner [91] (cf. their Table 12), even though we considered an obliquely rotating Earth in the absence of its atmosphere. In the case $\alpha\left(\Theta_{0}, \theta, \varphi\right)>0$, we would have $\overline{T_{s}}(\theta) \leq T_{Q}(\theta)<T_{F}(\theta)$. Consequently, one must conclude that the solar climate as derived by Defant and Obst [36] has to be discarded.

As illustrated by Figure 23, for any parallel of latitude, the slab temperature that represents the Earth's surface temperature in the absence of the atmosphere varies with time due to the Earth's daily rotation and annual orbit around the Sun. However, this slab temperature is based on a local energy balance equation (25) that also included the soil heat flux density [44]. The meridional distribution of the normal temperature along a parallel of latitude based on a local radiation balance would be the same as proposed 


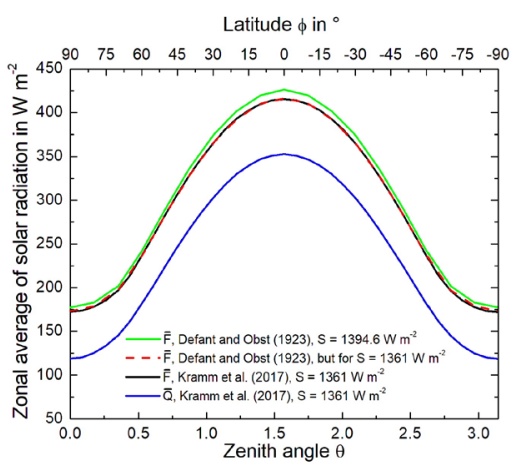

(a)

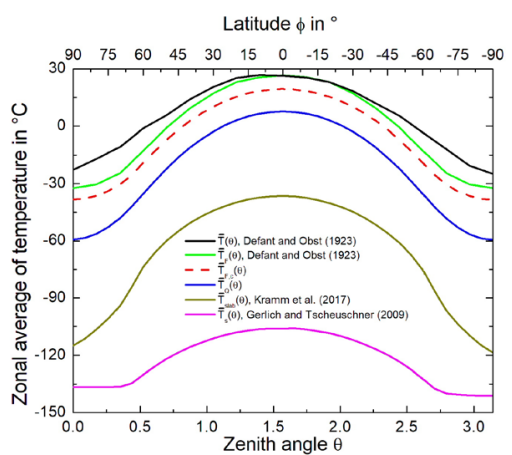

(b)

Figure 22. Meridional distributions of (a) the zonal averages of solar radiation, $\bar{F}(\theta)$, the absorbed solar radiation, $\bar{Q}(\theta)$, and (b) various normal temperatures, $\overline{T_{X}}(\theta)$, for the solar climate, where $X=F$ stands for the radiation temperature of Defant and Obst [36], $X=F, c$ for the radiation temperature corrected to $S=1361 \mathrm{~W} \cdot \mathrm{m}^{-2}, X=Q$ for the radiation temperature related to the absorbed solar radiation, $Q(\theta), X=$ slab for the slab temperature according to Kramm et al. [44], and $X=S$ for the local radiation temperature according to Gerlich and Tscheuschner [91]. Also shown is the meridional distribution of the real normal temperatures, $\bar{T}(\theta)$ (data adopted from Defant and Obst [36] and Kramm et al. [44]).

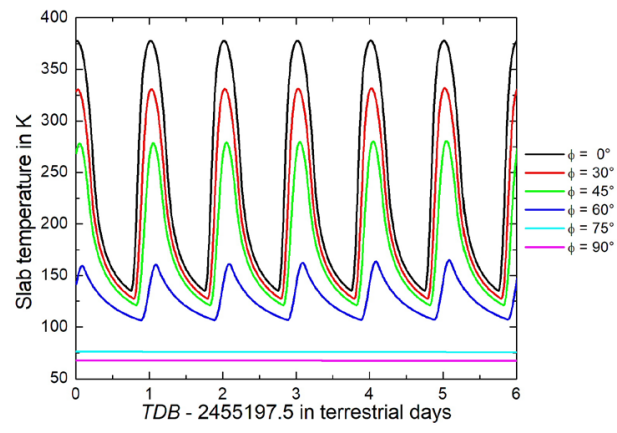

(a)

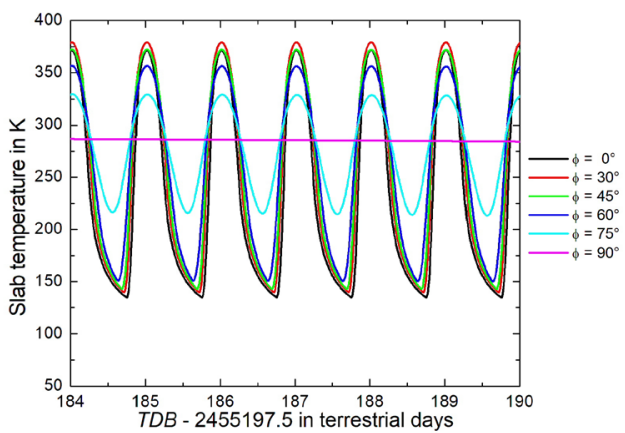

(c)

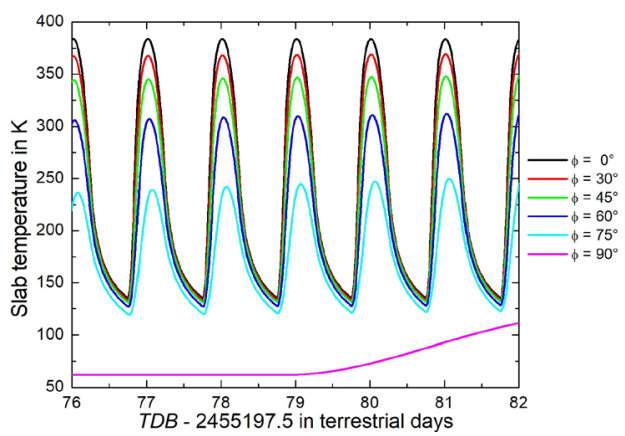

(b)

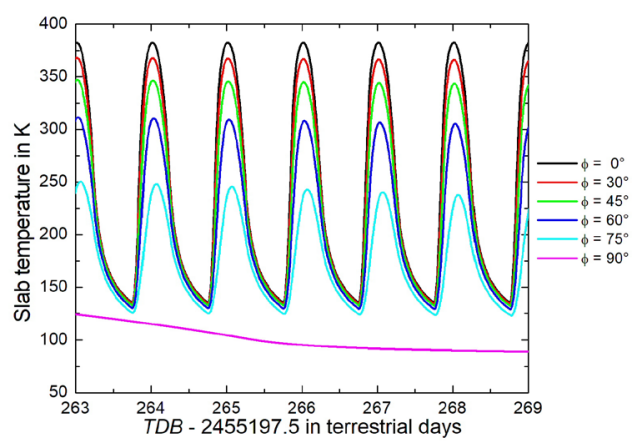

(d)

Figure 23. Diurnal variation of the slab temperature around (a) Perihelion; (b) Vernal Equinox; (c) Aphelion; and (d) Autumnal Equinox for the Earth in the absence of its atmosphere (data from Kramm et al. [44]). 
by Gerlich and Tscheuschner [91] because during nighttime the surface temperature derived from the local radiation balance would be zero Kelvin (see Equation (31)). Therefore, as illustrated in Figure 22(b), this meridional distribution of normal temperature is, by far, the lowest one.

Obviously, the existence of the atmosphere, the nonuniformity of the Earth's surface, the uneven ocean-land distribution, the airflows and ocean currents cause the transition from the solar climate to the real climate [92]. The difference between the solar climate and the real one is usually called the atmospheric effect. Thus, this atmospheric effect would vary with the parallels of latitude.

The atmosphere is a complex thermo-fluid dynamic system with various degrees of freedom. It consists of various layers (e.g., troposphere, stratosphere, mesosphere, thermosphere) separated by conceptual partitions called pauses [48]. It exhibits an impressive amount of detail and huge spatial and temporal variability of its properties [48]. More than $99 \%$ of the atmospheric mass of about $5.15 \times 10^{18} \mathrm{~kg}$ is below the altitude of $30 \mathrm{~km}$ above sea level. The atmospheric response time to an imposed change is of the order of days or weeks owing to its notable compressibility and its low density and specific heat [48]. Consequently, the response time corresponds to weather periods, rather than climate periods of, at least, 30 years. According to Fortak [93] and Peixoto and Oort [48], the total energy of the atmosphere is about $1.31 \times 10^{24} \mathrm{~J}$, i.e., less than $0.1 \%$ of the total energy of the oceans.

Based on recent observations, the solar insolation at the top of the atmosphere (TOA) corresponds to a globally averaged value of about $\langle F\rangle_{T O A}=340.3 \mathrm{~W} \cdot \mathrm{m}^{-2}$ (100 units). As sketched in Figure 24, only about $\langle Q\rangle=238.2 \mathrm{~W} \cdot \mathrm{m}^{-2}$ is absorbed by the entire Earth-atmosphere system (EAS). Compared with $\langle Q\rangle=279.7 \mathrm{~W} \cdot \mathrm{m}^{-2}$ of the solar climate of Kramm et al. [44], the solar radiation absorbed by the EAS is notably lower. The absorbed solar radiation of $\langle Q\rangle=238.2 \mathrm{~W} \cdot \mathrm{m}^{-2}$ is approximately balanced, on global average, by the infrared radiation, $\left\langle F_{I R}\right\rangle_{T O A}$ emitted to space by the entire EAS (Figure 24). Note that the TOA may be interpreted as a height of the intervening atmospheric layer. Above this height, neither solar radiation nor infrared radiation is remarkably affected by atmospheric constituents.

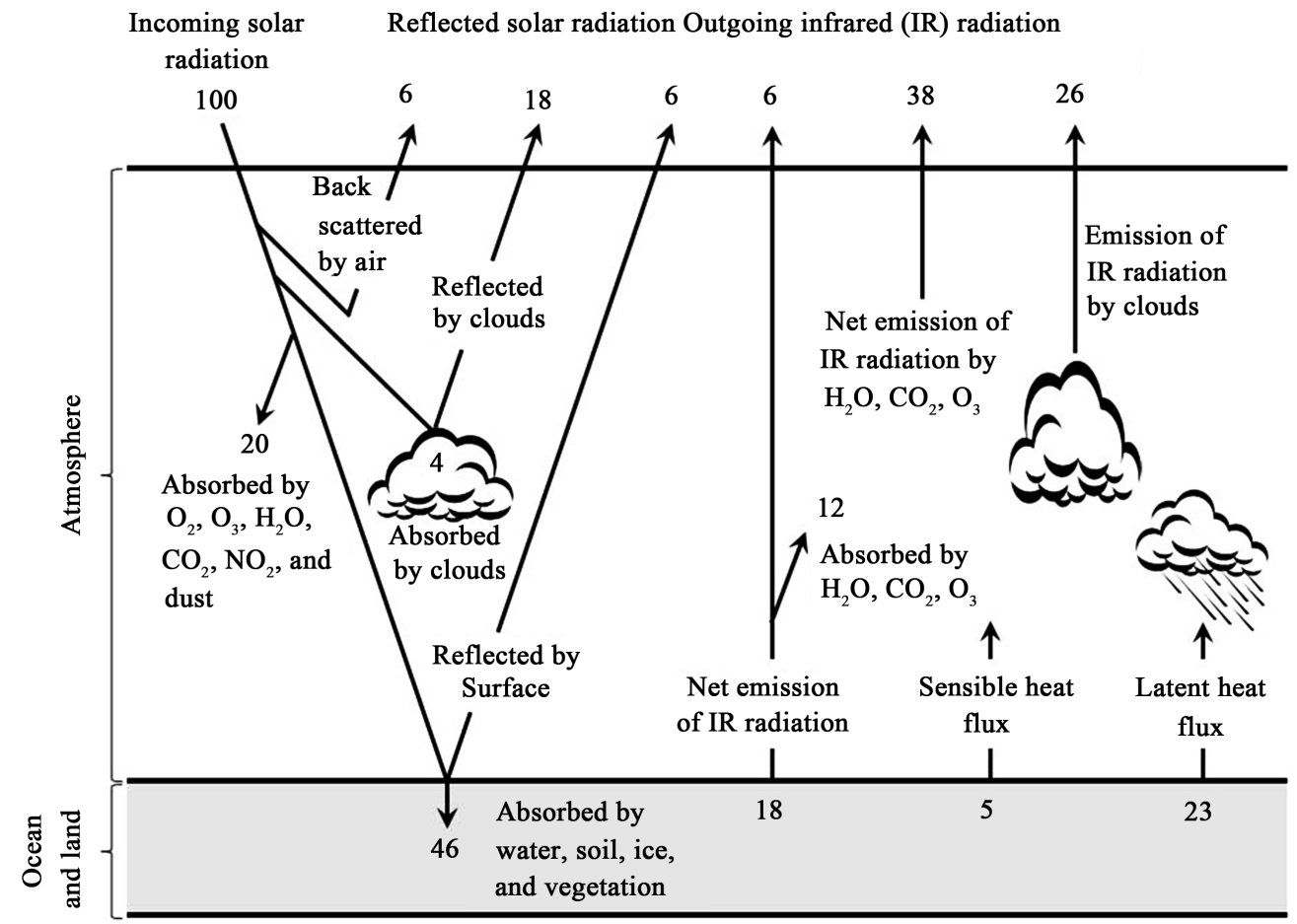

Figure 24. Sketch of the global energy budget of the system Earth-atmosphere (adopted from Mölders and Kramm [95]). Note that the values of the units slightly vary from author to author. These values just intend to assess the processes relative to each other. 
As sketched in Figure 24, a notable portion of the solar insolation penetrating into the atmosphere is absorbed in the ultraviolet and visible ranges as well as in the near infrared range by various gaseous and particulate atmospheric constituents $\left(20\right.$ units or $\left.68.1 \mathrm{~W} \cdot \mathrm{m}^{-2}\right)$ and clouds $\left(4\right.$ units or $\left.13.6 \mathrm{~W} \cdot \mathrm{m}^{-2}\right)$. Especially the absorption of solar radiation by molecular oxygen $\left(\mathrm{O}_{2}\right)$ and ozone $\left(\mathrm{O}_{3}\right)$ heats the atmosphere directly $[75,94]$. Water vapor $\left(\mathrm{H}_{2} \mathrm{O}\right)$ and $\mathrm{O}_{2}$ are also active in the visible and near infrared range; nitrogen dioxide $\left(\mathrm{NO}_{2}\right)$ is active in the visible range, too. Furthermore, a considerable portion of the solar radiation is back-scattered by molecules (Rayleigh scattering), cloud and aerosol particles (Lorenz-Mie scattering). A notable amount of solar radiation reaching the Earth's surface is reflected, either by the soil-vegetation and water systems on land or by the oceans. These processes contribute to a planetary albedo of about 30 units $\left(102.1 \mathrm{~W} \cdot \mathrm{m}^{-2}\right)$, on global average (Figure 24$)$. This means that the remaining 70 units $\left(238.2 \mathrm{~W} \cdot \mathrm{m}^{-2}\right)$ of solar radiation, on global average, feed the EAS with energy. However, only about 46 units $\left(156.5 \mathrm{~W} \cdot \mathrm{m}^{-2}\right)$ are absorbed by water (including ice) and land masses (including vegetation) in the close vicinity of the Earth's surface (Figure 24). Note that a fraction of the incident solar radiation may penetrate into the water or snow to considerable depths without notable absorption.

Atmospheric motions are stochastic to a certain extent. However, organized patterns like Rossby waves, mountain-induced gravity and inertial-gravity waves, cyclones and anticyclones, jet streams, and circulation pattern of different sizes like Hadley, Ferrel, and polar cells, monsoonal circulation, small-scale land-sea breezes, convection roles, etc. can be identified. Variations of these flow patterns may affect the energy conversion at the Earth's surface on local and regional scales. Turbulent motion can mainly be observed in the atmospheric boundary layer (ABL) and along jet streams. The exchange of sensible and latent heat between the land or water masses adjacent to the Earth's surface and the atmosphere is strongly controlled by molecular and turbulent transfer processes within the Prandtl layer (also called the atmospheric surface layer, ASL). Over canopies of tall vegetation, the outer edge of the Prandtl layer may be at $100 \mathrm{~m}$ height above ground. The climates of landscapes may be described by the Köppen-Geiger climate classification. An updated version was derived by Peel et al. [96] in 2007.

During cloud formation huge amounts of latent heat are released that heat the ambient air directly. Clouds of various horizontal and vertical extensions and compositions of hydrometeors mainly occur in the troposphere. They strongly interact with both solar and infrared radiation by absorption, scattering, and emission (only infrared radiation). Clouds also affect the energy conversion at the interface Earthatmosphere via radiation and by precipitation thereby altering the surface properties of vegetation and soils. Precipitation contributes in small amounts to the conversion of potential energy into kinetic energy which is finally converted into heat.

Solar radiation absorbed by water and soil layers adjacent to the Earth's surface is converted into heat. Hence, it contributes to warming these layers [75]. These layers also exchange energy with the ABL by flux densities (simply denoted as fluxes) of sensible ( 5 units or $17 \mathrm{~W} \cdot \mathrm{m}^{-2}$ ) and latent heat (23 units or 78.3 $\mathrm{W} \cdot \mathrm{m}^{-2}$ ). These fluxes, on global average, heat the atmosphere from below and cause convective transports of energy and mass into the upper troposphere. There, especially the release of latent heat during phase transition processes contributes to establish atmospheric circulation systems of different spatial and temporal scales $[75,93]$.

As the absorption of solar radiation by atmospheric constituents and the exchange of energy between the soil and/or water layers at the Earth-atmosphere interface by the fluxes of sensible and latent heat already heated the atmosphere (about $177.0 \mathrm{~W} \cdot \mathrm{m}^{-2}$ of the energetically relevant solar radiation, on global average), we have to expect that gaseous atmospheric constituents able to emit and absorb infrared (IR) radiation in finite spectral ranges, will emit energy in the IR range in all directions. The amount of this IR radiation depends on the local temperature of the mixture of these constituents. Therefore, it is indispensable to consider the down-welling IR radiation reaching the Earth's surface, where most of it is absorbed. The same is true for hydrometeors.

The water and soil layers adjacent to the Earth-atmosphere interface, of course, also emit IR radiation depending on their local temperatures. The net emission in the IR range (emitted radiation minus absorbed down-welling radiation) is about 18 units $\left(61.3 \mathrm{~W} \cdot \mathrm{m}^{-2}\right)$, on global average. A notable portion of 
this IR net emission is absorbed by atmospheric constituents and emitted in all directions, too. A small fraction propagates through the atmosphere (about 6 units or $20.4 \mathrm{~W} \cdot \mathrm{m}^{-2}$ ) with marginal extinction by intervening constituents. Such a spectral region is the so-called atmospheric window ranging from $8.3 \mu \mathrm{m}$ to $12.5 \mu \mathrm{m}$ (e.g., [74, 75, 82, 97, 98]). It only contains the $9.6 \mu \mathrm{m}$-band of ozone. Satellite-borne radiometers use the atmospheric window between $10 \mu \mathrm{m}$ and $12.5 \mu \mathrm{m}$ to measure radiation up-welling from the Earth's surface [97].

Gases like $\mathrm{H}_{2} \mathrm{O}$, carbon dioxide $\left(\mathrm{CO}_{2}\right)$, and $\mathrm{O}_{3}$ and hydrometeors also emit IR radiation to space. As shown in Figure 24, on global average, the net emission by these gases is about 38 units $\left(129.3 \mathrm{~W} \cdot \mathrm{m}^{-2}\right)$, and the emission by clouds to space is 26 units $\left(88.5 \mathrm{~W} \cdot \mathrm{m}^{-2}\right)$.

Besides the solar climate, the oceanic circulation affects the meridional distribution of normal temperatures [99]. As Wunsch pointed out, the mass fluxes in the upper hundred meters of the ocean are primarily wind-driven yielding major features like the Gulf Stream and the Antarctic Circumpolar Current; and secondarily driven by tidal forces.

The role of the thermohaline circulation is assessed somewhat controversy. Wunsch [99] argued "that the "thermohaline circulation" should be reserved for the separate circulations of heat and salt, and not conflated into one vague circulation with unknown or impossible energetics. No shortcut exists for determining property fluxes from the mass circulation without knowledge of the corresponding property distribution."On the contrary, Rahmstorf [100] stated that "the ocean's density distribution, which determines pressure gradients and thus circulation, is itself affected by currents and mixing. Thermohaline and wind-driven currents therefore interact in non-linear ways and cannot be separated by oceanographic measurements."

\section{RESULTS}

\subsection{Global and Hemispheric Temperature Averages}

To calculate the global and the hemispheric averages of the near-surface air temperature, we used Equation (8) and the datasets of the historical climatological and annual averages of temperature along numerous parallels of latitude(i.e., the zonal averages of temperature or normal temperatures) published between 1852 (Dove [19]) and 1913 (Börnstein [35]). The results are listed in Table 4. For comparison, also the results derived from the meridional distributions of the normal temperatures published by Defant and Obst [36], von Hann-Süring [38] (eventually adopted by Haurwitz and Austin [40] and Blüthgen [41]) and Sellers [39] as well as for the solar climate predicted by Kramm et al. [44] (but not explicitly published) are listed in Table 4. In some cases, we used Equation (23) to calculate the respective spheroidal mean near-surface temperature to assess the accuracy of spherical averaging as compared to spheroidal averaging.

Figure 25 shows results of the integrand $\bar{T}(\theta) \sin \theta$, as requested by Equation (8) for a spherical shape of the Earth, where Köppen's [37] maximum and minimum temperatures for numerous parallels of latitude (Table 3 ) were considered. Using the polygons related to the points of this integrand yields a globally averaged minimum temperature of $\left\langle T_{\min }\right\rangle=8.4^{\circ} \mathrm{C}$ and a globally averaged maximum temperature of $\left\langle T_{\max }\right\rangle=15.4^{\circ} \mathrm{C}$, respectively. For fitting this small number of points of these polygons, we used the asymmetric double sigmoidal peak function,

$$
I(\theta)=I_{0}+\frac{A}{1+\exp \left(-\frac{\theta-\theta_{c}+B / 2}{C}\right)}\left(1-\frac{1}{1+\exp \left(-\frac{\theta-\theta_{c}-B / 2}{D}\right)}\right)
$$

because the temperature distributions illustrated by Figure 20 require an asymmetric peak function. The parameters $A, B, C$, and $D$ are listed in Table 5. For Köppen's [37] dataset, this fit function provided

$\left\langle T_{\text {min }}\right\rangle=10.9^{\circ} \mathrm{C}$ and $\left\langle T_{\max }\right\rangle=18.0^{\circ} \mathrm{C}$, respectively. 
Table 4. Global and hemispheric averages of the near-surface air temperature based on polygons and Equation (36). Marginal differences in the second decimal place may cause some rounding effects.

\begin{tabular}{|c|c|c|c|c|c|c|c|c|}
\hline \multirow{3}{*}{$\begin{array}{c}\text { Author(s), and } \\
\text { dataset }\end{array}$} & \multicolumn{8}{|c|}{ Average near-surface air temperature in ${ }^{\circ} \mathrm{C}$} \\
\hline & \multicolumn{4}{|c|}{ Polygons } & \multicolumn{4}{|c|}{ Equation (36) } \\
\hline & $\mathrm{NH}$ & $\mathrm{SH}$ & $\Delta(\mathrm{NH}-\mathrm{SH})$ & Earth & $\mathrm{NH}$ & SH & $\Delta(\mathrm{NH}-\mathrm{SH})$ & Earth \\
\hline Dove [19], Do1852 & 14.9 & 11.8 & 3.1 & 13.3 & 15.3 & 14.3 & 1.0 & 14.8 \\
\hline Forbes [23], Fo1859 & 14.9 & 11.8 & 3.1 & 13.4 & 15.4 & 14.1 & 1.3 & 14.8 \\
\hline Ferrel [12], Fe1877 & 14.8 & 15.4 & -0.6 & 15.1 & 15.2 & 15.9 & -0.7 & 15.5 \\
\hline $\begin{array}{l}\text { Spitaler [10], Sp1885 } \\
\text { "Complete dataset" }\end{array}$ & 15.2 & 14.6 & 0.6 & 14.9 & 15.2 & 14.7 & 0.5 & 14.9 \\
\hline $\begin{array}{l}\text { Spitaler [10], Sp1885 } \\
\text { "Reduced dataset" }\end{array}$ & 14.7 & 14.1 & 0.6 & 14.4 & 15.2 & 14.7 & 0.5 & 15.0 \\
\hline $\begin{array}{l}\text { Batchelder [11], } \\
\text { Ba1894 }\end{array}$ & 14.7 & 13.3 & 1.4 & 14.0 & 15.2 & 14.0 & 1.2 & 14.6 \\
\hline $\begin{array}{l}\text { Arrhenius [26], } \\
\text { A1896-1 }\end{array}$ & 15.0 & 13.5 & 1.5 & 14.2 & 15.2 & 13.7 & 1.5 & 14.4 \\
\hline $\begin{array}{c}\text { Arrhenius }[14,26]^{\star} \\
\text { A1896-2 }\end{array}$ & 13.7 & 13.0 & 0.7 & 13.3 & 13.8 & 13.2 & 0.6 & 13.5 \\
\hline $\begin{array}{c}\text { von Bezold [7], } \\
\text { vB1901-1 } \\
\text { "Spitaler" }\end{array}$ & 15.3 & 14.4 & 0.9 & 14.9 & 15.0 & 14.1 & 0.9 & 14.6 \\
\hline $\begin{array}{l}\text { von Bezold [7], } \\
\text { vB1901-2 } \\
\text { "Batchelder" }\end{array}$ & 15.4 & 14.4 & 1.0 & 14.9 & 15.1 & 14.0 & 1.1 & 14.6 \\
\hline $\begin{array}{l}\text { Hopfner [33], } \\
\text { Ho1906-1 }\end{array}$ & 14.9 & 13.2 & 1.7 & 14.1 & 15.4 & 13.6 & 1.8 & 14.5 \\
\hline $\begin{array}{c}\text { Hopfner [33] } \\
\text { Ho1906-2 }\end{array}$ & 15.0 & 13.7 & 1.3 & 14.4 & 15.5 & 14.1 & 1.4 & 14.8 \\
\hline $\begin{array}{c}\text { von Hann [32], } \\
\text { vH1908 }\end{array}$ & 14.8 & 13.6 & 1.2 & 14.2 & 15.2 & 14.2 & 1.0 & 14.7 \\
\hline
\end{tabular}




\section{Continued}

von Bezold [29], vB1906,

Börnstein [35],

$\begin{array}{lll}15.5 & 13.7 & 1.8\end{array}$

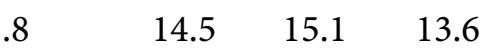

1.5

14.3

Bö1913,

"Complete dataset"

von Bezold [29], vB1906,

Börnstein [35]

$15.4 \quad 13.5$

1.9

$14.5 \quad 15.1 \quad 13.5$

1.6

14.3

Bö1913,

"Reduced dataset"

Defant and Obst [36], De1923

$14.7 \quad 13.1-1.6$

$13.9 \quad 15.2 \quad 13.7$

1.5

14.5

Köppen [37], $T_{\min }$

$9.1 \quad 7.8$

1.3

$8.4 \quad 11.4 \quad 10.5$

0.9

10.9

Köppen [37], $T_{\max }$

$17.0 \quad 13.8$

3.2

$15.4 \quad 19.6 \quad 16.4$

3.2

18.0

von Hann-Süring [38], vHS1939

$15.1 \quad 13.2$

1.9

$\begin{array}{lll}14.2 & 14.9 & 13.2\end{array}$

1.7

14.0

Haurwitz and Austin [40]

$14.7 \quad 12.5$

2.2

13.6

15.1

13.1

2.0

14.1

Sellers [39], Se1965

$12.7 \quad 11.1$

1.6

$11.9 \quad 13.1 \quad 11.8$

1.3

12.5

Kramm et al. [44] $-52.0-52.8$

$\begin{array}{llll}0.8 & -52.4 & -51.9 & -52.7\end{array}$

0.8 $-52.3$

*)Re-corrected to mean terrain height above sea level.

Table 5. Parameters provided by fitting the points $\bar{T}(\theta) \sin \theta$ using Equation (36) for the various datasets used in our study.

\begin{tabular}{cccccccc}
\hline Author(s), and dataset & Number of points & $I_{0}$ & $\theta_{c}$ & $A$ & $B$ & $C$ & $D$ \\
\hline Dove [19], Do1852 & 14 & -320.57 & 1.5636 & 1438.28 & 1.1416 & 0.8725 & 0.8819 \\
Forbes [23], Fo1859 & 14 & -270.56 & 1.5671 & 957.38 & 1.8252 & 0.7443 & 0.7501 \\
Ferrel [12], Fe1877 & 15 & -310.94 & 1.5710 & 1186.28 & 1.5531 & 0.8301 & 0.8321 \\
$\begin{array}{c}\text { Spitaler [10], Sp1885 } \\
\text { "Complete dataset" }\end{array}$ & 33 & -327.05 & 1.5543 & 1454.92 & 1.1475 & 0.8728 & 0.8993 \\
$\begin{array}{c}\text { Spitaler [10], Sp1885 } \\
\text { "Reduced dataset" }\end{array}$ & 19 & -340.78 & 1.5502 & 1764.13 & 0.7686 & 0.9096 & 0.9359 \\
$\begin{array}{c}\text { Batchelder [11], } \\
\text { Ba1895 }\end{array}$ & 14 & -317.30 & 1.5606 & 1429.10 & 1.1394 & 0.8664 & 0.8802 \\
\hline
\end{tabular}




\section{Continued}

\begin{tabular}{|c|c|c|c|c|c|c|c|}
\hline $\begin{array}{l}\text { Arrhenius [26], } \\
\text { A1896-1 }\end{array}$ & 13 & -264.31 & 1.5653 & 918.09 & 1.8838 & 0.7242 & 0.7367 \\
\hline $\begin{array}{c}\text { Arrhenius }[14,26]^{*}, \\
\text { A1896-2 }\end{array}$ & 13 & -278.01 & 1.5673 & 991.41 & 1.7855 & 0.7595 & 0.7681 \\
\hline $\begin{array}{l}\text { von Bezold [7], } \\
\text { vB1901-1, } \\
\text { "Spitaler" }\end{array}$ & 38 & -303.90 & 1.5608 & 1150.66 & 1.5838 & 0.8090 & 0.8300 \\
\hline $\begin{array}{l}\text { von Bezold [7], } \\
\text { vB1901-2, } \\
\text { "Batchelder" }\end{array}$ & 38 & -275.19 & 1.5652 & 986.81 & 1.7810 & 0.7526 & 0.7656 \\
\hline $\begin{array}{l}\text { Hopfner [33], } \\
\text { Ho1906-1 }\end{array}$ & 14 & -259.62 & 1.5653 & 901.82 & 1.8959 & 0.7169 & 0.7277 \\
\hline $\begin{array}{l}\text { Hopfner [33], } \\
\text { Ho1906-2 }\end{array}$ & 15 & -323.18 & 1.5568 & 1432.82 & 1.1634 & 0.8690 & 0.8891 \\
\hline $\begin{array}{c}\text { von Hann [32], } \\
\text { vH1908 }\end{array}$ & 19 & -298.00 & 1.5620 & 1151.37 & 1.5485 & 0.8076 & 0.8246 \\
\hline $\begin{array}{l}\text { von Bezold [29], } \\
\text { vB1906 }\end{array}$ & & & & & & & \\
\hline $\begin{array}{l}\text { Börnstein [35], } \\
\text { Bö1913 }\end{array}$ & 41 & -240.11 & 1.5664 & 809.04 & 2.0198 & 0.6693 & 0.6810 \\
\hline "Complete dataset" & & & & & & & \\
\hline $\begin{array}{l}\text { von Bezold [29], } \\
\text { Börnstein [35], } \\
\text { "Reduced dataset" }\end{array}$ & 21 & -254.79 & 1.5658 & 868.60 & 1.9525 & 0.7012 & 0.7127 \\
\hline $\begin{array}{l}\text { Defant and Obst [36], } \\
\text { De1923 }\end{array}$ & 19 & -267.45 & 1.5656 & 942.99 & 1.8404 & 0.7356 & 0.7463 \\
\hline Köppen [37], $T_{\min }$ & 9 & -311.71 & 1.5586 & 1605.24 & 0.8397 & 0.8809 & 0.8958 \\
\hline Köppen [37], $T_{\max }$ & 9 & -357.88 & 1.5420 & 1691.43 & 0.9473 & 0.9122 & 0.9469 \\
\hline $\begin{array}{l}\text { von Hann-Süring [38], } \\
\text { vHS1939 }\end{array}$ & 37 & -271.36 & 1.5658 & 957.96 & 1.8258 & 0.7435 & 0.7516 \\
\hline $\begin{array}{c}\text { Haurwitz and } \\
\text { Austin [40] }\end{array}$ & 19 & -313.92 & 1.5588 & 1341.92 & 1.2678 & 0.8513 & 0.8675 \\
\hline Sellers [39], Se1965 & 18 & -242.72 & 1.5693 & 831.23 & 1.9678 & 0.6893 & 0.6859 \\
\hline Kramm et al. [44] & 37 & -77.91 & 1.5691 & 376.50 & 2.0028 & 0.4250 & 0.4255 \\
\hline
\end{tabular}

*) Re-corrected to mean terrain height above sea level. 


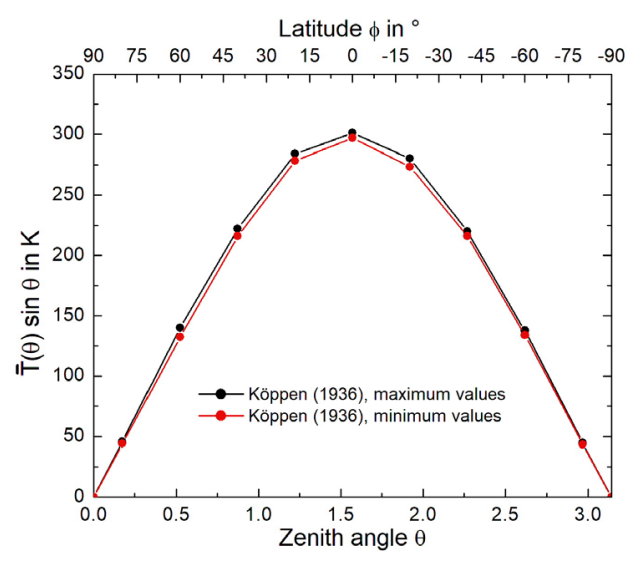

(a)

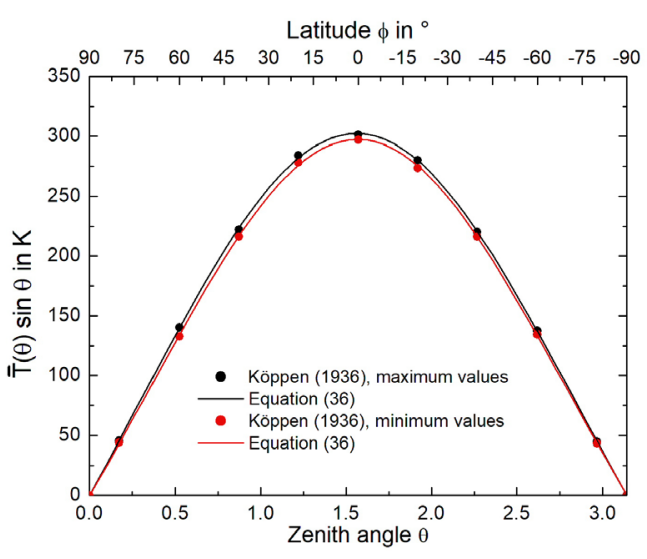

(b)

Figure 25. The integrand $\bar{T}(\theta) \sin \theta$ as requested by Equation (8), where Köppen's [37] maximum and minimum temperatures for numerous parallels of latitude listed in Table 3 were considered: (a) polygons and (b) fits provided by Equation (36).

With respect to the polygons, Köppen's [37] distributions of the zonal averages of minimum and maximum temperatures provided the highest and the lowest global and hemispheric averages, respectively. Beside the latter, only the datasets Do1853 [19] and Fo1859 [23] provided global averages remarkably lower than $\langle T\rangle=14^{\circ} \mathrm{C}$, namely $\langle T\rangle=13.3^{\circ} \mathrm{C}$ and $\langle T\rangle=13.4^{\circ} \mathrm{C}$, respectively. The results derived from the other historical distributions of normal temperatures published between 1877 and 1913 are ranging from $\langle T\rangle=14.0^{\circ} \mathrm{C} \quad(\mathrm{Ba} 1894[11])$ to $\langle T\rangle=15.1^{\circ} \mathrm{C} \quad$ (Fe1877 [12]), with $\langle T\rangle=14.5^{\circ} \mathrm{C} \quad$ (vB1906 [29] and Bö1913 [35]) falling in between.

Obviously, the poor coverage of the Southern Hemisphere by observations during that time indicated by the normal temperatures of Dove [19] and Forbes [23] (no zonal temperature averages beyond $40^{\circ} \mathrm{S}$ ) led to a hemispheric average of $\langle T\rangle_{S H}=11.8^{\circ} \mathrm{C}$. This value is remarkably lower than those derived from the meridional distributions of the historical normal temperatures published by the other authors. The respective averages for the Southern Hemisphere are ranging from $\langle T\rangle_{S H}=13.2^{\circ} \mathrm{C}$ (Ho1906-1 [33]) to $\langle T\rangle_{S H}=15.4^{\circ} \mathrm{C} \quad(\mathrm{Fe} 1877[12])$. The datasets vB1906 and Bö1913 provided $\langle T\rangle_{S H}=13.7^{\circ} \mathrm{C}$.

On the contrary, the average for the Northern Hemisphere based on Dove [19] and Forbes [23] is $\langle T\rangle_{N H}=14.9^{\circ} \mathrm{C}$. Thus, it substantially agrees with the results derived from the datasets of the other authors. Values are ranging from $\langle T\rangle_{N H}=14.7^{\circ} \mathrm{C} \quad(\mathrm{Ba} 1894[11])$ to $\langle T\rangle_{N H}=15.5^{\circ} \mathrm{C} \quad$ (vB1906 [29], Bö1913 [35]). Our results also confirmed that the average temperature for the Northern Hemisphere slightly exceeds that for the Southern Hemisphere. This is also true in case of the solar climate, but not in the case of Ferrel's [12] dataset Fe1877 (Table 4).

For comparison: The datasets of Defant and Obst [36] and von Hann-Süring [38] yielded:

$\langle T\rangle=13.9^{\circ} \mathrm{C},\langle T\rangle_{S H}=13.1^{\circ} \mathrm{C}$, and $\langle T\rangle_{N H}=14.7^{\circ} \mathrm{C}$ for De1923 and $\langle T\rangle=14.2^{\circ} \mathrm{C},\langle T\rangle_{S H}=13.2^{\circ} \mathrm{C}$, and $\langle T\rangle_{N H}=15.1^{\circ} \mathrm{C}$ for vHS1939, respectively. Sellers' [39] distribution of zonal averages of temperature, which were not reduced to sea level, provided $\langle T\rangle=11.9^{\circ} \mathrm{C},\langle T\rangle_{S H}=11.1^{\circ} \mathrm{C},\langle T\rangle_{N H}=12.7^{\circ} \mathrm{C}$. Note that Seller's distribution prohibits to use Equation (8) in an exact manner to calculate hemispheric averages of temperature because it omitted a zonal average of temperature for the Equator. Thus, we determined the zonal average for the Equator by interpolation. The same was also done for Arrhenius' datasets A1896-1 and A1896-2. Obviously, the results based on Sellers' dataset are remarkably lower than $\langle T\rangle=13.3^{\circ} \mathrm{C}$, $\langle T\rangle_{S H}=13.0^{\circ} \mathrm{C}$, and $\langle T\rangle_{N H}=13.7^{\circ} \mathrm{C}$ derived from the dataset A1896-2 that represents the normal temperatures of various parallels of latitude, re-corrected by Arrhenius to mean terrain height above sea level. For completeness, the differences between the hemispheric temperature averages expressed by 
$\Delta(N H-S H)=\langle T\rangle_{N H}-\langle T\rangle_{S H}$ are listed in Table 4 as well.

\subsection{Data Fitting}

As illustrated in Figure 25, the accuracy of the asymmetric double sigmoidal peak function (Equation (36)) seems to be acceptable, but the global averages of the minimum and maximum temperatures derived from Köppen's [37] data (Table 3) notably differ from those provided by the polygons. However, as expected from a mathematical perspective, for higher numbers of points, the difference between polygons and Equation (36) should decrease remarkably, as illustrated in Figure 26 for Spitaler's [10] complete dataset Sp1885 (Table 2) and an artificially reduced one based on it. Using Equation (8), the polygon and the Equation (36), provided for the complete dataset $\langle T\rangle=14.9^{\circ} \mathrm{C}$ (Table 4). Whereas for the reduced dataset, the integration of the polygon yielded $\langle T\rangle=14.4^{\circ} \mathrm{C}$ and that of Equation (36) provided $\langle T\rangle=15.0^{\circ} \mathrm{C}$. As aforementioned, the dataset of von Hann-Süring [38] (vHS1939) was adopted by Haurwitz and Austin [40] as well as Blüthgen [41]. However, Haurwitz and Austin [40] only considered the values at each $10^{\text {th }}$ degree of latitude, while Blüthgen [41] adopted the complete dataset. The dataset of Haurwitz and Austin [40] (Figure 27(a)) provided $\langle T\rangle=13.6^{\circ} \mathrm{C}$ for the polygon and $\langle T\rangle=14.1^{\circ} \mathrm{C}$ for Equation (36). The higher number of points as shown in Figure $27(\mathrm{~b})$ yields $\langle T\rangle=14.2^{\circ} \mathrm{C}$ for the polygon and $\langle T\rangle=14.0^{\circ} \mathrm{C}$ based on Equation (36). The results derived from the reduced datasets are also listed in Table 4, but not further discussed.

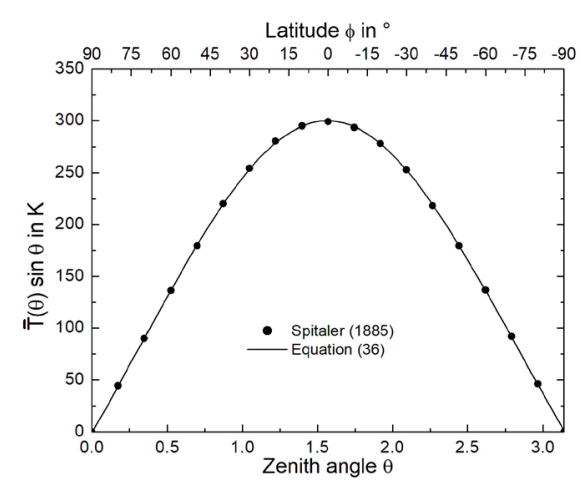

(a)

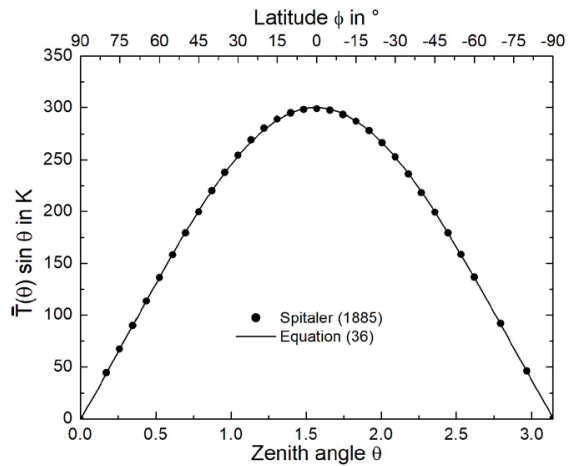

(b)

Figure 26. Comparison of the integrand $\bar{T}(\theta) \sin \theta$ (as requested by Equation (8)), derived from Sp1885 [10] using (a) the reduced dataset and (b) the complete one.

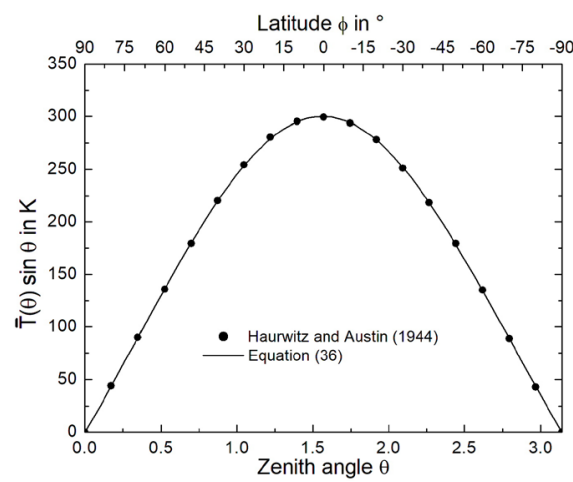

(a)

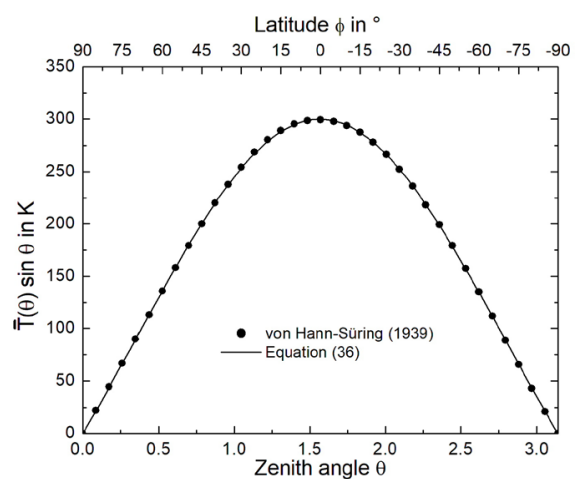

(b)

Figure 27. As in Figure 26, but for the datasets of (a) Haurwitz and Austin [40] and (b) von HannSüring [38]. 
By using Equation (36), we fitted the meridional distributions of the points of the integrand $\bar{T}(\theta) \sin \theta$ related to the historical distributions of normal temperatures. The parameters of our fitting procedure are listed in Table 5; the calculated global and hemispheric averages are listed in Table 4. Global averages are ranging from $\langle T\rangle=14.3^{\circ} \mathrm{C}$ (vB1906 [29], Bö1913 [35]) to $\langle T\rangle=15.5^{\circ} \mathrm{C}$ (Fe1877 [12]). The hemispheric averages are ranging from $\langle T\rangle_{S H}=13.6^{\circ} \mathrm{C}$ (Ho1906-1 [33], vB1906 [29], Bö1913 [35]) to $\langle T\rangle_{S H}=15.9^{\circ} \mathrm{C}$ (Fe1877 [12]) for the Southern Hemisphere (i.e., the results reveal that the poor coverage of the Southern Hemisphere as indicated by the normal temperatures of Dove [19] and Forbes [23] plays only a minor role) and $\langle T\rangle_{N H}=15.0^{\circ} \mathrm{C}$ (vB1901-1 [7]) to $\langle T\rangle_{N H}=15.5^{\circ} \mathrm{C}$ (Ho1906-2 [33]) for the Northern Hemisphere.

For comparison: Based on Equation (36), the datasets of Defant and Obst [36] and von Hann-Süring [38] yielded: $\langle T\rangle=14.5^{\circ} \mathrm{C},\langle T\rangle_{S H}=13.7^{\circ} \mathrm{C}$, and $\langle T\rangle_{N H}=15.2^{\circ} \mathrm{C}$ and $\langle T\rangle=14.0^{\circ} \mathrm{C},\langle T\rangle_{S H}=13.2^{\circ} \mathrm{C}$, and $\langle T\rangle_{N H}=14.9^{\circ} \mathrm{C}$, respectively. Sellers' [39] distribution of zonal averages of temperature (which are not reduced to sea level) provided $\langle T\rangle=12.5^{\circ} \mathrm{C},\langle T\rangle_{S H}=11.8^{\circ} \mathrm{C}$, and $\langle T\rangle_{N H}=13.1^{\circ} \mathrm{C}$. These results are remarkably lower than $\langle T\rangle=13.5^{\circ} \mathrm{C},\langle T\rangle_{S H}=13.2^{\circ} \mathrm{C},\langle T\rangle_{N H}=13.8^{\circ} \mathrm{C}$ derived from A1896-2 that represents the normal temperatures of various parallels of latitude, re-corrected by Arrhenius to mean terrain height above sea level.

\subsection{Uncertainty Analysis}

To estimate the uncertainty of our results, the numerical solution was repeated 50 times to create an ensemble of 50 realizations, where for each solution the zonal averages of the temperature for all parallels of latitude were randomly modified by adding temperature values, $\Delta_{R} T$, that are normally distributed within a standard deviation of $\sigma= \pm 2 \mathrm{~K}$. No seed was presupposed. This procedure was applied to each of the datasets of the zonal averages of temperature. Figure 28 illustrates examples of these randomly added temperatures. Based on the 16 ensembles of 50 realizations each, we calculated the uncertainty of the global and hemispheric averages and the differences between the hemispheres. The results are listed in Table 6 . As expected, the uncertainty depends on the number of zonal averages. The smallest values of uncertainty were obtained for vB1906 (Figure 3) and Bö1913 (Figure 5) followed by vB1901-1 (Figure 2) and vHS1939 (Table 2). The largest uncertainty occurred for Do1852, Fo1859, Fe1877, A1896-1, and A1896-2.

By using Equation (8), the integration of the polygon provided, for instance, for vB1906 and Bö1913 $\langle T\rangle=14.5^{\circ} \mathrm{C},\langle T\rangle_{S H}=13.7^{\circ} \mathrm{C},\langle T\rangle_{N H}=15.5^{\circ} \mathrm{C}$, and $\Delta(N H-S H)=1.8^{\circ} \mathrm{C}$ (Table 4). Our uncertainty analysis yielded for these datasets $\langle T\rangle=(14.5 \pm 0.3)^{\circ} \mathrm{C},\langle T\rangle_{S H}=(13.6 \pm 0.4)^{\circ} \mathrm{C},\langle T\rangle_{N H}=(15.3 \pm 0.4)^{\circ} \mathrm{C}$, and $\Delta(N H-S H)=(1.7 \pm 0.6)^{\circ} \mathrm{C}$ (Table 6). For comparison: vHS1939 yielded $\langle T\rangle=14.2^{\circ} \mathrm{C}$, $\langle T\rangle_{S H}=13.2^{\circ} \mathrm{C},\langle T\rangle_{N H}=15.1^{\circ} \mathrm{C}$, and $\Delta(N H-S H)=1.9^{\circ} \mathrm{C}$ (Table 4). Whereas the respective ensemble

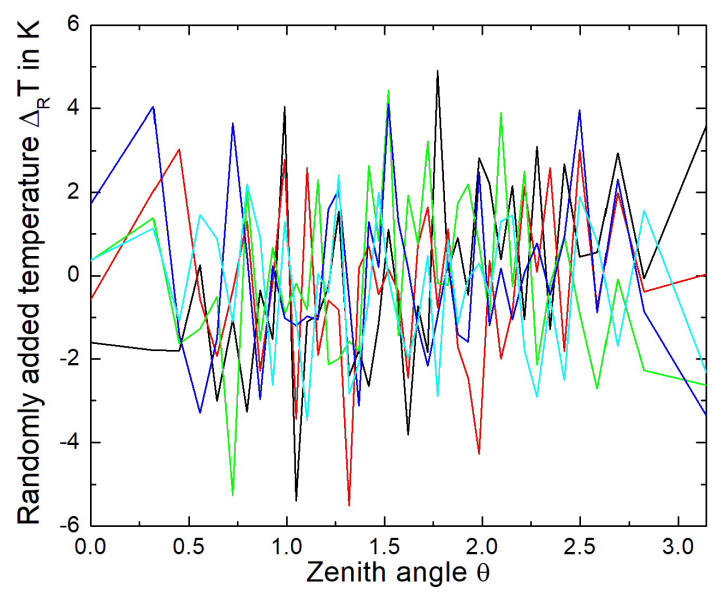

Figure 28. Five instances of $\Delta_{R} T$ randomly added to the climatological mean temperatures of various parallels of latitude listed in Börnstein's [35] table (Figure 5). 
Table 6. Uncertainty estimates as obtained from the ensemble averaging procedure. Marginal differences in the second decimal place may cause some rounding effects.

\begin{tabular}{|c|c|c|c|c|}
\hline \multirow{3}{*}{ Author(s), and dataset } & \multicolumn{4}{|c|}{ Average near-surface air temperature and standard deviation in ${ }^{\circ} \mathrm{C}$} \\
\hline & \multicolumn{4}{|c|}{ Polygons } \\
\hline & $\mathrm{NH}$ & $\mathrm{SH}$ & $\Delta(\mathrm{NH}-\mathrm{SH})$ & Earth \\
\hline Dove [19], Do1852 & $14.9 \pm 0.7$ & $11.7 \pm 1.1$ & $3.2 \pm 1.3$ & $13.3 \pm 0.6$ \\
\hline Forbes [23], Fo1859 & $15.0 \pm 0.7$ & $11.7 \pm 1.1$ & $3.3 \pm 1.3$ & $13.3 \pm 0.6$ \\
\hline Ferrel [12], Fe1877 & $14.7 \pm 0.7$ & $15.3 \pm 0.9$ & $-0.6 \pm 1.1$ & $15.0 \pm 0.6$ \\
\hline $\begin{array}{l}\text { Spitaler [10], Sp1885 } \\
\text { "Complete dataset" }\end{array}$ & $15.1 \pm 0.5$ & $14.6 \pm 0.6$ & $0.4 \pm 0.7$ & $14.8 \pm 0.4$ \\
\hline Batchelder [11], Ba1894 & $14.9 \pm 0.7$ & $13.0 \pm 0.9$ & $1.9 \pm 1.2$ & $13.9 \pm 0.5$ \\
\hline Arrhenius [26], A1896-1 & $15.1 \pm 0.8$ & $13.4 \pm 0.8$ & $1.8 \pm 1.1$ & $14.2 \pm 0.6$ \\
\hline Arrhenius $[14,26]^{*}$, A1896-2 & $13.7 \pm 0.8$ & $12.7 \pm 0.8$ & $1.0 \pm 1.1$ & $13.2 \pm 0.6$ \\
\hline $\begin{array}{l}\text { von Bezold [7], vB1901-1 } \\
\text { "Spitaler" }\end{array}$ & $15.3 \pm 0.4$ & $14.3 \pm 0.5$ & $1.0 \pm 0.8$ & $14.8 \pm 0.3$ \\
\hline $\begin{array}{l}\text { von Bezold [7], vB1901-2 } \\
\text { "Batchelder" }\end{array}$ & $15.3 \pm 0.4$ & $14.4 \pm 0.6$ & $0.9 \pm 0.8$ & $14.8 \pm 0.4$ \\
\hline Hopfner [33], Ho1906-1 & $15.1 \pm 0.7$ & $13.0 \pm 0.9$ & $2.1 \pm 1.2$ & $14.0 \pm 0.5$ \\
\hline Hopfner [33], Ho1906-2 & $14.9 \pm 0.7$ & $13.7 \pm 0.9$ & $1.2 \pm 1.1$ & $14.3 \pm 0.5$ \\
\hline von Hann [32], vH1908 & $14.7 \pm 0.7$ & $13.5 \pm 0.8$ & $1.1 \pm 1.1$ & $14.1 \pm 0.5$ \\
\hline $\begin{array}{c}\text { von Bezold [29], vB1906 } \\
\text { Börnstein [35], Bö1913 } \\
\text { "Complete dataset" }\end{array}$ & $15.3 \pm 0.4$ & $13.6 \pm 0.4$ & $1.7 \pm 0.6$ & $14.5 \pm 0.3$ \\
\hline Defant and Obst [36], De1923 & $14.6 \pm 0.7$ & $13.1 \pm 0.8$ & $1.5 \pm 1.1$ & $13.9 \pm 0.5$ \\
\hline von Hann-Süring [38], vHS1939 & $15.0 \pm 0.4$ & $13.1 \pm 0.5$ & $1.9 \pm 0.7$ & $14.1 \pm 0.3$ \\
\hline Sellers [39], Se1965 & $12.5 \pm 0.7$ & $10.9 \pm 0.7$ & $1.5 \pm 0.9$ & $11.7 \pm 0.5$ \\
\hline
\end{tabular}

*) Re-corrected to mean terrain height above sea level.

provided $\langle T\rangle=(14.1 \pm 0.3)^{\circ} \mathrm{C},\langle T\rangle_{S H}=(13.1 \pm 0.5)^{\circ} \mathrm{C},\langle T\rangle_{N H}=(15.0 \pm 0.4)^{\circ} \mathrm{C}$, and $\Delta(N H-S H)=(1.9 \pm 0.7)^{\circ} \mathrm{C} \quad($ Table 6).

Presupposing an oblate spheroid, the numerical solution of Equation (23) provided for vB1906 and Bö1913 $\langle T\rangle=14.6^{\circ} \mathrm{C},\langle T\rangle_{S H}=13.7^{\circ} \mathrm{C},\langle T\rangle_{N H}=15.5^{\circ} \mathrm{C}$, and $\Delta(N H-S H)=1.8^{\circ} \mathrm{C}$. One of these values is slightly higher than that provided by Equation (8); however, the increase is mainly a rounding effect due to a marginal change in the second decimal place. Based on our uncertainty analysis, we obtained for these 
datasets $\langle T\rangle=(14.5 \pm 0.3)^{\circ} \mathrm{C},\langle T\rangle_{S H}=(13.7 \pm 0.4)^{\circ} \mathrm{C},\langle T\rangle_{N H}=(15.4 \pm 0.4)^{\circ} \mathrm{C}$, and $\Delta(N H-S H)=(1.7 \pm 0.6)^{\circ} \mathrm{C}$. Again, any increase is mainly a rounding effect due to a marginal change in the second decimal place. For comparison: vHS1939 provided $\langle T\rangle=(14.1 \pm 0.3)^{\circ} \mathrm{C}$, $\langle T\rangle_{S H}=(13.2 \pm 0.5)^{\circ} \mathrm{C},\langle T\rangle_{N H}=(15.1 \pm 0.4)^{\circ} \mathrm{C}$, and $\Delta(N H-S H)=(1.9 \pm 0.7)^{\circ} \mathrm{C}$.

The normal temperatures of Kramm et al. [44] were also used to assess the accuracy of the spherical averaging procedure (Equation (8)) in comparison with spheroidal averaging procedure (Equation (23). The results confirmed that Equation (8) provides results with an acceptable accuracy $\left( \pm 0.04^{\circ} \mathrm{C}\right)$ even in the case of an oblate spheroid.

\section{SUMMARY AND CONCLUSIONS}

Zonal averages of temperature, the so-called normal temperatures, for numerous parallels of latitude published between 1852 and 1913 by Dove [19], Forbes [23], Ferrel [12], Spitaler [10], Batchelder [11], Arrhenius [14, 26], Hopfner [33], von Hann [32], von Bezold [7, 29], and Börnstein [35] served to quantify the global mean near-surface temperature of the terrestrial atmosphere. The investigation showed that only the datasets Do1852 and FO1859 of Dove [19] and Forbes [23] provided global averages below $\langle T\rangle=14^{\circ} \mathrm{C}$, namely $\langle T\rangle=13.3^{\circ} \mathrm{C}$ and $\langle T\rangle=13.4^{\circ} \mathrm{C}$, respectively. The results derived from the other historical distributions of normal temperatures published between 1877 and 1913 ranged from $\langle T\rangle=14.0^{\circ} \mathrm{C}$ (Ba1894 [11]) to $\langle T\rangle=15.1^{\circ} \mathrm{C}$ (Fe1877 [12]), with $\langle T\rangle=14.5^{\circ} \mathrm{C}$ (vB1906 [29] and Bö1913 [35]) falling in between.

The poor coverage of the Southern Hemisphere by observations during that time indicated by the normal temperatures of Dove [19] and Forbes [23] (no zonal averages of temperature for parallels of latitude beyond $40^{\circ} \mathrm{S}$ ) led to a hemispheric average of $\langle T\rangle_{S H}=11.8^{\circ} \mathrm{C}$. This value is notably below those derived from the other historical datasets investigated. The respective averages calculated for the Southern Hemisphere are ranging from $\langle T\rangle_{S H}=13.2^{\circ} \mathrm{C}$ (Ho1906-1 [33]) to $\langle T\rangle_{S H}=15.4^{\circ} \mathrm{C}$ (Fe1877 [12]). The datasets vB1906 and Bö1913 of von Bezold [29] and Börstein [35] provided $\langle T\rangle_{S H}=13.7^{\circ} \mathrm{C}$.

On the contrary, the average for the Northern Hemisphere of Dove [19] and Forbes [23] is

$\langle T\rangle_{N H}=14.9^{\circ} \mathrm{C}$. It substantially agrees with those calculated from the historical datasets of the other authors. The respective results are ranging from $\langle T\rangle_{N H}=14.7^{\circ} \mathrm{C}$ (Batchelder [11]) to $\langle T\rangle_{N H}=15.4^{\circ} \mathrm{C}$ (von Bezold [29]/Börnstein [35]). Our results confirmed von Hann's [15] [16] conclusion that both hemispheres have nearly the same average temperature, but the Southern Hemisphere would probably be slightly cooler than the northern one. This is also true for the solar climate, but not reflected by Ferrel's [12] data. Recently, Feulner et al. [67] confirmed von Hann's conclusion as well. They found that the annually averaged surface air temperature in the Northern Hemisphere is $1^{\circ} \mathrm{C}-2^{\circ} \mathrm{C}$ higher than in the Southern Hemisphere.

To estimate the uncertainty of our results, the zonal averages of temperatures for all parallels of latitude were randomly perturbed (without presupposed seed) by adding temperature values, $\Delta_{R} T$, that are normally distributed with a standard deviation of $\sigma= \pm 2 \mathrm{~K}$. For each of these historical datasets, ensembles of the 50 realizations of perturbed distributions were created. The numerical integrations of these perturbed distributions provided uncertainties in the global averages ranging from $\pm 0.3^{\circ} \mathrm{C}$ to $\pm 0.6^{\circ} \mathrm{C}$ where the magnitude of uncertainty increases with the decreasing number of normal temperatures available. The global and hemispheric means obtained from the ensembles of perturbed distributions well agreed with those derived from the original unperturbed datasets.

To assess the difference between spherical and spheroidal averaging special attention was paid to the distributions of climatological mean temperatures for numerous parallels of latitude published by von Bezold [29] and Börnstein's [35]. Global and spheroidal averaging provided $\langle T\rangle=14.5^{\circ} \mathrm{C}$ and

$\langle T\rangle=14.6^{\circ} \mathrm{C}$, respectively. The corresponding ensembles provided $\langle T\rangle=(14.5 \pm 0.3)^{\circ} \mathrm{C}$, and

$\langle T\rangle=(14.6 \pm 0.3)^{\circ} \mathrm{C}$, respectively. For comparison: The dataset of von Hann-Süring [38] yielded in both cases $\langle T\rangle=14.2^{\circ} \mathrm{C}$. The corresponding ensembles provided for both $\langle T\rangle=(14.1 \pm 0.3)^{\circ} \mathrm{C}$. This means that spherical averaging is sufficiently accurate.

Compared with our results, the hemispheric averages for the Northern Hemisphere of Dove [19], 
$\langle T\rangle_{N H}=15.5^{\circ} \mathrm{C}$, Ferrel [12], $\langle T\rangle_{N H}=15.3^{\circ} \mathrm{C}$, and Spitaler [10], $\langle T\rangle_{N H}=15.4^{\circ} \mathrm{C}$, and for the Southern Hemisphere of Ferrel [12], $\langle T\rangle_{S H}=16.0^{\circ} \mathrm{C}$, and Spitaler [10], $\langle T\rangle_{S H}=14.8^{\circ} \mathrm{C}$ and the global averages of Ferrel [12], $\langle T\rangle=15.7^{\circ} \mathrm{C}$, and Spitaler [10], $\langle T\rangle=15.1^{\circ} \mathrm{C}$, as reported by von Hann $[15,16]$, are remarkably higher. The same is true for the global average $\langle T\rangle=15.0^{\circ} \mathrm{C}$ suggested by von Hann $[15,16]$ and von Bezold [7, 29]. Von Hann's [32] value of $\langle T\rangle=14.4^{\circ} \mathrm{C}$ (also mentioned by Lockyer [34]) seems to be sufficiently adequate, but using his numbers we only obtained $\langle T\rangle=14.2^{\circ} \mathrm{C}$. The HadCRUT4 records provided $\langle T\rangle \cong 13.7^{\circ} \mathrm{C} \quad\left(\langle T\rangle_{S H}=13.1^{\circ} \mathrm{C}\right.$ and $\left.\langle T\rangle_{N H}=14.3^{\circ} \mathrm{C}\right)$ for $1851-1880$ and $\langle T\rangle \cong 13.6^{\circ} \mathrm{C} \quad\left(\langle T\rangle_{S H}=13.0^{\circ} \mathrm{C}\right.$ and $\left.\langle T\rangle_{N H}=14.3^{\circ} \mathrm{C}\right)$ for $1881-1910$. The Berkeley record provided $\langle T\rangle \cong 13.6^{\circ} \mathrm{C}$ and $\langle T\rangle \cong 13.5^{\circ} \mathrm{C}$ for these periods, respectively. The NASA GISS records yielded $\langle T\rangle \cong 13.6^{\circ} \mathrm{C} \quad\left(\langle T\rangle_{S H}=13.0^{\circ} \mathrm{C}\right.$ and $\langle T\rangle_{N H}=14.2^{\circ} \mathrm{C}$ ) for 1881-1910. Obviously, these results are notably lower than those calculated from the meridional distributions of historical zonal averages of temperature. Since the HadCrut4 record yielded $\langle T\rangle=14.4^{\circ} \mathrm{C} \quad\left(\langle T\rangle_{S H}=13.7^{\circ} \mathrm{C}\right.$ and $\left.\langle T\rangle_{N H}=15.2^{\circ} \mathrm{C}\right)$, the Berkeley record $\langle T\rangle=14.5^{\circ} \mathrm{C}$, and the NASA GISS records $\langle T\rangle=14.5^{\circ} \mathrm{C} \quad\left(\langle T\rangle_{S H}=13.7^{\circ} \mathrm{C}\right.$ and $\left.\langle T\rangle_{N H}=15.2^{\circ} \mathrm{C}\right)$ for 1991-2018, the results derived from the historical data suggest no change in the globally averaged near-surface temperature over the past 100 years.

Our results underline that reviewing the epoch-making literature from the $19^{\text {th }}$ century and the first two decades of the $20^{\text {th }}$ century is indispensable in the assessment of climate change since the end of the Little Ice Age in the first half of the $19^{\text {th }}$ century.

\section{ACKNOWLEDGEMENTS}

We thank the anonymous reviewers for fruitful comments. We thank Google Books and the Royal College of Physicians of Edinburgh for making the textbooks of von Hann and Börnstein and numerous reports available to us. We also thank ETH-Bibliothek Zürich for making the Atlas of Meteorology: a series of over four hundred maps prepared by John G. Bartholomew and Andrew J. Herbertson and edited by Alexander Buchan available to us as well.

\section{CONFLICTS OF INTEREST}

The authors declare no conflicts of interest regarding the publication of this paper.

\section{REFERENCES}

1. Hansen, J., Ruedy, R., Sato, M. and Lo, K. (2010) Global Surface Temperature Change. Reviews of Geophysics, 48, RG4004. https://doi.org/10.1029/2010RG000345

2. Rohde, R., Muller, R., Jacobsen, R., Perlmutter, S., Rosenfeld, A., Wurtele, J., Curry, J., Wickham, C. and Mosher, S. (2013) Berkeley Earth Temperature Averaging Process. Geoinformatics \& Geostatistics: An Overview, 1, 13. https://doi.org/10.4172/2327-4581.1000103

3. World Meteorological Organization (2017) WMO Guidelines on the Calculation of Climate Normals. World Meteorological Organization, Geneva.

4. Hansen, J., Johnson, D., Lacis, A., Lebedeff, S., Lee, P., Rind, D. and Russell, G. (1981) Climate Impact of Increasing Atmospheric Carbon-Dioxide. Science, 213, 957-966. https://doi.org/10.1126/science.213.4511.957

5. Jones, P.D. (1994) Hemispheric Surface Air Temperature Variations: A Reanalysis and an Update to 1993. Journal of Climate, 7, 1794-1802. https://doi.org/10.1175/1520-0442(1994)007<1794:HSATVA>2.0.CO;2

6. Jones, P.D., New, M., Parker, D.E., Martin, S. and Rigor, I.G. (1999) Surface Air Temperature and Its Changes 
over the Past 150 Years. Reviews of Geophysics, 37, 173-199. https://doi.org/10.1029/1999RG900002

7. Von Bezold, W. (1901) Über klimatologische Mittelwerthe für ganze Breitenkreise. In: Sitzungsberichte der Königlich Preussischen, Verlag der Akademie der Wissenschaften, Berlin, 1330-1343. https://books.google.com/books?id=JdcAAAAAYAAI

8. von Bezold, W. (1888) Zur Thermodynamik der Atmosphäre. In: Sitzungsberichte der Königlich Preussischen, Verlag der Akademie der Wissenschaften, Berlin, 1189-1206.

9. Meech, L.W. (1857) On the Relative Intensity of the Heat and Light of the Sun upon Different Latitudes of the Earth. Smithsonian Institution, Washington DC.

10. Spitaler, R. (1885) Die Wärmeverteilung auf der Erdoberfläche. In: Denkschriften der mathemnaturwiss. Klasse der Kaiserl, Akademie der Wissenschaften in Wien, Vienna.

11. Batchelder, S.F. (1894) A New Series of Isanomalous Temperature Charts, Based on Buchan's Isothermal Charts. The American Meteorological Journal, 10, 451-474.

12. Ferrel, W. (1877) Meteorological Researches. Govt. Print. Off., Washington DC.

13. Murray, J. (1887) On the Total Annual Rainfall on the Land of the Globe, and the Relation of Rainfall to the Annual Discharge of Rivers. Scottish Geographical Magazine, 3, 65-77. https://doi.org/10.1080/14702548708554511

14. Arrhenius, S. (1896) On the Influence of Carbonic Acid in the Air upon the Temperature of the Ground. Philosophical Magazine and Journal of Science, 41, 237-276. https://doi.org/10.1080/14786449608620846

15. Hann, J. (1897) Handbuch der Klimatologie. Englehorn, Stuttgart.

16. Hann, J. and Ward, R.D.C. (1903) Handbook of Climatology. Macmillan, London.

17. World Meteorological Organization (2018) Guide to Climatological Practices-Third Edition.

18. Hann, J. (1883) Handbuch der Klimatologie. J. Engelhorn, Stuttgart.

19. Dove, H.W. (1852) Verbreitung der Wärme auf der Oberfläche der Erde: Erläutert durch Isothermen, thermische Isanomalen und Temperaturkurven: Berlin, Germany.

20. Schoch, W. (1856) Über die Darstellung der mittlern Jahrestemperatur eines Ortes als Function seiner geographischen Länge und Breite. F. Walder \& Sohn.

21. Sartorius von Waltershausen, W. (1865) Untersuchungen über die Klimate der Gegenwart und der Vorwelt, mit besonderer Berücksichtigung der Gletscher-Erscheinungen in der Diluvialzeit. Haarlem.

22. Morice, C.P., Kennedy, J.J., Rayner, N.A. and Jones, P.D. (2012) Quantifying Uncertainties in Global and Regional Temperature Change Using an Ensemble of Observational Estimates: The HadCRUT4 Data Set. Journal of Geophysical Research-Atmospheres, 117, D08101. https://doi.org/10.1029/2011JD017187

23. Forbes, J.D. (1859) Inquiries about Terrestrial Temperatures. Translation of the Royal Society of Edinburgh, 22, 75-92.

24. Wild, H. (1881) Atlas zu "Die Temperaturverhältnisse des Russischen Reiches": St. Petersburg.

25. Hann, J. (1887) Atlas der Meteorologie. In: Berghaus' Physikalischer Atlas, Gotha.

26. Arrhenius, S. (1896) Ueber den Einfluss des atmosphärischen Kohlensäuregehalts auf die Temperatur der Erdoberfläche. In: Bihang till Kongl. Svenska Vetenskaps-Akademiens Handlingar, K. Svenska Vetenskaps-Akademien, Stockholm, 1-102. https://books.google.com/books?id=3OoVAAAAYAAI

27. Buchan, A. (1889) Report on Atmospheric Circulation Based on the Observations Made on Board H.M.S. Challenger during the Years 1873-1876, and Other Meteorological Observations. In: Voyage of H.M.S. Challenger, Physics and Chemistry, London, Edinburg, Dublin.

28. Hann, J. (1882) Ueber die Temperatur der südlichen Hemisphäre. Kaiserliche Akademie der Wissenschaften, 
Mathematisch-Naturwissenschaftliche Classe: Wien.

29. von Bezold, W. (1906) Über Strahlungsnormalen und Mittellinien der Temperatur. In: Pernter, J.M., Von Hann, J. and Hellmann, G., Eds., Meteorologische Zeitschrift. Hann-Band zum vierzigjährigen Redaktionsjubiläum J. Hann's von Freunden und Kollegen gewidmet, F. Vieweg, 279-287.

30. Hann, J. (1902) W. V. Bezold: Ueber klimatologische Mittelwerthe für ganze Breitenkreise. Meteorologische Zeitschrift, 19, 260-269.

31. Börnstein, R. (1906) Leitfaden der Wetterkunde: Gemeinverständlich bearbeitet. F. Vieweg \& Sohn.

32. Hann, J. (1908) Handbuch der Klimatologie. J. Engelhorn, Stuttgart.

33. Hopfner, F. (1906) Die thermischen Anomalien auf der Erdoberfläche. Petermanns geographische Mitteilungen, $52,32-36$.

34. Lockyer, W.J.S. (1906) Studies of Temperature and Pressure Observations. Nature, 73, 594-595. https://doi.org/10.1038/073594a0

35. Börnstein, R. (1913) Leitfaden der Wetterkunde. F. Vieweg und Sohn.

36. Defant, A. and Obst, E. (1923) Lufthuille und Klima. F. Deuticke, Leipzig, Wien.

37. Köppen, W. (1936) Das geographische System der Klimate. Borntraeger, Berlin, C5-C44.

38. von Hann, J. and Süring, R.J. (1939) Lehrbuch der Meteorologie. W. Keller, Leipzig.

39. Sellers, W.D. (1965) Physical Climatology. University of Chicago Press, Chicago.

40. Haurwitz, B. and Austin, J.M. (1944) Climatology. McGraw-Hill Book Company, Incorporated, New York, London.

41. Blüthgen, J. (1966) Allgemeine Klimageographie. De Gruyter, Berlin. https://doi.org/10.1515/9783111440293

42. Kramm, G., Dlugi, R. and Zelger, M. (2009) Comments on the "Proof of the Atmospheric Greenhouse Effect" by Arthur P. Smith. http://arxiv.org/abs/0904.2767v3

43. Riley, K.F., Hobson, M.P. and Bence, S.J. (1998) Mathematical Methods for Physics and Engineering. Cambridge University Press, Cambridge.

44. Kramm, G., Dlugi, R. and Mölders, N. (2017) Using Earth's Moon as a Testbed for Quantifying the Effect of the Terrestrial Atmosphere. Natural Science, 9, 251-288. https://doi.org/10.4236/ns.2017.98026

45. Kasten, F. and Raschke, E. (1974) Reflection and Transmission Terminology by Analogy with Scattering. Applied Optics, 13, 450-464. https://doi.org/10.1364/AO.13.0460_1

46. Hantel, M. and Haimberger, L. (2016) Grundkurs Klima. Springer-Verlag Berlin, Heidelberg. https://doi.org/10.1007/978-3-662-48193-6

47. Peixoto, J.P. and Oort, A.H. (1984) Physics of Climate. Reviews of Modern Physics, 56, 365-429. https://doi.org/10.1103/RevModPhys.56.365

48. Peixoto, J.P. and Oort, A.H. (1992) Physics of Climate. American Institute of Physics, New York. https://doi.org/10.1063/1.2809772

49. Wiin-Nielsen, A. and Chen, T.C. (1993) Fundamentals of Atmospheric Energetics. Oxford University Press, Oxford.

50. Agency, D.M. (1990) Datums, Ellipsoids, Grids, and Grid Reference Systems. Defense Mapping Agency, Fairfax.

51. Beyer, W.H. and Company, C.R. (1978) CRC Handbook of Mathematical Sciences. CRC Press, Boca Raton.

52. Hilbert, D. and Cohn-Vossen, S. (1990) Geometry and the Imagination. Chelsea, New York.

53. Hansen, J. and Lebedeff, S. (1987) Global Trends of Measured Surface Air Temperature. Journal of Geophysical Research: Atmospheres, 92, 13345-13372. https://doi.org/10.1029/JD092iD11p13345 
54. Krümmel, O. (1907) Handbuch der Ozeanographie. J. Engelhorn, Stuttgart. https://doi.org/10.5962/bhl.title.28378

55. PaiMazumder, D. and Mölders, N. (2009) Theoretical Assessment of Uncertainty in Regional Averages Due to Network Density and Design. Journal of Applied Meteorology and Climatology, 48, 1643-1666. https://doi.org/10.1175/2009JAMC2022.1

56. von Humboldt, A. (1817) Des lignes isothermes et de la distribution de la chaleur sur le globe. Perronneau.

57. Hann, J. (1906) Lehrbuch der Meteorologie. C. H. Tauchnitz, Leipzig.

58. Kahlig, P. (1993) Some Aspects of Julius Von Hann's Contribution to Modern Climatology. In: Mcbean, G. and Hantel, M., Eds., Interactions between Global Climate Subsystems: The Legacy of Hann, American Geophysical Union, Washington DC, 1-7. https://doi.org/10.1029/GM075p0001

59. Blackman, R.B. and Tukey, J.W. (1958) The Measurements of Power Spectra. Dover, New York.

60. Bartholomew, J.G., Herbertson, A.J. and Buchan, A. (1899) Atlas of Meteorology: A Series of over Four Hundred Maps Prepared by John G. Bartholomew and Andrew J. Herbertson and Edited by Alexander Buchan. Geographical Institute, Edinburgh.

61. Dunwoody, H.H.C. (1893) Summary of International Meteorological Observations. US Department of Agriculture, Weather Bureau, Washington DC. https://archive.org/details/CAT31402346/page/n2

62. DeCourcy Ward, R. (1900) Notes on Climatology. Journal of the American Geographical Society of New York, 32, 158-161.

63. Supan, A. (1896) Grundzüge der physischen Erdkunde. Veit \& comp.

64. Levitus, S. (1982) Climatological Atlas of the World Ocean. In: NOAA Professional Paper No. 13, U.S. Department of Commerce, National Oceanic and Atmospheric Administration, Rockwell, MD173.

65. Locarnini, R.A., Mishonov, A.V., Baranova, O.K., Boyer, T.P., Zweng, M.M., Garcia, H.E., Reagan, J.R., Seidov, D., Weathers, K.W., Paver, C.R. and Smolyar, I.V. (2019) World Ocean Atlas 2018, Volume 1: Temperature. US Department of Commerce, National Oceanic and Atmospheric Administration, Silver Spring, MD52.

66. Hann, J. (1888) Zur Konstruktion der Isothermen. Petermanns geographische Mitteilungen, 34, 54-56.

67. Feulner, G., Rahmstorf, S., Levermann, A. and Volkwardt, S. (2013) On the Origin of the Surface Air Temperature Difference between the Hemispheres in Earth's Present-Day Climate. Journal of Climate, 26, 7136-7150. https://doi.org/10.1175/JCLI-D-12-00636.1

68. Trewartha, G.T. (1954) An Introduction to Climate. McGraw-Hill, New York.

69. Bretagnon, P. (1974) Termes a longues periodes dans le systeme solaire. Astronomy \& Astrophysics, 30, 141-154.

70. Berger, A. (1978) Long-Term Variations of Daily Insolation and Quaternary Climatic Changes. Journal of the Atmospheric Sciences, 35, 2362-2367. https://doi.org/10.1175/1520-0469(1978)035<2362:LTVODI >2.0.CO;2

71. Berger, A. (1988) Milankovitch Theory and Climate. Reviews of Geophysics, 24, 624-657. https://doi.org/10.1029/RG026i004p00624

72. Lindzen, R.S. (1994) Climate Dynamics and Global Change. Annual Review of Fluid Mechanics, 26, 353-378. https://doi.org/10.1146/annurev.fl.26.010194.002033

73. Monin, A.S. and Shishkov, Y.A. (2000) Climate as a Problem in Physics. Uspekhi Fizicheskikh Nauk, 170, 419445. https://doi.org/10.3367/UFNr.0170.200004d.0419

74. Liou, K.N. (2002) An Introduction to Atmospheric Radiation-Second Edition. Academic Press, San Diego.

75. Kramm, G. and Dlugi, R. (2011) Scrutinizing the Atmospheric Greenhouse Effect and Its Climatic Impact. Natural Science, 3, 971-998. https://doi.org/10.4236/ns.2011.312124

76. Keihm, S.J. (1984) Interpretation of the Lunar Microwave Brightness Temperature Spectrum: Feasibility of Or- 
bital Heat Flow Mapping. Icarus, 60, 568-589. https://doi.org/10.1016/0019-1035(84)90165-9

77. Paige, D.A., Foote, M.C., Greenhagen, B.T., Schofield, J.T., Calcutt, S., Vasavada, A.R., Preston, D.J., Taylor, F.W., Allen, C.C., Snook, K.J., Jakosky, B.M., Murray, B.C., Soderblom, L.A., Jau, B., Loring, S., Bulharowski, J., Bowles, N.E., Thomas, I.R., Sullivan, M.T., Avis, C., De Jong, E.M., Hartford, W. and McCleese, D.J. (2009) The Lunar Reconnaissance Orbiter Diviner Lunar Radiometer Experiment. Space Science Reviews, 150, 125-160. https://doi.org/10.1007/s11214-009-9529-2

78. Vasavada, A.R., Bandfield, J.L., Greenhagen, B.T., Hayne, P.O., Siegler, M.A., Williams, J.-P. and Paige, D.A. (2012) Lunar Equatorial Surface Temperatures and Regolith Properties from the Diviner Lunar Radiometer Experiment. Journal of Geophysical Research, 117, E00H18. https://doi.org/10.1029/2011JE003987

79. Iqbal, M. (1983) An Introduction to Solar Radiation. Academic Press Canada.

80. Kondratyev, K.Y. (1969) Radiation in the Atmosphere. Academic Press, New York/London.

81. Haltiner, G.J. and Martin, F.L. (1957) Dynamical and Physical Meteorology. McGraw-Hill Book Company, New York/Toronto/London.

82. Möller, F. (1973) Einführung in die Meteorologie. Bibliographisches Institut, Mannheim/Wien/Zürich.

83. Emilio, M., Kuhn, J.R., Bush, R.I. and Scholl, I.F. (2012) Measuring the Solar Radius from Space during the 2003 and 2006 Mercury Transits. The Astrophysical Journal, 750, 135. https://doi.org/10.1088/0004-637X/750/2/135

84. Stefan, J. (1879) Über die Beziehung zwischen der Wärmestrahlung und der Temperatur. Wiener Ber. II, 79, 391-428.

85. Boltzmann, L. (1884) Ableitung des Stefan'schen Gesetzes, betreffend die Abhängigkeit der Wärmestrahlung von der Temperatur aus der electromagnetischen Lichttheorie. Wiedemann's Annalen, 22, 291-294. https://doi.org/10.1002/andp.18842580616

86. Williams, J.G., Boggs, D.H. and Folkner, W.M. (2013) DE430 Lunar Orbit, Physical Librations and Surface Coordinates. In: JPL Interoffice Memorandum (Internal Document), Jet Propulsion Laboratory, California Institute of Technology, Pasadena, 19.

87. Folkner, W.M., Williams, J.G., Boggs, D.H., Park, R.S. and Kuchynka, P. (2014) The Planetary and Lunar Ephemerides DE430 and DE431. In: IPN Progress Report, Jet Propulsion Laboratory, California Institute of Technology, Pasadena, 81.

88. Kopp, G. and Lean, J.L. (2011) A New, Lower Value of Total Solar Irradiance: Evidence and Climate Significance. Geophysical Research Letters, 38, L01706. https://doi.org/10.1029/2010GL045777

89. Kopp, G., Fehlmann, A., Finsterle, W., Harber, D., Heuerman, K. and Willson, R. (2012) Total Solar Irradiance Data Record Accuracy and Consistency Improvements. Metrologia, 49, S29-S33. https://doi.org/10.1088/0026-1394/49/2/S29

90. Kopp, G., Krivova, N., Wu, C.J. and Lean, J. (2016) The Impact of the Revised Sunspot Record on Solar Irradiance Reconstructions. Solar Physics, 291, 2951-2965. https://doi.org/10.1007/s11207-016-0853-x

91. Gerlich, G. and Tscheuschner, R.D. (2009) Falsification of the Atmospheric $\mathrm{CO}_{2}$ Greenhouse Effects within the Frame of Physics. International Journal of Modern Physics B, 23, 275-364. https://doi.org/10.1142/S021797920904984X

92. van Bebber, J. (1883) Das Klima der Erde. Humboldt. Monatsschrift Für Die Gesamten Naturwissenschaften, 1, 343-349.

93. Fortak, H. (1971) Meteorologie. Deutsche Buch-Gemeinschaft, Berlin/Darmstadt/Wien.

94. Brasseur, G.P. and Solomon, S. (2005) Aeronomy of the Middle Atmosphere. Springer, Dordrecht.

95. Mölders, N. and Kramm, G. (2014) Lectures in Meteorology. Springer International Publishing, Berlin. 
https://doi.org/10.1007/978-3-319-02144-7

96. Peel, M.C., Finlayson, B.L. and McMahon, T.A. (2007) Updated World Map of the Koppen-Geiger Climate Classification. Hydrology and Earth System Sciences, 11, 1633-1644. https://doi.org/10.5194/hess-11-1633-2007

97. Kidder, S.Q. and Vonder Haar, T.H. (1995) Satellite Meteorology. Academic Press, San Diego/New York/Boston/London/Sydney/Tokyo/Toronto.

98. Petty, G.W. (2004) A First Course in Atmospheric Radiation. Sundog Publishing, Madison.

99. Wunsch, C. (2002) What Is the Thermohaline Circulation? Science, 298, 1179-1181.

https://doi.org/10.1126/science.1079329

100. Rahmstorf, S. (2006) Thermohaline Ocean Circulation. In: Elias, A.S., Ed., Encyclopedia of Quaternary Sciences, Elsevier, Amsterdam, 1-10. 